\title{
Ammonia Results Review for Retained Gas Sampling
}

L. A. Mahoney

September 2000

Prepared for the U.S. Department of Energy under Contract DE-AC06-76RLO 1830

Pacific Northwest National Laboratory

Richland, Washington 99352 



\section{DISCLAIMER}

This report was prepared as an account of work sponsored by an agency of the United States Government. Neither the United States Government nor any agency thereof, nor any of their employees, make any warranty, express or implied, or assumes any legal liability or responsibility for the accuracy, completeness, or usefuiness of any information, apparatus, product, or process disclosed, or represents that its use would not infringe privately owned rights. Reference herein to any specific commercial product, process, or service by trade name, trademark, manufacturer, or otherwise does not necessarily constitute or imply its endorsement, recommendation, or favoring by the United States Government or any agency thereof. The views and opinions of authors expressed herein do not necessarily state or reflect those of the United States Government or any agency thereof. 


\section{DISCLAIMER}

Portions of this document may be illegible in electronic image products. Images are produced from the best available original document. 


\section{Preface}

This report was prepared as part of a task supporting the deployment of the retained gas sampler (RGS) system in Flammable Gas Watch List Tanks. The emphasis of this report is on presenting supplemental information about the ammonia measurements resulting from retained gas sampling of Tanks 241-AW-101, A-101, AN-105, AN-104, AN-103, U-103, S-106, BY-101, BY-109, SX-106, AX-101, S-102, S-111, U-109, and SY-101. This information provides a better understanding of the accuracy of past RGS ammonia measurements, which will assist in determining flammable and toxicological hazards. 



\section{Executive Summary}

This report provides information to supplement the gas composition and volume results obtained for the tanks sampled with the retained gas sampler (RGS) and reported by Mahoney et al. (1999): 241-AW-101, 241-AN-105, 241-A-101, 241-AN-104, 241-AN-103, 241-U-103, 241-S-106, 241-BY-101, 241-BY-109, 241-SX-106, 241-AX-101, 241-S-102, 241-S-111, 241-U-109, and 241-SY-101. (Hereafter, these tanks will be referred to without the prefix 241-, following standard practice.)

The RGS is a modified version of the universal core sampler used to sample Hanford tanks. It is designed specifically for use in concert with the gas extraction equipment in the hot cell to capture and extrude a gas-containing waste sample in a hermetically sealed system. The retained gases are then extracted and stored in small gas canisters and the composition of the gases contained in the canisters is measured by mass spectroscopy. The total gas volume in the sample is obtained from analyzing pressure, volume, and temperature data from the extraction process.

The final report documenting the RGS sampling results from late 1997 to early 1999 was Retained Gas Sampling Results for the Flammable Gas Program (Mahoney et al. 1999). This report is a supplement to that document. Some of the tables provided in this report are revisions of summary tables in the earlier report, though not all tables from that report are presented here in revised form. The reader is advised to use the earlier report only in conjunction with the data and perspectives presented in this document. By the same token, this report is not a stand-alone document, and some topics are more completely described in the original report.

This report covers two topics: first, experiment-based changes to the solubility model used by Mahoney et al. (1999) to predict ammonia vapor pressures from known ammonia concentrations; second, experimental tests of the accuracy of RGS ammonia measurement methods.

Solubility Model: Two different sets of ammonia vapor pressure data have been collected for Hanford waste simulants (Norton and Pederson 1994; Hedengren et al. 2000). This report reviews the Hanford data sets and correlates them to revise the coefficients in the commonly used Schumpe ammonia solubility model and to test the model's predictions for simulated Hanford waste. The results and conclusions of this work are the following:

- The model coefficients that were based on correlation of the Norton and Pederson data were $-0.03575 \mathrm{~L} / \mathrm{mol}$ and $-3.999 \times 10^{-4} \mathrm{~L} / \mathrm{mol} \mathrm{K}$, and the coefficients based on correlation of the Hedengren et al. data were $-0.04932 \mathrm{~L} / \mathrm{mol}$ and $-3.660 \times 10^{-4} \mathrm{~L} / \mathrm{mol} \mathrm{K}$. The model previously used in RGS studies had coefficients of $-0.0506 \mathrm{~L} / \mathrm{mol}$ and $0 \mathrm{~L} / \mathrm{mol} \mathrm{K}$ (Mahoney et al. 1999).

- Because of the differences between the Norton and Pederson data and the Hedengren et al. data, the two sets of coefficients were used to calculate, respectively, the upper and lower bounds on the in situ ammonia mole fraction in retained gas. The RGS data from Mahoney et al. (1999) were reinterpreted in this way. The model changes have the greatest effect on the mole fraction of ammonia vapor in the retained gas in cases where the gas volume fraction is high, as it was in the crust of SY-101 before waste was transferred and diluted. 
- Within the range of salt concentrations found in Hanford wastes, salt concentration makes a difference of less than $\pm 30 \%$ in the revised models' predictions compared with the corresponding experimental data.

- The correction of the units error acted to decrease the ammonia vapor pressure and had insignificant effects on the composition of the low-solubility portion of the retained gas.

RGS Ammonia Measurement: Two methods predominated among those used in RGS measurement of ammonia concentrations. The method used on the most recently sampled tanks involved adding a standard solution of ${ }^{15} \mathrm{NH}_{4} \mathrm{OH}$ and using mass spectrometry to measure the isotopic ratio ${ }^{15} \mathrm{NH}_{3}{ }^{14} \mathrm{NH}_{3}$ in the extracted ammonia vapor. The method used on earlier tanks required finding the initial ammonia partial pressure after the sample was extruded. Each of the methods was used on a large number of tank samples and proved to be vulnerable to ammonia adsorption on surfaces and mass-transfer limitations on ammonia equilibration between phases.

RGS ammonia measurement methods were found to be of low accuracy for samples from which only a small amount of ammonia could be extracted-that is, samples that had a low ammonia partial pressure in the extractor. Most of the samples whose ammonia was measured by the isotopic solution method (samples from tanks SX-106, AX-101, S-102, S-111, U-109, and SY-101) fell into the low partial pressure category. The exceptions were sample SX-106-6-6A and almost all of the SY-101 samples. Some of the samples on which the initial partial pressure method was used to measure ammonia also had low ammonia pressures. This includes most of the samples from U-103, S-106, and BY-109. Samples from AW-101, A-101, AN-105, AN-104, and AN-103 had higher ammonia partial pressures and are considered more reliable.

In general, we regard the uncertainties of RGS ammonia measurement methods as being larger for samples with low-ammonia partial pressures than the uncertainties stated by Mahoney et al. (1999). That reference estimated the ammonia concentration uncertainties as $\pm 50 \%$ for the initial partial pressure method and (in most cases) less than $\pm 30 \%$ for the isotopic solution method. Based on FY 2000 work, there could well be an error of a factor of 2 or more in ammonia measurements made by either of these methods for samples with low ammonia partial pressure. Different measurement methods can yield ammonia concentrations that differ by a factor of 2 or more, though there are also cases where different methods give similar results (see Table 3.5). Unfortunately, the FY 2000 experimental program was not completed because of vacuum pump malfunctions, and, as a result, the high uncertainty cannot be quantified. The ammonia vapor pressures (and the ammonia mole fractions in the retained gas) contain the uncertainty in the ammonia concentration and an additional model uncertainty of $\pm 40 \%$, which is based on a comparison of the model predictions with experimental ammonia solubility data.

Table S.1 summarizes the gas volume fractions, gas volumes, and hydrogen fractions of the significant gas-retaining waste regions in tanks subjected to RGS sampling. The values in the table are derived from RGS data alone and are based on the revised coefficient ammonia solubility model and the units correction. The resulting changes may be seen by comparing this table with Table S.1 in Mahoney et al. (1999). The few changes that were greater than roundoff of the last digit are bolded. 
Table S.1. $\quad$ Overview of Tank Gas Contents Based on RGS Data (all values derived from RGS data alone)

\begin{tabular}{|c|c|c|c|c|c|c|}
\hline & $\begin{array}{c}\text { Average } \\
\text { In Situ Gas } \\
\text { Volume } \\
\text { Percent } \\
\end{array}$ & $\begin{array}{c}\text { Maximum } \\
\text { In Situ Gas } \\
\text { Volume } \\
\text { Percent } \\
\end{array}$ & $\begin{array}{c}\text { Average } \\
{\mathrm{Mol} \% \mathrm{H}_{2}^{(\mathrm{a})}} \\
\end{array}$ & $\begin{array}{c}\text { Average } \\
\mathrm{Mol} \% \\
\mathrm{~N}_{2}^{(\mathrm{a})} \\
\end{array}$ & $\begin{array}{c}\text { Average } \\
\mathrm{Mol} \% \\
\mathrm{~N}_{2} \mathrm{O}^{(\mathrm{a})} \\
\end{array}$ & $\begin{array}{c}\text { Total STP } \\
\text { Free Gas } \\
\left(\mathrm{m}^{3}\right) \\
\end{array}$ \\
\hline AW-101 (one convective sample) & $\ldots$ & $0.8 \pm 0.1$ & $26 \pm 9.4$ & $68 \pm 32$ & $1.8 \pm 0.7$ & $28 \pm 9$ \\
\hline AW-101 (nonconvective layer) & $3.7 \pm 1.8^{(\mathrm{b})}$ & $5.2 \pm 0.5$ & $32 \pm 3.2$ & $56 \pm 6.2$ & $7.2 \pm 0.8$ & $85 \pm 42^{(\mathrm{b})}$ \\
\hline AN-105 (nonconvective layer) & $5.1 \pm 2.6^{(\mathrm{b})}$ & $12 \pm 0.8$ & $60 \pm 5.4$ & $24 \pm 4.0$ & $14 \pm 1.5$ & $185 \pm 92^{(6)}$ \\
\hline A-101 (nonconvective layer) & $18 \pm 9.0^{(\mathrm{b})}$ & $22 \pm 2.1$ & $72 \pm 7.1$ & $19 \pm 4.9$ & $5.8 \pm 0.6$ & $335 \pm 168^{(b)}$ \\
\hline AN-104 (nonconvective layer) & $8.0 \pm 4.0^{(\mathrm{b})}$ & $17 \pm 1.9$ & $45 \pm 6.9$ & $29 \pm 4.8$ & $23 \pm 3.7$ & $255 \pm 127^{(b)}$ \\
\hline AN-103 (one crust sample) & $\ldots$ & $16 \pm 1.4$ & $62 \pm 6.4$ & $29 \pm 3.2$ & $6.9 \pm 0.7$ & $54 \pm 27^{(b)}$ \\
\hline AN-103 (nonconvective layer) & $9.2 \pm 4.6^{(\mathrm{b})}$ & $12 \pm 1.5$ & $61 \pm 7.7$ & $33 \pm 4.3$ & $4.1 \pm 0.6$ & $259 \pm 129^{(b)}$ \\
\hline U-103 (nonconvective layer) & $19 \pm 9.5^{(\mathrm{b})}$ & $42 \pm 2.6$ & & & & $328 \pm 164^{(b)}$ \\
\hline S-106 (nonconvective layer) & $10 \pm 5.0^{(b)}$ & $14 \pm 1.2$ & $63 \pm 5.7$ & $25 \pm 3.7$ & $11 \pm 1.0$ & $223 \pm 111^{(b)}$ \\
\hline BY-101 & \multicolumn{6}{|c|}{ No results are available for this tank. } \\
\hline BY-109 (layer below ILL) & $9.4 \pm 4.7^{(\mathfrak{b})}$ & $12 \pm 1.0$ & $50 \pm 5.5$ & $29 \pm 5.1$ & $18 \pm 2.5$ & $122 \pm 61^{(b)}$ \\
\hline SX-106 (nonconvective layer) & $26 \pm 13^{(b)}$ & $36 \pm 2.2$ & $50 \pm 4.5$ & $20 \pm 3.8$ & $24 \pm 2.8$ & $430 \pm 215^{(b)}$ \\
\hline $\begin{array}{l}\text { AX-101 (one nonconvective } \\
\text { sample) }\end{array}$ & $\ldots$ & $17 \pm 1.3$ & $61 \pm 5.5$ & $17 \pm 2.6$ & $11 \pm 1.0$ & \\
\hline S-102 (all the waste) & $26 \pm 13^{(b)}$ & $33 \pm 4.3$ & $33 \pm 3.0$ & $32 \pm 4.3$ & $33 \pm 3.1$ & $600 \pm 300^{(b)}$ \\
\hline S-111 (one convective sample) & $\ldots$ & $0.8 \pm 0.2$ & $6.3 \pm 3.4$ & $90 \pm 68$ & $1.7 \pm 1.0$ & $0.3 \pm 0.1$ \\
\hline S-111 (nonconvective layer) & $15 \pm 7.5^{(\mathrm{b})}$ & $23 \pm 3.2$ & $66 \pm 10$ & $21 \pm 5.6$ & $11 \pm 1.7$ & $381 \pm 190^{(b)}$ \\
\hline U-109 (nonconvective layer) & $22 \pm 11^{(\mathrm{b})}$ & $30 \pm 1.9$ & $25 \pm 3.1$ & $46 \pm 7.8$ & $27 \pm 3.5$ & $441 \pm 220^{(b)}$ \\
\hline SY-101 (crust and bubble slurry) & $40 \pm 20^{(b)}$ & $73 \pm 7$ & $35 \pm 4.4$ & $28 \pm 4.6$ & $20 \pm 2.5$ & $224 \pm 112^{(b)}$ \\
\hline SY-101 (mixed slurry layer) & $2.8 \pm 1.4^{(\mathrm{b})}$ & $3.5 \pm 1.2$ & $27 \pm 8.3$ & $41 \pm 14$ & $26 \pm 7.3$ & $164 \pm 82^{(b)}$ \\
\hline \multicolumn{7}{|c|}{$\begin{array}{l}\text { (a) The uncertainty bands on the average composition represent only the instrument uncertainty. There were too few } \\
\text { samples to define the spatial variability of gas compositions. Lateral variation is not included. } \\
\text { (b) The RGS gas inventories and average gas volume fractions are assigned a } 50 \% \text { uncertainty because of the limited } \\
\text { number of samples on which the estimates are based. } \\
\text { Values in bold are those in which the ammonia model coefficient revision and units correction caused a change } \\
\text { greater than roundoff in the last digit. }\end{array}$} \\
\hline
\end{tabular}

\section{References}

Hedengren DC, SJ Geelhood, VF Medina, SK Early, and M Mercer. August 2000. "Ammonia Solubility Project Report." Washington State University, Richland, Washington.

Mahoney LA, ZI Antoniak, JM Bates, and ME Dahl. 1999. Retained Gas Sampling Results for the Flammable Gas Program. PNNL-13000, Pacific Northwest National Laboratory, Richland, Washington.

Norton JD and LR Pederson. 1994. Ammonia in Simulated Hanford Double-Shell Tank Wastes: Solubility and Effects on Surface Tension. PNL-10173, Pacific Northwest Laboratory, Richland, Washington. 



\section{Acknowledgments}

The authors would especially like to acknowledge the role played in testing the Retained Gas Sampler System by the following Hanford staff: Bruce Hey, Bev Crawford, and Lino Guerra. Dave Hedengren's and Larry Pederson's studies of ammonia solubility have been very enlightening. Also, we would like to thank Jim Bates, Joe Brothers, and in particular Judi Cuta for reviewing the document and the associated spreadsheets. We also thank Sheila Bennett for her meticulous editing of the RGS reports. 



\section{Contents}

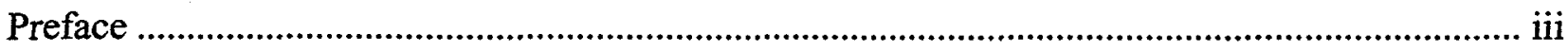

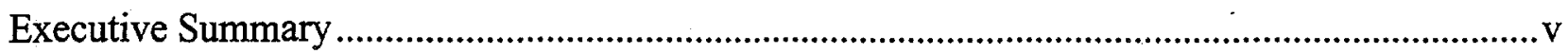

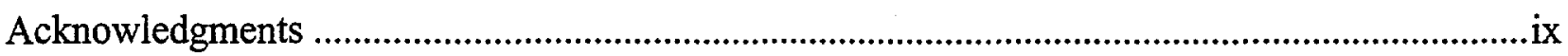

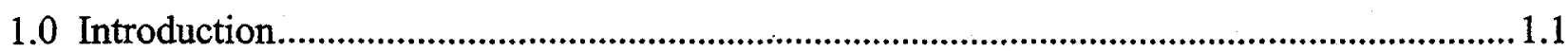

1.1 Ammonia Solubility Measurements and Models ......................................................1.1

1.2 RGS Ammonia Concentration Measurement Methods................................................... 1.2

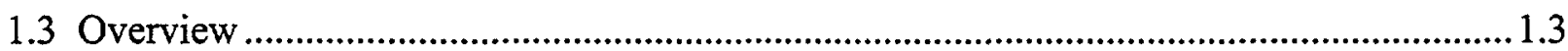

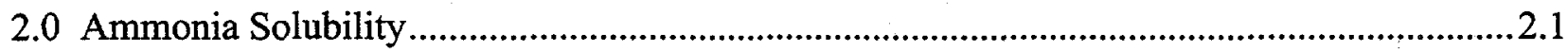

2.1 Ammonia Solubility Modeling at Hanford-Background...............................................2.1

2.2 Ammonia Solubility Experiments (1994-1995) .......................................................2.2

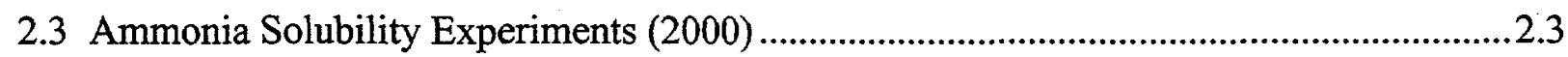

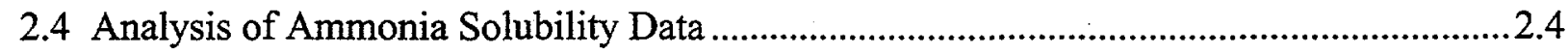

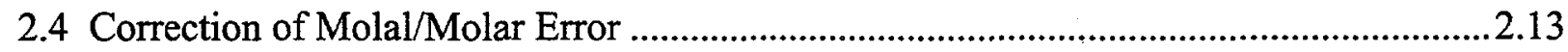

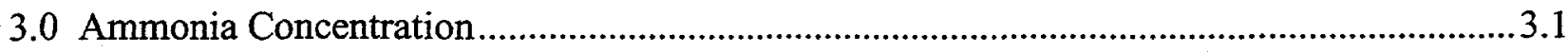

3.1 Vulnerabilities of Ammonia Measurement Methods......................................................3.2

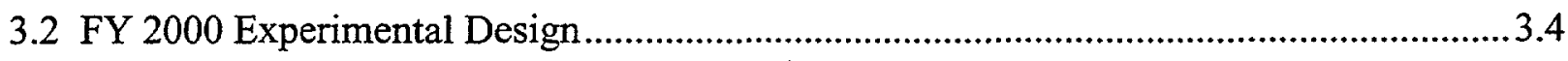

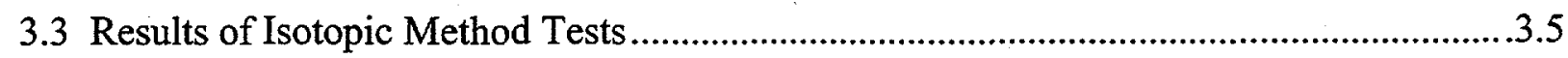

3.4 Results of Tests of the Initial Ammonia Partial Pressure Method ....................................3.9

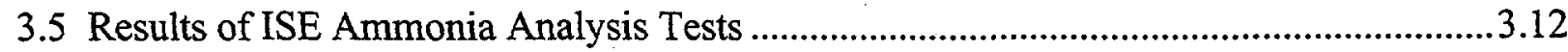

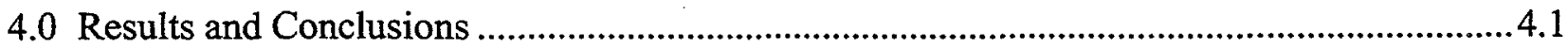

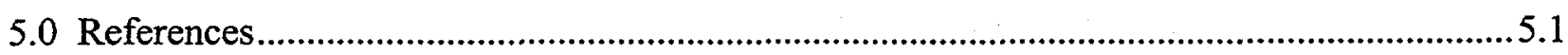




\section{Figures}

2.1 Comparison of Ammonia Solubility Constants in Potassium Hydroxide Solutions .2 .5

2.2 Comparison of Hanford Ammonia Solubility Data Sets .2 .6

2.3 Normalized Prediction Error for Selected Ammonia Solubility Data Sets based on Coefficients Correlated from Norton and Pederson 1994 .2 .9

2.4 Normalized Prediction Error for Selected Ammonia Solubility Data Sets based on Coefficients Correlated from Hedengren et al. 2000.

2.5 Schumpe Model Error for $\mathrm{NaOH}$ Data from Norton and Pederson .2 .12

2.6 Schumpe Model Error for $\mathrm{KOH}$ Data from Hedengren et al. .2 .12

2.7 Schumpe Model Error for KOH Data From Sorina et al. .2 .13

3.1 Schematic of the RGS Extraction System 3.4

\section{Tables}

S.1 Overview of Tank Gas Contents Based on RGS Data .................................................... vii

2.1 Comparison of Ammonia Solubility Constants in Sodium Hydroxide Solutions .................2.4

2.2 Ammonia Solubility Correlation Information ............................................................2.8

2.3 In Situ Compositions and Volume Fractions of Retained Gas from RGS Data ................2.15

2.4 Changes in In Situ Compositions and Volume Fractions of Free Gas from RGS Data ......2.19

2.5 In Situ Composition Ratios in Free Gas from RGS Data ..............................................2.2.20

2.6 Concentrations of Dissolved Gases Calculated from RGS Data ...................................2.2.21

2.7 Figures and Tables in Mahoney et al. (1999) Affected by Correction ...............................2.22

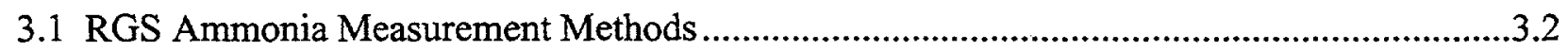

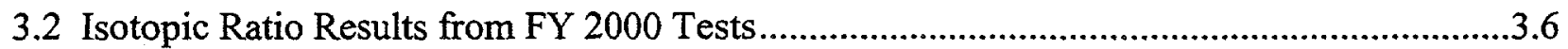

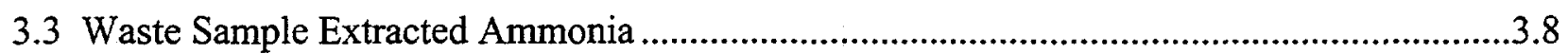

3.4 Ammonia and Water Partial Pressures over Standard $\mathrm{NH}_{4} \mathrm{OH}$ Solution............................3.10

3.5 Comparison of Ammonia Concentrations by Different Methods.....................................3.13

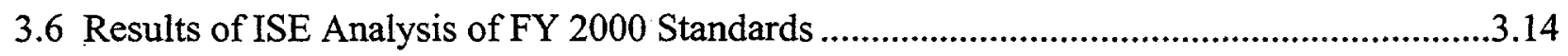




\subsection{Introduction}

Ammonia is present in the waste in many, if not all, Hanford waste storage tanks; it is a moderately flammable gas (Mahoney et al. 2000) and is also of toxicological concern (Van Keuren et al. 1996). Because ammonia is highly soluble, large ammonia releases are not likely to originate from retained gas bubbles but rather from evaporation from the freshly wetted waste surface when the waste is disturbed by a gas release. Salt-well pumping also exposes wetted surfaces in the drained waste pores and may increase ammonia releases (Peurrung et al. 1998). Thus, an understanding of both the concentration and the volatility of ammonia in waste is necessary to resolve concerns about risks from waste gas releases.

The volatility of any gas over a solution is inversely proportional to the solubility of the gas, so models that predict solubility also predict volatility. Ammonia solubility depends on the concentrations of salts in the waste liquid and on the waste temperature. In Hanford work, an algorithm commonly referred to as the Schumpe model has been used to predict the solubility of gases, including ammonia, in the waste liquid. Two different sets of ammonia vapor pressure data have been collected for Hanford waste simulants (Norton and Pederson 1994; Hedengren et al. 2000). This report correlates the Hanford data sets to revise coefficients used in the model and test the model's predictions of ammonia solubility in Hanford wastes, as summarized in Section 1.1.

Ammonia concentrations in Hanford waste have been measured by several methods. The most common method is chemical analysis of dissolved ammonia in grab samples and drainable liquid from core samples, typically using the ion-specific electrode (ISE) analytical technique. There is some reason to believe that these dissolved ammonia measurements tend to underestimate the true dissolved ammonia concentration because of ammonia evaporation during sample handling (Peurrung et al. 1998). Data obtained from retained gas sampling (RGS) measurements have also been used to measure dissolved ammonia (Mahoney et al. 1999), as summarized in Section 1.2.

\subsection{Ammonia Solubility Measurements and Models}

Ammonia solubility has been predicted at Hanford by using the Schumpe model, which consists of

1. the Sechenov approximation that gas solubility in a salt solution depends on a linear function of the salt molality (Sechenov 1889)

2. a set of empirical solubility proportionality coefficients determined by Schumpe and coinvestigators, who correlated data in the open literature (Schumpe 1993; Hermann et al. 1995; Weisenberger and Schumpe 1996).

The Schumpe model depends on the approximation that the logarithm of the gas solubility varies linearly with salt concentration. This approximation is accurate at low salt concentrations, up to about 0.1 molal, but can cause the model to overestimate the salting-out effect (decrease of solubility or increase of vapor pressure) that occurs at higher salt concentrations (Schumpe 1993). Because of uncertainty about the effect of nonlinear salting-out at the high salt 
concentrations in Hanford waste liquid, Mahoney et al. (1999) analyzed RGS data by presenting retained gas compositions based on both upper- and lower-bound estimates of gas solubilities.

Two sets of ammonia vapor pressure data have been collected for Hanford waste simulants (Norton and Pederson 1994; Hedengren et al. 2000). In this report, the two Hanford data sets are correlated to determine the solubility model coefficients for ammonia that produced the smallest sum of the squares of the prediction errors. The revised correlations are used to recalculate the ammonia vapor pressures and retained gas compositions under in situ conditions for all RGS samples.

At the time the ammonia vapor pressures were recalculated, an error made by Mahoney et al. (1999) in molal/molar concentration units conversion was discovered and corrected. Both the ammonia coefficient change and the error correction caused the ammonia vapor pressure to decrease. The error had negligible effect on the composition of the ammonia-free, low-solubility gases. The gas volume fractions were decreased significantly only for the few samples in which ammonia had made up more than a few percent of the retained gas.

\subsection{RGS Ammonia Concentration Measurement Methods}

RGS samples consisted of standard core samples collected in hermetically sealed samplers; the samples are extruded into an evacuated vessel that is vacuum pumped to extract the gas in the sample. The RGS data pertaining to sample ammonia concentration have been consistently more difficult to obtain and interpret than those for less soluble gases because the RGS extraction system was originally designed primarily to measure the hydrogen fraction and the total gas volume fraction. Measuring the nitrogenous gases, including ammonia, was of less concern at the time of design (Wootan 1995). However, increased concern about the toxicity of ammonia releases (Hedengren 2000) combined with high ammonia vapor pressures predicted by the Schumpe model (Peurrung et al. 1998) led to attempts to modify the RGS extraction procedure and data analysis to improve ammonia measurement.

Throughout the RGS program, sample gases were collected by pumping them from the extractor vessel (which contained the extruded RGS core sample) into collection canisters. This technique extracted only the small amount of ammonia that evaporated from the sample, not the much larger amount that remained dissolved. Furthermore, careful data analysis was required to calculate how much ammonia had been extracted. Much of it dissolved in the water that condensed on the walls of the collection canister as a result of pumping and so was not detected by mass spectrometry of the gas and vapor in the collection canister. Although the total collected ammonia could be calculated from the available data, it did not provide enough mass balance information to calculate the residual (dissolved unextracted) ammonia that remained in the sample. This residual ammonia made up most of the total sample ammonia concentration. Over the course of the program, several different approaches were taken to calculating the residual and total ammonia concentrations. (Details can be found in Section 3 of Mahoney et al. 1999.)

Although the last method used, the standard isotopic solution method, was believed at the time to be the most accurate of the RGS methods, its accuracy had not been determined as of the end of the RGS sampling program. In addition, the RGS results gained by isotopic solution 
analysis were frequently higher than ISE ammonia measurements made on non-RGS samples. For these and other reasons, experiments were carried out in FY 2000 to test the accuracy of the standard isotopic solution method. The experiments yielded inconclusive results, partly because they were cut short by staff shortages and equipment breakdowns. This report provides a final review of the methods used to calculate ammonia concentrations from RGS data and of the results of the isotopic solution method tests.

\subsection{Overview}

This report is intended as a supplement to Mahoney et al. (1999), which provided the RGS results for the tanks sampled during the RGS program: AW-101, A-101, AN-105, AN-104, AN-103, U-103, S-106, BY-101, BY-109, SX-106, AX-101, S-102, S-111, U-109, and SY-101. (a) Some of the tables provided in this report are revisions of summary tables in Mahoney et al. (1999), though not all tables from the earlier report are revised here. (Table 2.7 lists the tables from the earlier report that were affected.) The reader is advised to use the earlier report only in conjunction with the data and perspectives presented in this document. By the same token, this report is not a stand-alone document, and some topics are more completely described in Mahoney et al. (1999).

Section 2 of this report describes the models that have been used in the past to predict ammonia solubility in a salt solution, the Hanford experiments that have been carried out to provide solubility data specific to tank wastes, and the use of those data to provide a revised model for ammonia vapor pressure. Section 3 describes the experiments and resulting data that were carried out to assess the effectiveness of RGS ammonia concentration measurement methods, particularly the isotopic solution method. Section 4 presents the conclusions of the report and Section 5 the references.

(a) Hanford waste tanks are numbered beginning with the prefix 241-. However, in this report, the prefix will not be used, as is common practice when referring to the tanks at Hanford. 


\subsection{Ammonia Solubility}

Because of its solubility, almost all of the ammonia in Hanford tank waste is stored in solution, and evaporation is the major source of actual or hypothetical releases. An ammonia solubility model is used to calculate ammonia vapor pressures, which are needed to estimate ammonia releases, from measured ammonia concentrations.

The remainder of Section 2 discusses the models that have been used in the past to predict ammonia solubility in a salt solution (Section 2.1), the Hanford experiments that have been carried out to provide solubility data specific to tank wastes (Sections 2.2 and 2.3), and the use of those data to provide a revised model for ammonia vapor pressure (Section 2.4).

\subsection{Ammonia Solubility Modeling at Hanford-Background}

Gas solubilities in aqueous solutions are frequently well described by Henry's Law, which approximates the vapor pressure of a dilute solute as being directly proportional to the concentration of the solute in solution:

$$
\mathrm{p}=\mathrm{c}_{\mathrm{G}} / \mathrm{K}_{\mathrm{H}}
$$

where $\mathrm{p}$ is the vapor pressure, $\mathrm{c}_{\mathrm{G}}$ is the concentration of the solute, and $\mathrm{K}_{\mathrm{H}}$ is the Henry's Law constant in units of dissolved concentration per partial pressure of solute. (It should be noted that some of the literature defines the Henry's Law constant as the inverse of the $\mathrm{K}_{\mathrm{H}}$.) Ammonia modeling at Hanford has used Henry's Law with the assumption that dissolved ammonia concentrations are low enough that ammonia vapor pressures are proportional to dissolved ammonia concentrations. Henry's Law has also been used to model the other dissolved waste gases.

Gas and vapor pressures over solutions are also affected by temperature and by the presence of other solutes in solution. The primary model used in predicting the effect of salts on gas solubilities has been the Schumpe model. This model describes gas solubility in an electrolyte solution, such as Hanford waste liquid, in the following way:

$$
\log \left(\mathrm{K}_{\mathrm{H}, 0} / \mathrm{K}_{\mathrm{H}}\right)=\sum_{\mathrm{i}}\left(\mathrm{h}_{\mathrm{i}}+\mathrm{h}_{\mathrm{G}, 0}+\mathrm{h}_{\mathrm{GT}}(\mathrm{T}-298.15)\right) \mathrm{c}_{\mathrm{i}}
$$

where $\mathrm{K}_{\mathrm{H}, 0}$ is the Henry's Law constant of a particular gas in pure water, $\mathrm{K}_{\mathrm{H}}$ is the solubility of the same gas in the presence of a dissolved salt, $h_{i}$ represents a set of ion-specific coefficients, $h_{G}$ and $h_{G T}$ are gas-specific coefficients, $c_{i}$ is a set of ion concentrations and $T$ the absolute temperature.

Early studies (Schumpe 1993; Hermann et al. 1995) gave the coefficients $h_{i}$ and $h_{G, 0}$ only for a nominal ambient temperature of $298 \mathrm{~K}$. The data to determine the temperature-dependent coefficient $h_{\mathrm{GT}}$ were lacking at that time. A later article (Weisenberger and Schumpe 1996) provided the $h_{G T}$ coefficients and new values of $h_{G, 0}$ for a number of gases; however, the $h_{G T}$ of ammonia was not determined. This omission meant that the ammonia vapor pressure had to be 
modeled with $h_{\mathrm{Gr}}=0$. In other words, ammonia was modeled as having the same temperature dependence in salt solution as in pure water. The molal Henry's Law constant for ammonia in water (Clegg and Brimblecombe 1989) is given as:

$$
\ln \mathrm{K}_{\mathrm{H}, 0}=-8.0964+3917.50 / \mathrm{T}-0.00314 \mathrm{~T}
$$

The RGS reports (Shekarriz et al. 1997; Mahoney et al. 1997; Mahoney et al. 1999) and Peurrung et al. (1998) used the early coefficients determined by Schumpe (1993) and Hermann et al. (1995) because those coefficients had been found by Norton and Pederson (1995) to be reasonably accurate over a temperature range typical of Hanford wastes. Other work (Hedengren 2000) used the later coefficients obtained by Weisenberger and Schumpe (1996), which included non-zero $\mathrm{h}_{\mathrm{Gr}}$ (except for ammonia) and predicted higher ammonia vapor pressures than the early coefficients, assuring conservatism.

While Equation (2.2) is reasonably applicable to describing gas solubilities at low electrolyte concentrations-between 2 and $5 \underline{\mathrm{M}}$, according to Weisenberger and Schumpe (1996)-it tends to overestimate the salting-out effect (the lowering of gas solubility) at higher electrolyte concentrations such as those often found in Hanford wastes. The possible underestimation of gas solubility could in theory be substantial. ${ }^{(a)}$ Furthermore, ion-specific interaction parameters are not known for all the components of Hanford wastes. Aluminate is a prime example. Therefore, two sets of experiments were carried out to explore the accuracy and applicability of the Schumpe model for gases dissolved in Hanford waste. These experiments are briefly described in Sections 2.2 and 2.3.

\subsection{Ammonia Solubility Experiments (1994-1995)}

Norton and Pederson (1994) measured the vapor pressures of water and ammonia over salt solutions, varying the salt and ammonia concentrations and the temperature. The salt solutions included sodium hydroxide (concentration ranging from 0.5 to $7.0 \mathrm{~m} \mathrm{NaOH}$ ) and two $\mathrm{SY}-101$ waste simulants. Of the simulants, one (SY1-SIM-91A) had a total ionic concentration of $24.6 \mathrm{M}$ and was heterogeneous - that is, it contained precipitate, the amount of which varied with temperature. The actual ionic concentration of the heterogeneous simulant was less than 24.6 $\mathrm{M}$ because some of the salts were in solid form. The other (SY1-SIM-93B) had a total ionic concentration of $13.9 \underline{\mathrm{M}}$ and was homogeneous (free of solids). Temperatures varied from about $25^{\circ}$ to $70^{\circ} \mathrm{C}$.

First, the water vapor pressure of the degassed salt solution was measured over the full temperature range, using an isoteniscope designed to avoid any loss of ammonia by reaction with or dissolution in the manometer fluid. Next, a known amount of $30 \mathrm{wt} \% \mathrm{NH}_{4} \mathrm{OH}$ solution was injected into the sample, with precautions to avoid introducing air. The ammonia/water vapor pressure was then measured over the temperature range and the water vapor pressure subtracted to give the ammonia vapor pressure. The measurement technique did not require any vapor samples to be taken.

(a) Kubic WL Jr. 1996. Evaluation of Weisenberger and Schumpe Correlation for Gas Solubility. Letter report, Los Alamos National Laboratory, Los Alamos, New Mexico. 
The salt concentrations in the liquid of the heterogeneous sample varied with temperature as a result of dissolution and precipitation. Hedengren et al. (2000) found that at $20^{\circ} \mathrm{C}$ the total ion concentration in solution was $20 \mathrm{M}$, indicating that 4.6 moles/liter of ions were present as precipitate. In our interpretation of the data from Norton and Pederson (1994), we adjusted the total salt concentration for temperature. The ion concentration at $70^{\circ} \mathrm{C}$ was not measured and therefore was approximated as being $1.2 \mathrm{M}$ higher than the $20 \mathrm{M}$ measured at $20^{\circ} \mathrm{C}$. Version 6.4 of the WaterAnalyzer ${ }^{\circledR}$ chemical thermodynamics model (OLI 1998), including the GENTANKW chemistry specifications, was used to model the heterogeneous simulant at both temperatures. This model calculated a $1.2 \mathrm{M}$ difference in salt concentration in the liquid between $20^{\circ}$ and $70^{\circ} \mathrm{C}$. Solids were modeled (and observed) to be present at $70^{\circ} \mathrm{C}$.

The density of the liquid in the heterogeneous simulant was not stated in Norton and Pederson (1994). Based on the WaterAnalyzer results, a density of $1463 \mathrm{~g} / \mathrm{L}$ was used.

\subsection{Ammonia Solubility Experiments (2000)}

Hedengren et al. (2000) measured the ammonia concentrations in $\mathrm{NH}_{4} \mathrm{OH}$ and ammoniated salt solutions. ${ }^{(2)}$ Both the salt and $\mathrm{NH}_{4} \mathrm{OH}$ solutions were exposed to the same ammonia vapor pressure so that the ratio of the ammonia concentrations in water and salt solution was equal to the ratio of their respective Henry's Law constants. Most of the tests were carried out with SY1-SIM-91A simulant that was filtered at $20^{\circ} \mathrm{C}$ to remove solids. The simulant was used at full strength and at volumetric dilutions ranging from 0.33 water: 1 simulant to 5 water:1 simulant. Solutions of $0.95 \underline{\mathrm{M}}, 3.15 \underline{\mathrm{M}}$, and $5.35 \underline{\mathrm{M}}$ potassium hydroxide were also tested. Temperatures ranged from about $20^{\circ}$ to $70^{\circ} \mathrm{C}$.

Each experiment began by interconnecting the vapor space over three flasks-the first containing concentrated $\mathrm{NH}_{4} \mathrm{OH}$, the second water, and the third salt solution. The concentrated $\mathrm{NH}_{4} \mathrm{OH}$ solution served as a source of ammonia to the two receiver flasks, which, after some time, were isolated from the source flask and the atmosphere and left in communication with each other. The solutions were held at the same temperature and stirred or agitated with a shaker table. Samples were taken periodically to determine ammonia, salt, and water concentrations. Ammonia was measured with a spectrophotometric technique.

The initial proof-of-concept tests (Hedengren 2000, Appendix F) were performed at Washington State University (WSU) in mostly full $500-\mathrm{mL}$ flasks interconnected by Tygon ${ }^{\circledR}$ tubing, all at room temperature. The contents were mixed by an electric stirrer. These tests showed differences of a factor of 6 between the measured salt/water solubility ratios and Schumpe model predictions (made using the Weisenberger and Schumpe coefficients). One week was required to reach equilibrium following removal of the ammonia source, which raised questions about the results.

The first phase of systematic testing (Hedengren et al. 2000) was carried out at WSU with apparatus designed to produce more complete mixing of the solution and to reduce the volume of vapor space. The solutions were contained in $15-\mathrm{mL}$ vials placed in a sealed $250-\mathrm{mL}$ jar that

(a) Bechtold DB. 2000. Report of Ammonia Solubility Experiments. Letter report FH-002361, CH2M Hill Hanford Group, Richland, Washington. 
provided the common vapor space. The jar was in a thermostatically controlled bath. The vial contents were mixed by a shaker bath. Initial tests showed that equilibrium was reached within one day after the ammonia source was removed. Similar experiments were performed in the second phase of testing ${ }^{(a)}$ in the 222-S Laboratory. The solutions were contained in $15-\mathrm{mL}$ vials placed in a sealed $500-\mathrm{mL}$ jar, which was in a thermostatically controlled shaker bath.

The second phase encountered difficulties because the larger jars had more surface area above the surface of the constant-temperature bath. Water condensed on this exposed surface and rained down into the salt solution. White precipitates formed in the simulant solution, often redissolving after some days. The "rain" and precipitate were most noticeable in the highertemperature runs of the second phase. They had not been apparent in the first-phase tests. However, water concentration measurements showed that water transport had occurred in both the first and second phases of the experiments and caused measurable dilution of the salt solutions. In a few cases, second-phase tests were re-run because a combination of the shaker-table motion and aspiration by vacuum in the jar had allowed water from the bath to enter the samples.

\subsection{Analysis of Ammonia Solubility Data}

We compared the data obtained from the Hanford experiments discussed in Sections 2.2 and 2.3 with literature data (Sing et al. 1999; Sorina et al. 1967) for $\mathrm{NaOH}$ and $\mathrm{KOH}$ solutions. The comparison of Hanford experimental results with single-salt data in the literature roughly confirms the Hanford results.

Sing et al. (1999) collected only two data points in the range of $\mathrm{NaOH}$ concentrations and temperatures used by Norton and Pederson (1994). The data from the two references agreed within $14 \%$ at both conditions. Table 2.1 provides a comparison of the molar Henry's Law constants measured in the two sets of experiments.

Table 2.1. Comparison of Ammonia Solubility Constants in Sodium Hydroxide Solutions

\begin{tabular}{||l|c|c|c||}
\hline \multicolumn{1}{|c|}{ Data } & $\begin{array}{c}\mathrm{NaOH} \\
(\mathrm{M})\end{array}$ & $\begin{array}{c}\text { Temperature } \\
\left({ }^{\circ} \mathrm{C}\right)\end{array}$ & $\begin{array}{c}\text { Measured Henry's } \\
\text { Law Constant } \\
(\mathrm{mol} / \mathrm{L} \text { atm })\end{array}$ \\
\hline Norton and & 2.5 & 38.1 & 18.2 \\
Peterson (1994) & & 43.1 & 14.9 \\
& 3.9 & 37.8 & 11.6 \\
& & 43.6 & 9.1 \\
\hline Sing et al. (1999) & 3.0 & 40 & 13.0 \\
\hline Norton and & 5.3 & 38.1 & 9.2 \\
Peterson (1994) & & 43.9 & 7.5 \\
& 6.7 & 38.2 & 5.7 \\
& & 43.3 & 4.8 \\
\hline Sing et al. (1999) & 5.8 & 40 & 6.6 \\
\hline
\end{tabular}

(a) Bechtold DB. 2000. Report of Ammonia Solubility Experiments. Letter report FH-002361, CH2M Hill Hanford Group, Richland, Washington. 
Hedengren et al. designed their $\mathrm{KOH}$ test series (Section 2.3) to match the conditions of the experiments performed by Sorina et al. (1967). Figure 2.1 compares the molar Henry's Law constants measured by Hedengren et al. with those of Sorina et al. (1967). The two sets of results match well at $3 \underline{\mathrm{M}} \mathrm{KOH}$. At $0.95 \underline{\mathrm{M} \mathrm{KOH}}$, the solubilities from the first phase of the Hedengren test series are consistently roughly $30 \%$ greater than those of Sorina et al. (1967). The two measurements made during the second phase of the Hedengren et al. tests are within $15 \%$ of the Sorina et al. values.

The apparent scatter in Sorina's data between solubility values measured at the same temperature and $\mathrm{KOH}$ concentration is, in part, the result of varying the ammonia concentration between $0.3 \mathrm{M}$ and $1.2 \mathrm{M}$. As an example, at $50^{\circ} \mathrm{C}$ and $0.95 \underline{\mathrm{M}} \mathrm{KOH}$, the Henry's Law constant of ammonia increased from $9.4 \mathrm{~mol} /(\mathrm{L} \mathrm{atm})$ at $0.28 \underline{\mathrm{M} ~ N H_{3}}$ to $12 \mathrm{~mol} /(\mathrm{L}$ atm $)$ at $1.2 \mathrm{M} \mathrm{NH}_{3}$. This variation indicates that, for ammonia concentrations similar to those in Hanford waste, the Henry's Law assumption in Equation (2.1) does not account for nonlinear effects of ammonia. These effects amount to about $20 \%$ variation in the Henry's Law constant for a change of $1 \mathrm{M}$ $\mathrm{NH}_{3}$. The ammonia concentrations in the Hedengren et al. tests ranged only from 0.1 to $0.6 \mathrm{M}$, so differences in ammonia concentrations are unlikely to account for the differences between the $0.95 \underline{\mathrm{M}} \mathrm{KOH}$ data of Sorina et al. and of the first-phase tests of Hedengren et al.

The two Hanford data sets do not match each other closely. Figure 2.2 shows the simulant data from the Norton and Pederson study and the Hedengren et al. study. The data are represented as the ratio of the ammonia partial pressure measured over salt solution to the ammonia partial pressure over ammonia in water. This ratio is a directly measured datum for the Hedengren et al. data, but in the case of the Norton and Pederson data the ratio is calculated from the measured ammonia partial pressure over the salt solution and a predicted ammonia partial pressure over an ammonia-water solution at the same temperature and ammonia concentration.

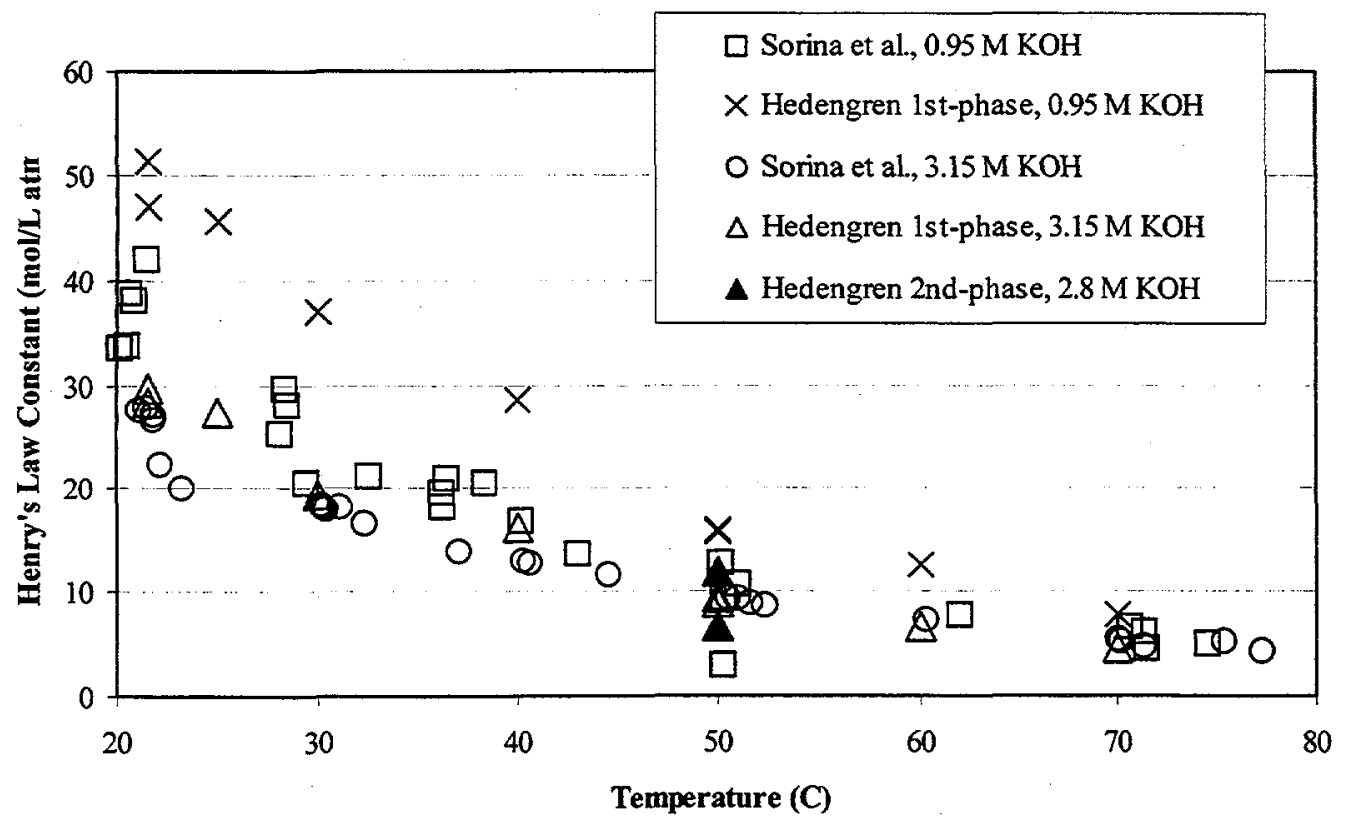

Figure 2.1. Comparison of Ammonia Solubility Constants in Potassium Hydroxide Solution 


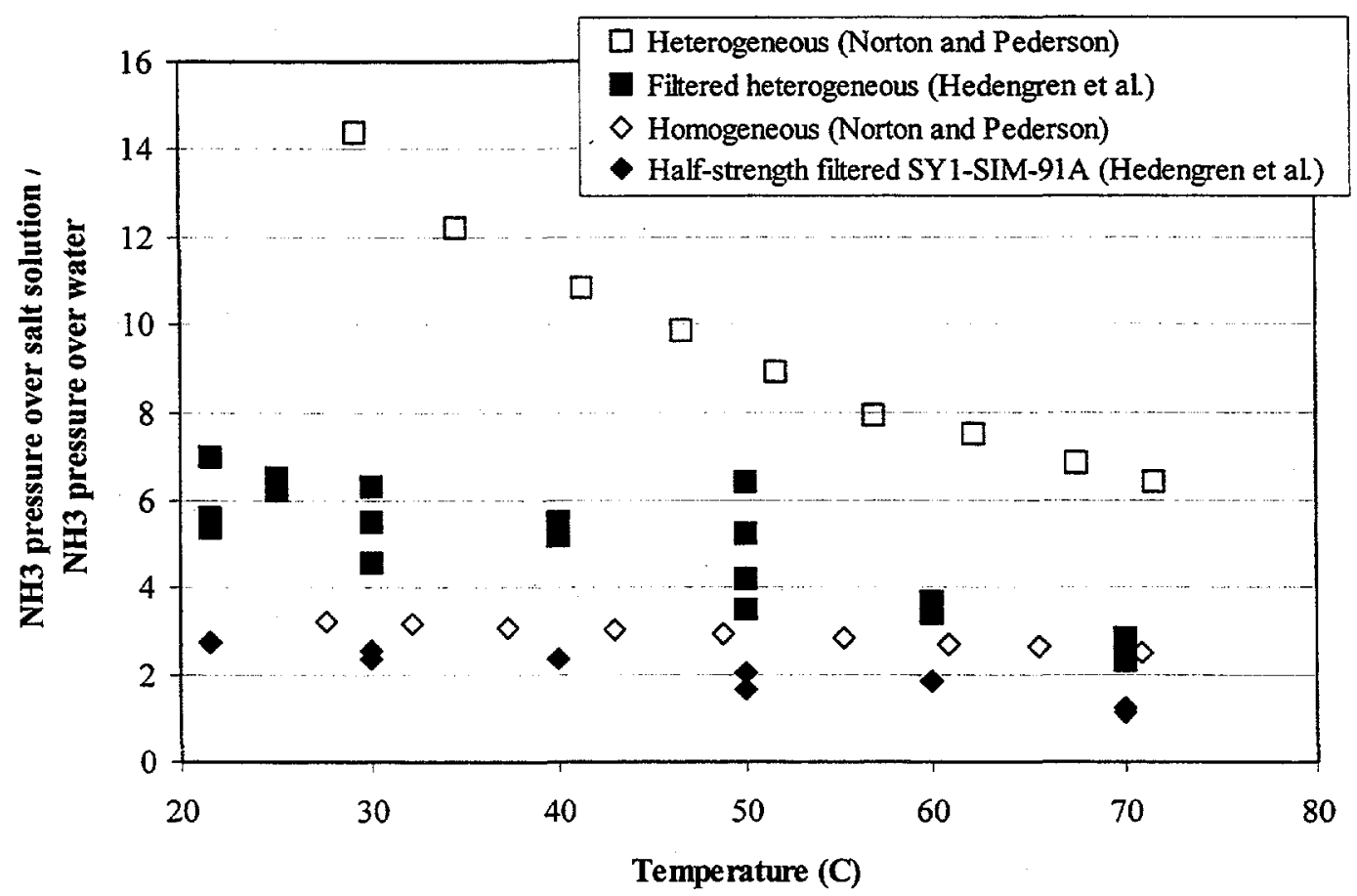

Figure 2.2. Comparison of Hanford Ammonia Solubility Data Sets

As will be seen, this distinction between measured and predicted ammonia pressures over saltfree solutions is of some importance.

The filtered heterogeneous simulant used by Hedengren et al. (2000) had a dissolved salt concentration that at $20^{\circ} \mathrm{C}$ was the same as that in the unfiltered heterogeneous simulant used by Norton and Pederson (1994), and at $70^{\circ} \mathrm{C}$ was 90 to $95 \%$ of the Norton and Pederson dissolved salt concentration. It is unlikely that this small concentration difference is the sole reason for the fact that the Norton and Pederson partial pressures are more than a factor of two as high as those measured by Hedengren et al. The same can be said for the difference between the ammonia partial pressures measured over the homogeneous Norton and Pederson simulant (6.0 $\underline{M}$ in sodium) and the half-strength Hedengren et al. simulant (5.0 $\underline{\mathrm{M}}$ in sodium).

It has been shown that a difference in the basic assumptions of the measurement methods might have caused the difference between the Hedengren et al. results and the Norton and Pederson results that appears in Figure 2.2. ${ }^{(a)}$ The Norton and Pederson experiments directly measured the partial pressure of ammonia $\mathrm{p}_{\text {meas }}^{\text {salt }}$ over salt solutions. The predicted partial pressures were found from the predicted salt-solution Henry's Law constant $K_{\text {pred }}^{\text {salt }}$ and the experimental dissolved ammonia concentration $\mathrm{c}_{\text {meas }}^{\text {salt }}$ :

$$
\mathrm{p}_{\text {pred }}^{\text {salt }}=\frac{\mathrm{c}_{\text {meas }}^{\text {salt }}}{K_{\text {pred }}^{\text {salt }}} \quad \text { for Norton and Pederson data }
$$

(a) Personal communication from JM Cuta to LA Mahoney, August 30, 2000. 
and the pressure-ratio quantity that is used in error calculation and model correlation is

$$
\frac{p_{\text {pred }}^{\text {salt }}}{p_{\text {meas }}^{\text {salt }}}=\frac{c_{\text {meas }}^{\text {salt }}}{K_{\text {pred }}^{\text {salt }} p_{\text {meas }}^{\text {salt }}}=\frac{K_{\text {meas }}^{\text {salt }}}{K_{\text {pred }}^{\text {salt }}} \text { for Norton and Pederson data }
$$

The experiments of Hedengren et al. measured the ratio $c_{\text {meas }}^{\text {water }} / c_{\text {meas }}^{\text {salt }}$, which could be converted to $\mathrm{K}_{\text {meas }}^{\text {water }} / \mathrm{K}_{\text {meas }}^{\text {salt }}$ because both concentrations were measured at the same partial pressure of ammonia.

The predicted ratio of ammonia partial pressures over salt solution and water, $\mathrm{p}_{\text {pred }}^{\text {salt }} / \mathrm{p}_{\mathrm{pred}}^{\text {water }}$, is equal to $\mathrm{K}_{\text {pred }}^{\text {water }} / \mathrm{K}_{\text {pred }}^{\text {salt }}$ by definition. Similarly, the ratio of ammonia partial pressures, $\mathrm{p}_{\text {meas }}^{\text {salt }} / \mathrm{p}_{\text {meas }}^{\text {water }}$, that would correspond to the measured ratio of solubilities is equal to $\mathrm{K}_{\text {meas }}^{\text {water }} / \mathrm{K}_{\text {meas }}^{\text {salt }}$. Therefore,

$$
\frac{\mathrm{p}_{\text {pred }}^{\text {salt }}}{\mathrm{p}_{\text {meas }}^{\text {salt }}}=\frac{\mathrm{K}_{\text {pred }}^{\text {water }} / \mathrm{K}_{\text {pred }}^{\text {salt }}}{\mathrm{K}_{\text {meas }}^{\text {water }} / \mathrm{K}_{\text {meas }}^{\text {salt }}}=\frac{\mathrm{K}_{\text {meas }}^{\text {salt }}}{\mathrm{K}_{\text {pred }}^{\text {salt }}} \frac{\mathrm{K}_{\text {pred }}^{\text {water }}}{\mathrm{K}_{\text {meas }}^{\text {water }}} \text { for Hedengren et al. data }
$$

This is not the same prediction/measurement relationship as for the Norton and Pederson data in Equation (2.5) unless the ammonia vapor pressure over an ammonia/water solution, as measured by the method of Hedengren et al., equals the predicted value. In other words, for the two relationships to be the same the measurements must show that $p_{\text {meas }}^{\text {water }}=p_{\text {pred }}^{\text {wate }}$. Lacking measurements to prove that, the possibility exists that prediction-error comparisons between the two experiments are inaccurate because of additional scatter introduced by the $\mathrm{K}_{\text {pred }}^{\text {water }} / \mathrm{K}_{\text {meas }}^{\text {water }}$. The same is true for correlations that are based on both sets of data.

Having checked the Hanford data sets against the literature and each other, we carried out two correlations, one with Norton and Pederson simulant data and one with Hedengren et al. simulant data, to determine what coefficients $h_{G, 0}$ and $h_{G T}$ best fit Equation (2.2) to the ammonia vapor pressure data. The $\mathrm{NaOH}$ and $\mathrm{KOH}$ data were excluded from the correlation database as being less pertinent. The fits were accomplished by using the Excel ${ }^{\circledR}$ Solver module to find the coefficients that minimized the sum of the squares of the normalized prediction errors over the entire simulant data set. The normalized prediction error for each data point is defined as

$$
\text { norm. pred. error }=\frac{\text { Schumpe prediction }- \text { measured value }}{\text { measured value }}
$$

Table 2.2 shows the results of the correlations and a description of the data sets. The revised coefficients based on the Norton and Pederson simulant data are quite different from those provided by Hermann et al. (1995), $h_{\mathrm{G}, 0}=-0.0506$, and Weisenberger and Schumpe $(1996), \mathrm{h}_{\mathrm{G}, 0}=$ -0.0481 . The revised coefficients based on the Hedengren simulant data are closer to the literature values, bearing in mind that the literature data sets were not complete enough to allow an $h_{G T}$ to be calculated. 
Table 2.2. Ammonia Solubility Correlation Information

\begin{tabular}{|c|c|c|c|c|}
\hline Source & $\begin{array}{l}\text { Number } \\
\text { of data } \\
\text { points }\end{array}$ & $\begin{array}{c}\text { Temperature } \\
\left({ }^{\circ} \mathrm{C}\right)\end{array}$ & $\begin{array}{l}\mathrm{NH}_{3} \\
(\underline{\underline{\mathrm{M}}}) \\
\end{array}$ & $\begin{array}{c}\text { Total ion } \\
\text { concentration } \\
(\underline{M})\end{array}$ \\
\hline $\begin{array}{l}\text { Norton and Pederson } \\
\text { (1994), simulants }\end{array}$ & 60 & $28-71$ & $0.7-2.8$ & $12,24.6$ \\
\hline $\begin{array}{l}\text { Norton and Pederson } \\
(1994), \mathrm{NaOH}\end{array}$ & 46 & $27-71$ & $0.6-0.7$ & $1-14$ \\
\hline $\begin{array}{l}\text { Hedengren et al. (2000), } \\
\text { phase } 1 \text {, simulants }\end{array}$ & 50 & $21-70$ & $0.06-0.8$ & $3.2-20$ \\
\hline $\begin{array}{l}\text { Hedengren et al. (2000), } \\
\text { phase } 2 \text {, simulants } \\
\text { (a) }\end{array}$ & 13 & $30-70$ & $0.3-0.8$ & $3.2-20$ \\
\hline $\begin{array}{l}\text { Hedengren et al. (2000), } \\
\text { phase } 1, \mathrm{KOH}\end{array}$ & 27 & $21-70$ & $0.1-1.0$ & $1.9,6.3,11$ \\
\hline $\begin{array}{l}\text { Hedengren et al. (2000), } \\
\text { phase } 2, \mathrm{KOH}^{(a)}\end{array}$ & 1 & 50 & 0.6 & 5.9 \\
\hline \multicolumn{5}{|c|}{$\begin{array}{l}\text { Results of the correlation of the Norton and Pederson simulant data: } \\
\mathrm{h}_{\mathrm{G}, \mathrm{O}}=-0.03575 \mathrm{~L} / \mathrm{mole} \\
\mathrm{h}_{\mathrm{GT}}=-3.999 \times 10^{-4} \mathrm{~L} / \text { mole } \mathrm{K} \\
\text { Results of the correlation of the Hedengren et al. simulant data: } \\
\mathrm{h}_{\mathrm{G}, 0}=-0.04932 \mathrm{~L} / \mathrm{mole} \\
\mathrm{h}_{\mathrm{GT}}=-3.660 \times 10^{-4} \mathrm{~L} / \text { mole } \mathrm{K}\end{array}$} \\
\hline $\begin{array}{l}\text { (a) Bechtold DB. 2000. } \\
002361, \text { CH2M Hill Hanford }\end{array}$ & $2+x_{1}$ & nia somon & & Lette \\
\hline
\end{tabular}

Figure 2.3 shows how the normalized prediction error behaves for representative subsets of the data, for the model with the revised coefficients based on the Norton and Pederson data. The Norton and Pederson (1994) simulant data comprise two sets, one with the half-strength simulant SY1-SIM-93B that contained no solids, and one with the full-strength simulant SY1-SIM-91A that contained solids. These are the results:

- The homogeneous simulant data (black x's in the plot) from Norton and Pederson are overpredicted by $25 \%$ or less, and the heterogeneous simulant data are underpredicted by $30 \%$ or less (black asterisks).

- The Hedengren et al. simulant data (blue diamonds, circles, and squares) are overpredicted, generally by less than $125 \%$. No obvious temperature trend exists in the error. Much larger overprediction is seen for many of the second-phase tests (solid blue diamonds, circles, and squares) even though the model inputs accounted for the dilution of second-phase simulants by "condensate rain." Considering the experimental difficulties during this phase, it seems likely that these highly overpredicted data points are outliers. They should not be taken as proof that the model with revised coefficients based on Norton and Pederson data overpredicts ammonia vapor pressure by up to $350 \%$, as depicted. 


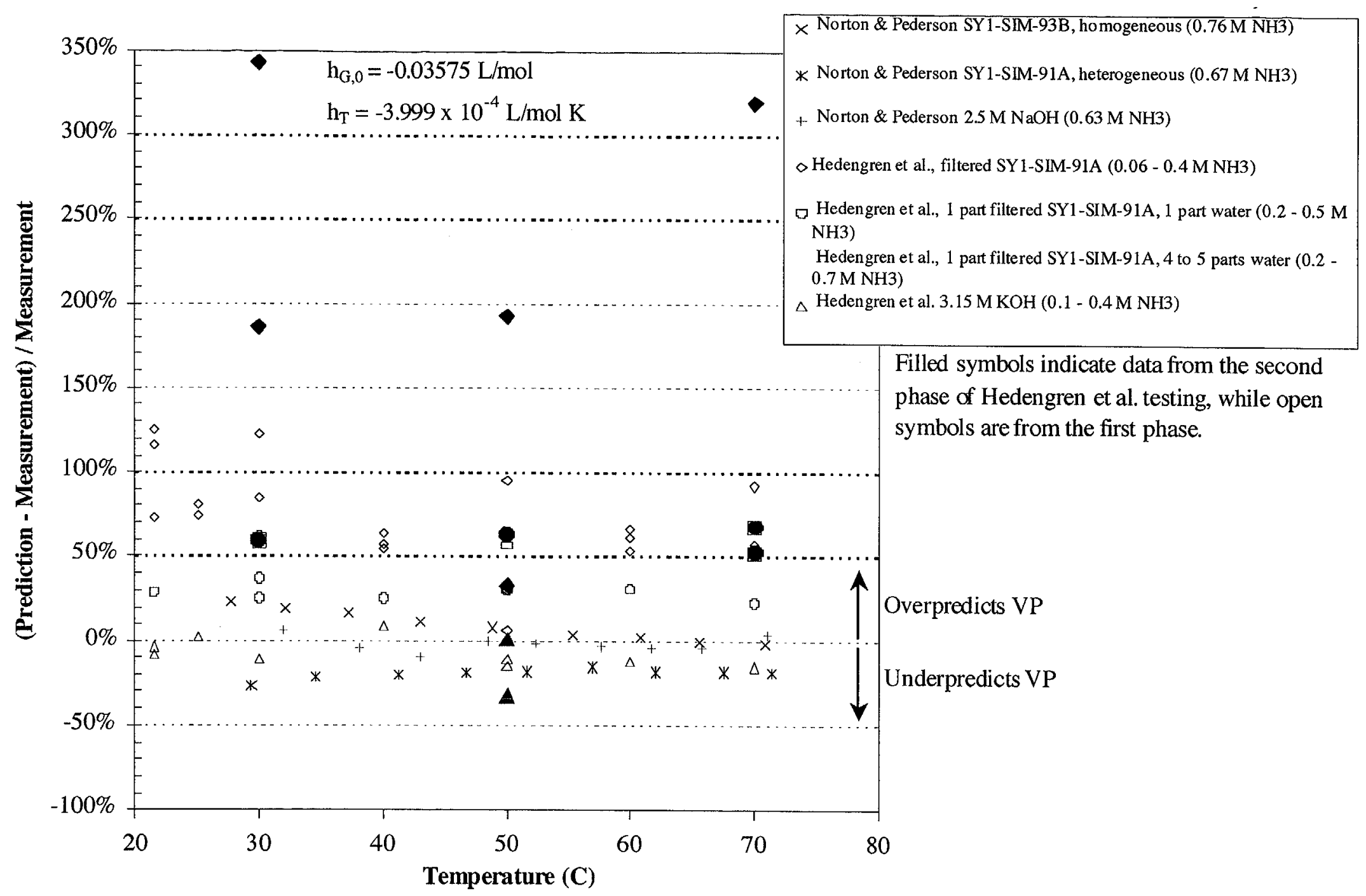

Figure 2.3. Normalized Prediction Error for Selected Ammonia Solubility Data Sets Based on Coefficients Correlated from Norton and Pederson (1994) Data 
- The Schumpe model with revised coefficients based on Norton and Pederson data tends to predict vapor pressures very closely for $\mathrm{NaOH}$ solutions at 5 to $6 \underline{\mathrm{M}}$ total ion concentration (green crosses). It does the same for the $\mathrm{KOH}$ solutions at $6 \underline{\mathrm{M}}$ total ion concentration (red triangles) from Hedengren et al. (2000).

Figure 2.4 shows how the normalized prediction error behaves for representative subsets of the data using the model with the revised coefficients based on the Hedengren et al. data. The results are

- The predictions for the Hedengren simulant data are within $25 \%$ or less of measurements. The notable exceptions are the four outliers from the second phase of testing that were not included in the correlation database.

- The Norton and Pederson simulant data are underpredicted by 15 to $30 \%$ for homogeneous simulant and by 50 to $60 \%$ for heterogeneous simulant. There is no obvious temperature trend in the error.

- The Schumpe model with revised coefficients based on Hedengren et al. data tends to underpredict vapor pressures by 25 to $30 \%$ for $\mathrm{NaOH}$ solutions at 5 to $6 \underline{\mathrm{M}}$ total ion concentration from Norton and Pederson (1994) and for $\mathrm{KOH}$ solutions at $6 \underline{\mathrm{M}}$ total ion concentration from Hedengren et al. (2000).

A comparison of the model and the data for other $\mathrm{NaOH}$ concentrations (up to a total ion concentration of $14 \underline{\mathrm{M}}$ ) showed that the tendency for the model to underpredict the vapor pressure consistently increased with the total concentration, as it did for the SY-101 simulants in the 1994 tests. Exactly the same trend was seen for the KOH data from the Hedengren et al. tests, but the $\mathrm{KOH}$ data from Sorina et al. (1967) showed the opposite trend. Figures 2.5, 2.6, and 2.7 show the Norton and Pederson $\mathrm{NaOH}$ prediction errors, the Hedengren et al. $\mathrm{KOH}$ prediction errors, and the Sorina et al. $\mathrm{KOH}$ prediction errors, respectively. These figures are all based on the model with the revised coefficients based on Norton and Pederson data, but the concentration dependences of the prediction errors are the same no matter which set of revised coefficients is used.

For comparison, the coefficients from Hermann et al. (1995) that were used in the Schumpe model in RGS studies overpredicted the vapor pressures for most of the Hanford database. The normalized prediction error was spread predominantly between $-10 \%$ and $+75 \%$ for the simulant data from the Hedengren et al. (2000) tests, and between $+10 \%$ and $-60 \%$ for the simulant data from the Norton and Pederson (1994) tests. In both of these data subsets, the errors trended strongly and consistently toward greater overprediction (more positive error values) as the temperature increased. At higher temperatures, both sets of revised coefficients can therefore be expected to overpredict less, or underpredict more, than the Hermann et al. set.

Because the two simulant data sets cannot be combined into a joint correlation, we have chosen to use them to provide lower-bound and upper-bound ammonia solubilities in reinterpreting the RGS data. This approach is described in Section 2.4. 


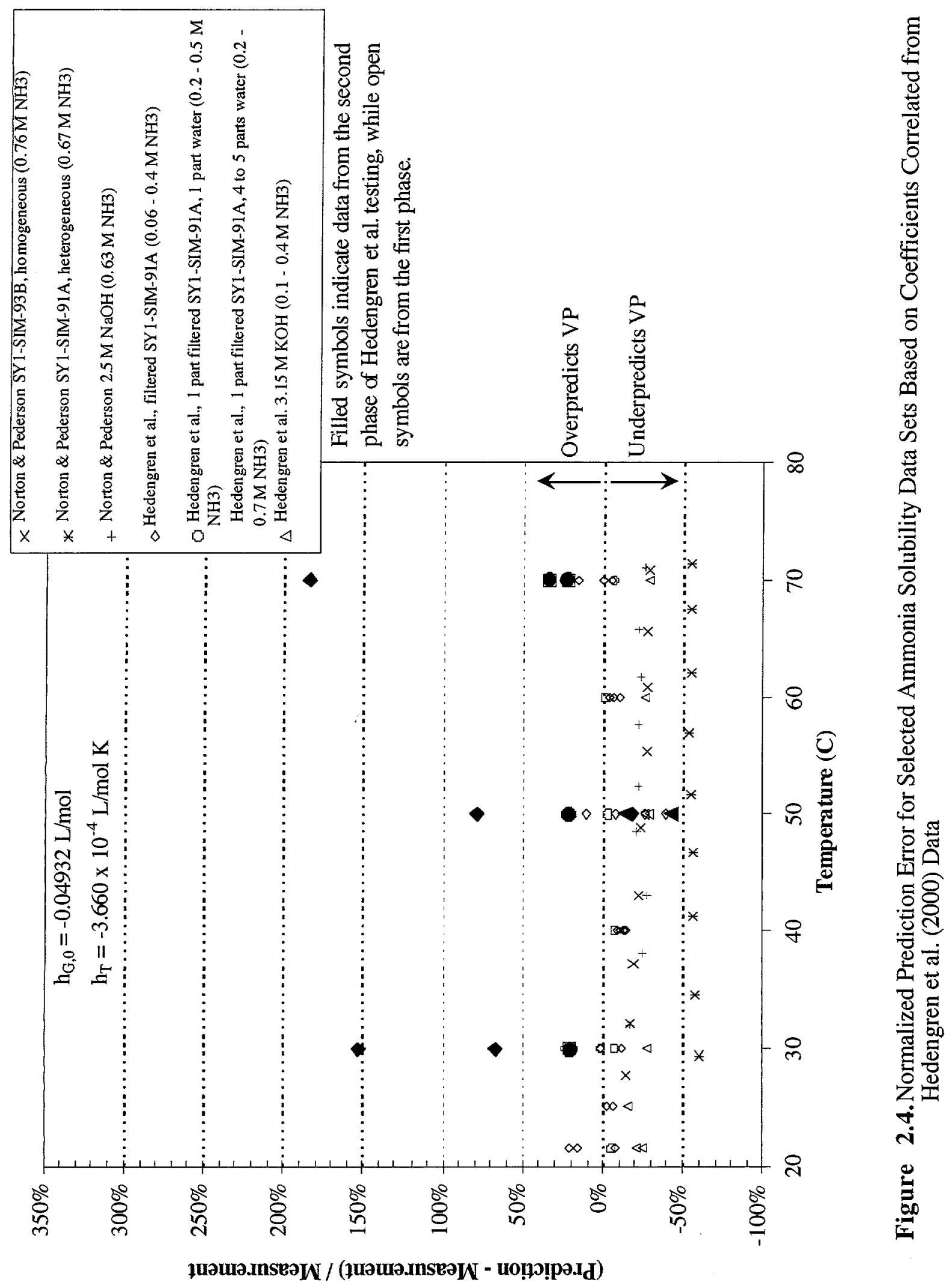




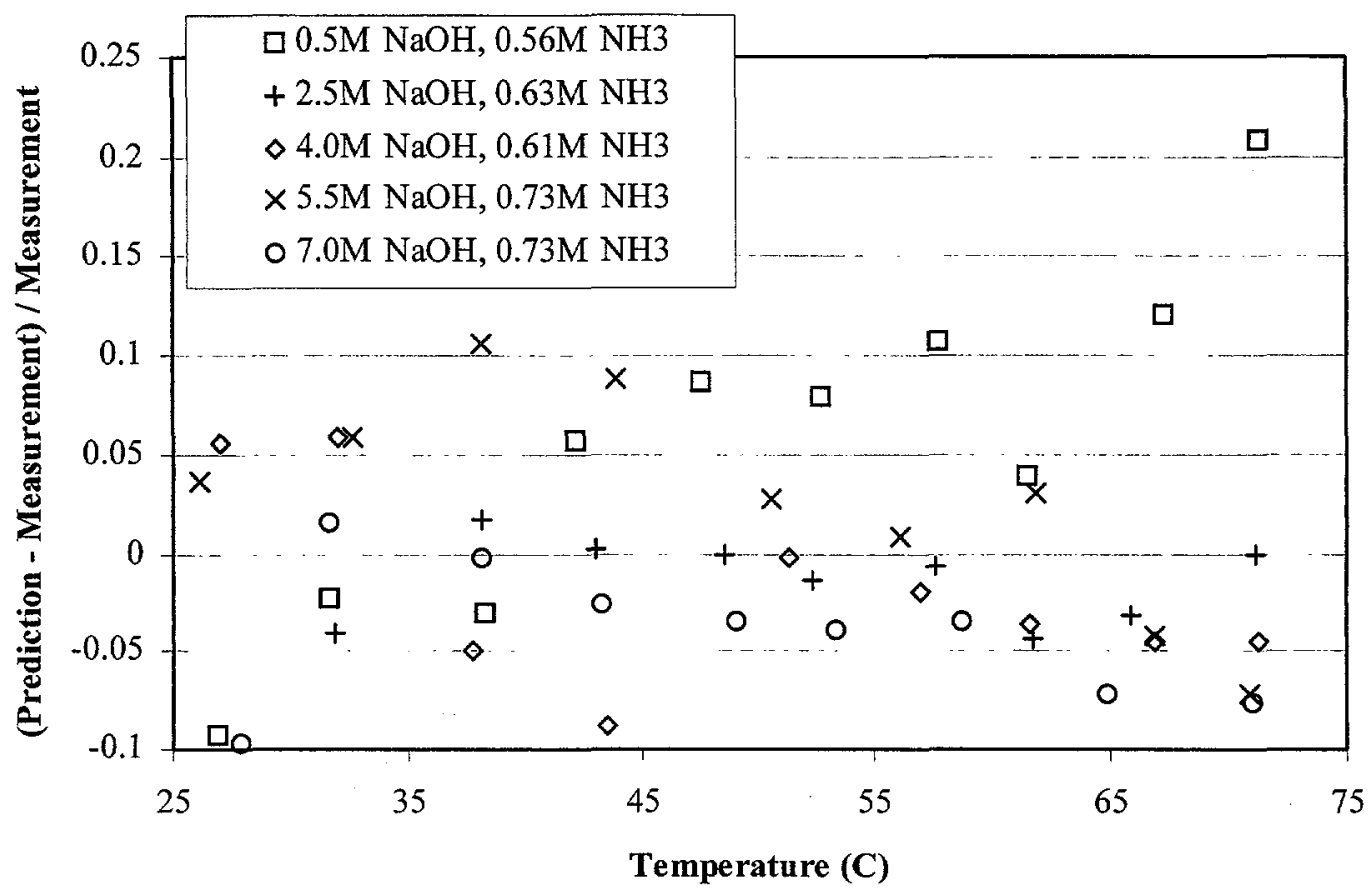

Figure 2.5. Schumpe Model Error for $\mathrm{NaOH}$ Data from Norton and Pederson (1994) Based on Coefficients Correlated from Norton and Pederson Data

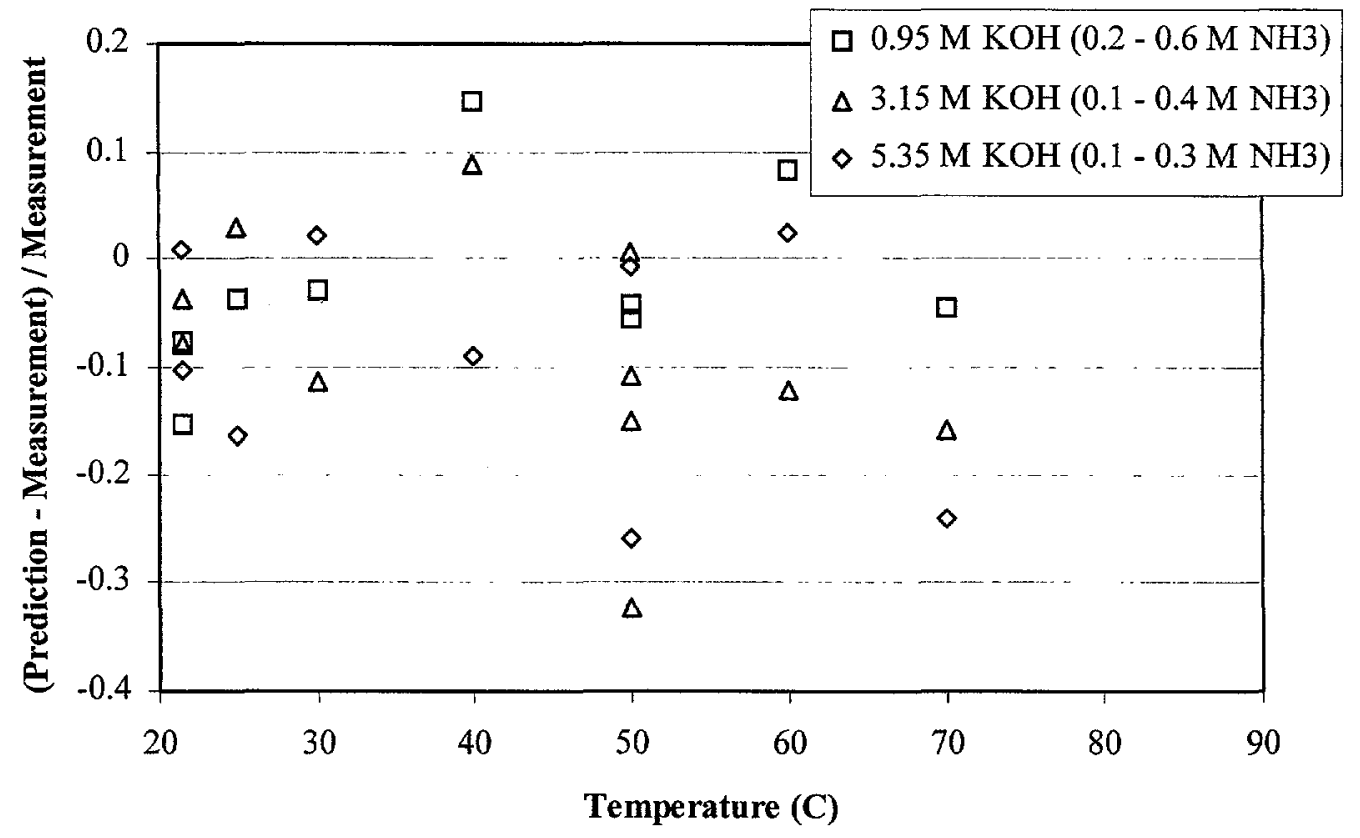

Figure 2.6. Schumpe Model Error for KOH Data from Hedengren et al. (2000) Based on Coefficients Correlated from Norton and Pederson (1994) Data 


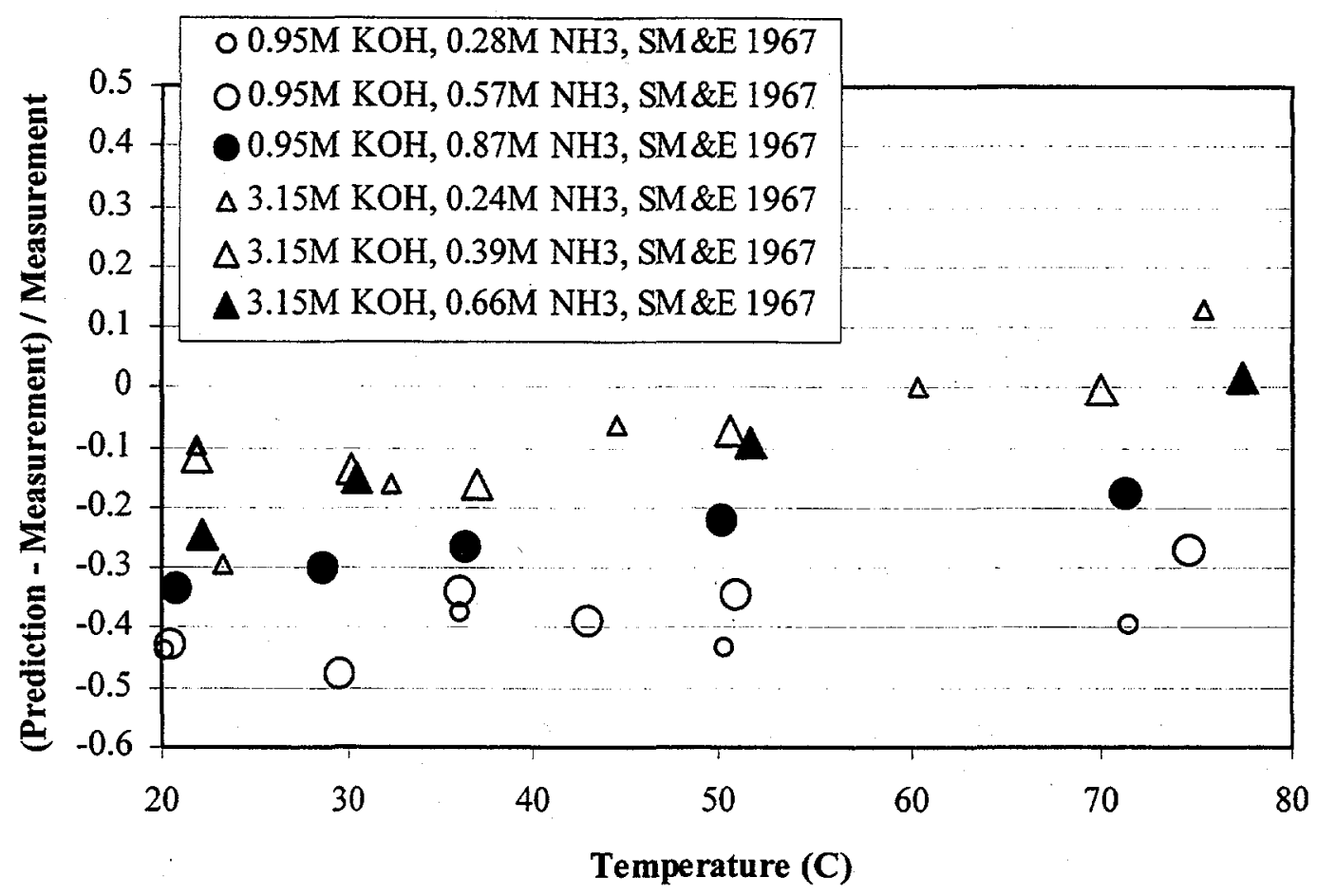

Figure 2.7. Schumpe Model Error for KOH Data from Sorina et al. (1967), Based on Coefficients Correlated from Norton and Pederson (1994) Data

\subsection{Correction of Molal/Molar Error}

The original journal articles describing the Schumpe model (Schumpe 1993; Hermann et al. 1995; Weisenberger and Schumpe 1996) put all the solute and ion concentrations in terms of molarity, mole/L solution. Other references, in common with most of the solubility research, put concentration in terms of molality, mole/kg water. The RGS reports (Shekarriz et al. 1997; Mahoney et al. 1997; Mahoney et al. 1999) misinterpreted an equation in which molarity rather than molality was used, and therefore used incorrect Henry's Law constants to calculate gas compositions and volume fractions under in situ conditions.

Specifically, in Equation (3.6.2) of Mahoney et al. (1999) the ratio of Henry's Law constants was taken to be in molal terms, when it was actually in molar terms. The equation is reproduced below:

$$
\log \left(\mathrm{c}_{\mathrm{G}, 0} / \mathrm{c}_{\mathrm{G}}\right)=\log \left(\frac{\mathrm{K}_{\mathrm{H}, \mathrm{G}}(\text { water })}{\mathrm{K}_{\mathrm{H}, \mathrm{G}}(\text { solution })}\right)=\sum_{\mathrm{i}}\left(\mathrm{h}_{\mathrm{i}}+\mathrm{h}_{\mathrm{G}}\right) \mathrm{c}_{\mathrm{i}}
$$

Because the $\mathrm{K}$ ratio was actually molar, the Henry's Law constant obtained from the above equation was (per $\mathrm{L}$ of liquid), rather than (per $\mathrm{kg}$ water in liquid) as it was treated by Mahoney et al. (1999). The conversion in Equation (3.6.4) of Mahoney et al. (1999) should have been

$$
\mathrm{K}_{\mathrm{H}} \text {, L waste basis }=\left(\mathrm{K}_{\mathrm{H}}, \mathrm{L} \text { liquidbasis }\right)\left(1-\mathrm{x}_{\mathrm{s}}\right)
$$


which means that the Henry's law constants were unnecessarily multiplied by a term $\left(\rho_{L} \omega_{L}\right)$ making them too small and overestimating vapor pressures.

The RGS calculation spreadsheets on the CD that was distributed with Mahoney et al. (1999) must be corrected before use. The pertinent cells are in the "In situ" worksheet in columns E ("pure water K"), F ("Henry's K"), and L ("K HA... at extractor temperature"). The calculations in column $\mathrm{E}$ must be divided by the density of water at the segment's in situ temperature to give the pure-water Henry's Law constant in molar rather than molal terms. In columns $\mathrm{F}$ and $\mathrm{L}$, the $\rho_{\mathrm{L}} \omega_{\mathrm{L}}$ term (typically expressed as $\$ C \$ 27 * \$ C \$ 28$ ) must be deleted.

Correcting the molal/molar error and using the revised Schumpe model coefficients given in Section 2.3 reduced the ammonia mole fraction in the retained gas but caused little change in the mole fractions of the major sparingly soluble gas constituents $\left(\mathrm{H}_{2}, \mathrm{~N}_{2}\right.$, and $\left.\mathrm{N}_{2} \mathrm{O}\right)$ or in the gas volume fraction. There were few cases in which the changes in sparingly soluble gases exceeded the roundoff error.

Table 2.3 contains the compositions and gas volume fractions for all the RGS samples based on the corrected model with the revised coefficients for ammonia solubility. Each mole fraction and gas volume fraction is expressed as a range between two values, each of which has its own \pm uncertainty. The first number in the range is the value for the lower-bound estimate of gas solubility, and the second number is the value for the higher-bound solubility estimate. The \pm uncertainty on each of those numbers represents the measurement uncertainty. The upper- and lower-bound solubilities of the low-solubility gas constituents were calculated as described in Section 3.6.1 of Mahoney et al. (1999). The lower-bound ammonia solubility was given by the Schumpe model with the revised coefficients based on data from Norton and Pederson (1994). The revised coefficients based on data from Hedengren et al. (2000) were used to provide an upper bound for the ammonia solubility.

Table 2.4 shows the changes that were made to the mole fractions of the major constituents and to the gas volume fractions. In most cases, the changes were less than the roundoff error, and in almost all were less than the uncertainty. Most of the larger changes occurred in SY-101. SY-101 was also the only case in which the changes in gas volume fraction that resulted from correction were greater than roundoff error. Where changes were perceptible, it was the result of a decrease in the ammonia vapor pressure (and mole fraction), not of a change in the relative solubilities of the sparingly soluble gases.

Table 2.5 gives the $\mathrm{H}_{2} / \mathrm{N}_{2} \mathrm{O}$ and $\mathrm{H}_{2} / \mathrm{N}_{2}$ ratios before and after the molal/molar correction. These changes result only from the units correction; the change in the ammonia vapor-pressure model had no effect on the relations between the low-solubility gases. The table confirms that the correction had little effect on the composition of the low-solubility portion of the retained gas. Table 2.6 shows the dissolved gas concentrations of the major low-solubility constituents before and after correction. The units are in terms of moles per liter of liquid, not of gas-free waste or bulk waste. In most cases, the corrected gas concentrations in the liquid are less than double the previous values. Table 2.7 lists the figures and tables in Mahoney et al. (1999) that are affected by the correction and the extent to which the data in this report replace the figures and tables in the earlier report. 
Table 2.3. In Situ Compositions and Volume Fractions of Retained Gas from RGS Data ${ }^{(a)}$

\begin{tabular}{|c|c|c|c|c|c|c|c|c|}
\hline \multirow{2}{*}{$\begin{array}{l}\text { Tank } \\
\text { Sample } \\
\text { (or layer) }\end{array}$} & \multicolumn{6}{|c|}{ Mole Percent of Constituent in Bubbles } & \multirow{2}{*}{$\begin{array}{c}\text { In Situ Gas Volume } \\
\text { (percent) }\end{array}$} & \multirow{2}{*}{$\begin{array}{l}\text { Elevation (cm, } \\
\text { in.) }\end{array}$} \\
\hline & $\mathrm{H}_{2}$ & $\mathrm{~N}_{2}$ & $\mathrm{~N}_{2} \mathrm{O}$ & $\mathrm{CH}_{4}$ & $\mathrm{NH}_{3}$ & Other & & \\
\hline AW-101-24A-8 & $26 \pm 9.4$ to $24 \pm 8.8$ & $68 \pm 32$ to $70 \pm 34$ & $1.8 \pm 0.7$ to $0.5 \pm 0.2$ & $1.0 \pm 0.4$ & $0.4 \pm 0.2$ & $3.0 \pm 1.4$ to $3.6 \pm 1.6$ & $0.8 \pm 0.1$ to $0.7 \pm 0.1$ & $700,276.5$ \\
\hline AW-101-24A-17 & $29 \pm 3.9$ & $59 \pm 8.9$ to $62 \pm 9.3$ & $5.5 \pm 0.9$ to $2.9 \pm 0.4$ & $1.8 \pm 0.3$ & $0.6 \pm 0.3$ & $3.4 \pm 0.6$ to $3.6 \pm 0.6$ & $2.7 \pm 0.3$ to $2.5 \pm 0.3$ & $265,104.5$ \\
\hline $\mathrm{AW}-101-24 \mathrm{~B}-18$ & $19 \pm 3.1$ & $68 \pm 14$ to $71 \pm 14$ & $6.7 \pm 1.2$ to $3.2 \pm 0.6$ & $2.0 \pm 0.4$ & $0.3 \pm 0.1$ & $4.2 \pm 0.7$ to $4.6 \pm 0.8$ & $2.1 \pm 0.4$ to $1.9 \pm 0.4$ & $217, \quad 86.5$ \\
\hline AW-101-24A-19 & $43 \pm 3.5$ to $44 \pm 3.6$ & $47 \pm 4.1$ to $48 \pm 4.1$ & $5.7 \pm 0.5$ to $3.9 \pm 0.3$ & $1.4 \pm 0.1$ & $0.8 \pm 0.4$ & $1.9 \pm 0.2$ to $2.0 \pm 0.2$ & $5.2 \pm 0.5$ to $5.0 \pm 0.5$ & $169, \quad 66.5$ \\
\hline AW-101-24A-21 & $30 \pm 2.5$ to $31 \pm 2.6$ & $57 \pm 4.8$ to $59 \pm 5.0$ & $8.0 \pm 0.7$ to $5.3 \pm 0.5$ & $1.8 \pm 0.3$ & $0.7 \pm 0.3$ & $2.5 \pm 0.3$ to $2.6 \pm 0.3$ & $5.1 \pm 0.5$ to $4.8 \pm 0.5$ & $72.3,36.5$ \\
\hline AW-101-24B-22 & $13 \pm 2.1$ to $14 \pm 2.1$ & $67 \pm 11$ to $72 \pm 12$ & $12 \pm 2.0$ to $5.2 \pm 0.9$ & $2.2 \pm 0.4$ to $2.3 \pm 0.5$ & $0.3 \pm 0.1$ & $5.3 \pm 1.3$ to $6.0 \pm 1.4$ & $2.0 \pm 0.4$ to $1.8 \pm 0.4$ & $24,1, \quad 9.5$ \\
\hline$A W-101-C^{(b)}$ & $26 \pm 9.4$ to $24 \pm 8.8$ & $68 \pm 32$ to $70 \pm 34$ & $1.8 \pm 0.7$ to $0.5 \pm 0.2$ & $1.0 \pm 0.4$ & $0.4 \pm 0.2$ & $3.0 \pm 1.4$ to $3.6 \pm 1.6$ & $0.8 \pm 0.3$ to $0.7 \pm 0.3$ & $673, \quad 265$ \\
\hline$A W-101-N C^{(b)}$ & $32 \pm 3.2$ to $33 \pm 3.2$ & $56 \pm 6.2$ to $58 \pm 6.4$ & $7.2 \pm 0.8$ to $4.4 \pm 0.5$ & $1.7 \pm 0.2$ & $0.6 \pm 0.3$ & $3.0 \pm 0.5$ to $3.2 \pm 0.5$ & $3.7 \pm 1.8$ to $3.5 \pm 1.8$ & $133, \quad 52$ \\
\hline $\mathrm{AN}-105-7 \mathrm{~B}-4$ & $25 \pm 12$ to $24 \pm 12$ & $58 \pm 42$ to $66 \pm 49$ & $11 \pm 5.6$ to $3.4 \pm 1.8$ & $1.4 \pm 0.9$ & $0.6 \pm 0.4$ & $3.2 \pm 1.4$ to $4.3 \pm 2.0$ & $0.7 \pm 0.3$ to $0.5 \pm 0.3$ & $893,351.5$ \\
\hline AN-105-12A-15 & $20 \pm 14$ to $18 \pm 14$ & $64 \pm 64$ to $73 \pm 73$ & $11 \pm 8.1$ to $3.1 \pm 2.4$ & $1.4 \pm 1.1$ & $0.4 \pm 0.4$ & $3.0 \pm 1.7$ to $4.4 \pm 2.7$ & $0.5 \pm 0.2$ to $0.3 \pm 0.2$ & $362,142.5$ \\
\hline AN-105-7B-16 & $19 \pm 5.9$ to $17 \pm 5.6$ & $71 \pm 28$ to $77 \pm 31$ & $7.1 \pm 2.6$ to $2.1 \pm 0.8$ & $0.8 \pm 0.4$ & $0.3 \pm 0.2$ & $2.1 \pm 0.9$ to $2.7 \pm 1.1$ & $0.7 \pm 0.2$ to $0.5 \pm 0.2$ & $314,123.5$ \\
\hline AN-105-12A-17 & $65 \pm 5.2$ to $67 \pm 5.3$ & $22 \pm 2.0$ to $23 \pm 2.1$ & $11 \pm 1.0$ to $7.9 \pm 0.7$ & $0.6 \pm 0.1$ & $0.6 \pm 0.3$ & $0.7 \pm 0.1$ & $6.9 \pm 0.7$ to $6.5 \pm 0.7$ & $265,104.5$ \\
\hline AN-105-7B-18 & $55 \pm 7.8$ to $57 \pm 8.1$ & $31 \pm 5.0$ to $33 \pm 5.3$ & $11 \pm 1.9$ to $6.3 \pm 1.1$ & $0.8 \pm 0.2$ & $0.5 \pm 0.2$ & $1.7 \pm 0.5$ to $1.8 \pm 0.6$ & $2.7 \pm 0.4$ to $2.4 \pm 0.4$ & $217,85.5$ \\
\hline AN-105-12A-19 & $65 \pm 4.9$ to $66 \pm 5.0$ & $21 \pm 3.4$ to $22 \pm 3.5$ & $12 \pm 1.0$ to $10 \pm 0.8$ & $0.6 \pm 0.06$ & $0.5 \pm 0.2$ & $0.4 \pm 0.1$ & $12 \pm 0.8$ & $169, \quad 66.5$ \\
\hline AN-105-12A-21 & $57 \pm 4.0$ to $60 \pm 4.2$ & $22 \pm 1.6$ to $24 \pm 1.7$ & $19 \pm 1.5$ to $14 \pm 1.2$ & $0.8 \pm 0.06$ & $0.3 \pm 0.2$ & $0.5 \pm 0.1$ & $7.4 \pm 0.7$ to $6.9 \pm 0.7$ & $72.4,28.5$ \\
\hline $\mathrm{AN}-105-\mathrm{C}$ & $25 \pm 12$ to $24 \pm 12$ & $58 \pm 42$ to $66 \pm 49$ & $11 \pm 5.6$ to $3.4 \pm 1.8$ & $1.4 \pm 0.9$ & $0.6 \pm 0.4$ & $3.2 \pm 1.4$ to $4.3 \pm 2.0$ & $0.5 \pm 0.2$ to $0.4 \pm 0.2$ & $608, \quad 239$ \\
\hline $\mathrm{AN}-105-\mathrm{NC}$ & $60 \pm 5.4$ to $62 \pm 5.5$ & $24 \pm 4.0$ to $25 \pm 3.9$ & $14 \pm 1.5$ to $11 \pm 1.1$ & $0.7 \pm 0.09$ & $0.5 \pm 0.2$ & $0.6 \pm 0.1$ & $5.1 \pm 2.6$ to $4.8 \pm 2.4$ & $142, \quad 56$ \\
\hline A-101-24-2 & $63 \pm 5.5$ to $64 \pm 5.6$ & $26 \pm 4.9$ to $27 \pm 4.9$ & $7.4 \pm 0.7$ to $6.5 \pm 0.6$ & $0.4 \pm 0.1$ & $2.1 \pm 1.0$ & $0.5 \pm 0.07$ & $16 \pm 1.4$ & $845,332.5$ \\
\hline A-101-15-5 & $75 \pm 8.1$ & $15 \pm 4.8$ & $5.7 \pm 0.6$ to $5.2 \pm 0.6$ & $0.7 \pm 0.1$ & $3.5 \pm 1.2$ & $0.3 \pm 0.06$ & $18 \pm 2.1$ & $700,275.5$ \\
\hline A-101-15-8 & $76 \pm 7.8$ & $16 \pm 5.4$ & $5.3 \pm 0.6$ to $5.0 \pm 0.5$ & $0.7 \pm 0.08$ & $2.0 \pm 0.6$ & $0.3 \pm 0.04$ & $20 \pm 2.1 \mathrm{~s}$ & $555,218.5$ \\
\hline A-101-24-9 & $70 \pm 6.1$ & $23 \pm 4.6$ & $4.9 \pm 0.4$ to $4.5 \pm 0.4$ & $0.8 \pm 0.09$ & $1.7 \pm 0.3$ & $0.2 \pm 0.03$ & $22 \pm 2.1$ to $21 \pm 2.1$ & $507,199.5$ \\
\hline $\mathrm{A}-101-15-12$ & $12 \pm 4.4$ & $63 \pm 29$ to $73 \pm 34$ & $15 \pm 6.7$ to $4.9 \pm 2.2$ & $3.1 \pm 1.7$ to $3.2 \pm 1.8$ & $3.7 \pm 1.9$ & $2.6 \pm 1.4$ to $3.6 \pm 1.9$ & $0.7 \pm 0.3$ to $0.5 \pm 0.3$ & $362,142.5$ \\
\hline A-101-24-16 & $15 \pm 4.2$ to $14 \pm 4.0$ & $64 \pm 20$ to $74 \pm 24$ & $14 \pm 4.4$ to $4.1 \pm 1.3$ & $0.9 \pm 0.3$ & $3.7 \pm 1.8$ & $2.2 \pm 0.9$ to $3.0 \pm 1.3$ & $0.6 \pm 0.3$ to $0.5 \pm 0.3$ & $169, \quad 66.5$ \\
\hline A-101-24-19 & $18 \pm 4.5$ & $65 \pm 20$ to $72 \pm 23$ & $12 \pm 3.4$ to $4.2 \pm 1.2$ & $0.7 \pm 0.2$ & $3.3 \pm 1.6$ & $1.3 \pm 0.5$ to $1.6 \pm 0.7$ & $1.0 \pm 0.3$ to $0.8 \pm 0.3$ & $24.1, \quad 9.5$ \\
\hline$A-101-N C$ & $72 \pm 7.1$ & $19 \pm 4.9$ & $5.8 \pm 0.6$ to $5.3 \pm 0.5$ & $0.7 \pm 0.1$ & $2.5 \pm 0.9$ & $0.3 \pm 0.05$ & $18 \pm 9.0$ & $652, \quad 257$ \\
\hline$A-101-C$ & $15 \pm 4.5$ & $64 \pm 24$ to $73 \pm 27$ & $14 \pm 4.9$ to $4.4 \pm 1.6$ & $1.7 \pm 0.8$ & $3.5 \pm 1.8$ & $2.1 \pm 0.9$ to $2.8 \pm 1.3$ & $0.7 \pm 0.3$ to $0.6 \pm 0.3$ & $207, \quad 81$ \\
\hline
\end{tabular}


Table 2.3. (contd)

\begin{tabular}{|c|c|c|c|c|c|c|c|c|}
\hline \multirow{2}{*}{$\begin{array}{l}\text { Tank and Sample } \\
\text { (or layer) }\end{array}$} & \multicolumn{6}{|c|}{ Mole Percent of Constituent in Bubbles } & \multirow{2}{*}{$\begin{array}{c}\text { In Situ Gas Volume } \\
\text { (percent) }\end{array}$} & \multirow{2}{*}{$\begin{array}{c}\text { Elevation } \\
\text { (cm, in.) }\end{array}$} \\
\hline & $\mathrm{H}_{2}$ & $\mathrm{~N}_{2}$ & $\mathrm{~N}_{2} \mathrm{O}$ & $\mathrm{CH}_{4}$ & $\mathrm{NH}_{3}$ & Other & & \\
\hline $\mathrm{AN}-104-10 \mathrm{~A}-3$ & $25 \pm 13$ & $56 \pm 49$ to $65 \pm 58$ & $14 \pm 7.6$ to $4.0 \pm 2.4$ & $1.9 \pm 1.3$ & $0.8 \pm 0.5$ & $2.6 \pm 1.4$ to $3.5 \pm 1.9$ & $0.9 \pm 0.3$ to $0.7 \pm 0.3$ & $893,351.5$ \\
\hline AN-104-10A-13 & $41 \pm 8.2$ to $44 \pm 8.6$ & $41 \pm 9.7$ to $45 \pm 11$ & $14 \pm 3.7$ to $6.7 \pm 1.8$ & $1.3 \pm 0.5$ to $1.4 \pm 0.5$ & $0.4 \pm 0.2$ & $1.9 \pm 0.7$ to $2.2 \pm 0.8$ & $2.2 \pm 0.4$ to $1.9 \pm 0.4$ & $410,161.5$ \\
\hline $\mathrm{AN}-104-10 \mathrm{~A}-15$ & $50 \pm 8.1$ to $52 \pm 8.4$ & $32 \pm 5.7$ to $34 \pm 6.0$ & $13 \pm 2.5$ to $8.8 \pm 1.6$ & $1.1 \pm 0.3$ to $1.2 \pm 0.3$ & $1.9 \pm 0.9$ & $1.3 \pm 0.4$ to $1.4 \pm 0.5$ & $4.7 \pm 0.8$ to $4.4 \pm 0.8$ & $314,123.5$ \\
\hline $\mathrm{AN}-104-10 \mathrm{~A}-17$ & $29 \pm 6.0$ to $30 \pm 6.3$ & $53 \pm 13$ to $55 \pm 14$ & $14 \pm 3.1$ to $10 \pm 2.2$ & $1.5 \pm 0.3$ to $1.6 \pm 0.4$ & $0.7 \pm 0.3$ & $1.6 \pm 0.4$ to $1.7 \pm 0.4$ & $5.7 \pm 0.8$ to $5.3 \pm 0.8$ & $217,85.5$ \\
\hline AN-104-12A-18 & $45 \pm 3.6$ to $47 \pm 3.8$ & $37 \pm 3.0$ to $38 \pm 3.2$ & $15 \pm 1.5$ to $12 \pm 1.1$ & $1.1 \pm 0.2$ & $0.5 \pm 0.2$ & $1.4 \pm 0.4$ to $1.5 \pm 0.4$ & $7.1 \pm 0.7$ to $6.7 \pm 0.7$ & $169,66.5$ \\
\hline AN-104-10A-21 & $47 \pm 7.8$ to $49 \pm 8.1$ & $21 \pm 3.5$ to $22 \pm 3.6$ & $30 \pm 5.1$ to $27 \pm 4.6$ & $0.6 \pm 0.1$ & $0.9 \pm 0.4$ & $0.3 \pm 0.07$ & $17 \pm 1.9$ to $16 \pm 1.9$ & $24.1, \quad 9.5$ \\
\hline $\mathrm{AN}-104-\mathrm{C}$ & $25 \pm 13$ & $56 \pm 49$ to $65 \pm 58$ & $14 \pm 7.6$ to $4.0 \pm 2.4$ & $1.9 \pm 1.3$ & $0.8 \pm 0.5$ & $2.6 \pm 1.4$ to $3.5 \pm 1.9$ & $0.5 \pm 0.2$ to $0.4 \pm 0.2$ & $673, \quad 265$ \\
\hline $\mathrm{AN}-104-\mathrm{NC}$ & $45 \pm 6.9$ to $47 \pm 7.1$ & $29 \pm 4.8$ to $31 \pm 5.1$ & $23 \pm 3.7$ to $20 \pm 3.2$ & $0.9 \pm 0.2$ & $0.9 \pm 0.4$ & $0.8 \pm 0.2$ to $0.9 \pm 0.2$ & $8.0 \pm 4.0$ to $7.5 \pm 3.8$ & $119, \quad 47$ \\
\hline AN-103-12A-2 & $62 \pm 6.4$ to $63 \pm 6.4$ & $29 \pm 3.2$ & $6.9 \pm 0.7$ to $6.0 \pm 0.6$ & $0.6 \pm 0.07$ & $1.4 \pm 0.6$ & $0.25 \pm 0.04$ & $16 \pm 1.4$ & $845,332.5$ \\
\hline AN-103-12A-5 & $19 \pm 10$ to $18 \pm 10$ & $69 \pm 54$ to $75 \pm 60$ & $7.9 \pm 4.7$ to $2.3 \pm 1.4$ & $1.7 \pm 1.3$ & $1.0 \pm 0.7$ & $1.4 \pm 0.7$ to $1.7 \pm 0.8$ & $0.8 \pm 0.3$ to $0.6 \pm 0.3$ & $700,275.5$ \\
\hline AN-103-21A-10 & $20 \pm 13$ to $18 \pm 13$ & $70 \pm 70$ to $76 \pm 76$ & $7.0 \pm 4.8$ to $1.8 \pm 1.3$ & $1.2 \pm 0.9$ to $1.1 \pm 0.9$ & $0.8 \pm 0.6$ & $1.4 \pm 0.7$ to $1.8 \pm 0.9$ & $0.6 \pm 0.3$ to $0.5 \pm 0.3$ & $458,180.5$ \\
\hline AN-103-12A-14 & $55 \pm 8.8$ & $38 \pm 6.5$ to $39 \pm 6.6$ & $4.9 \pm 0.8$ to $3.8 \pm 0.6$ & $0.7 \pm 0.2$ & $0.7 \pm 0.3$ & $0.4 \pm 0.1$ & $6.7 \pm 1.2$ to $6.5 \pm 1.2$ & $265,104.5$ \\
\hline AN-103-21A-16 & $64 \pm 7.2$ & $30 \pm 3.5$ to $31 \pm 3.5$ & $3.8 \pm 0.4$ to $3.3 \pm 0.4$ & $0.6 \pm 0.1$ & $0.6 \pm 0.2$ & $0.4 \pm 0.09$ & $12 \pm 1.5$ & $169,66.5$ \\
\hline AN-103 crust & $62 \pm 6.4$ to $63 \pm 6.4$ & $29 \pm 3.2$ & $6.9 \pm 0.7$ to $6.0 \pm 0.6$ & $0.6 \pm 0.07$ & $1.4 \pm 0.6$ & $0.2 \pm 0.03$ & $16 \pm 7.9$ & $839, \quad 330$ \\
\hline $\mathrm{AN}-103-\mathrm{C}$ & $19 \pm 12$ to $18 \pm 12$ & $70 \pm 62$ to $76 \pm 69$ & $7.5 \pm 4.8$ to $2.1 \pm 1.4$ & $1.4 \pm 1.1$ & $0.9 \pm 0.6$ & $1.4 \pm 0.6$ to $1.7 \pm 0.8$ & $0.7 \pm 0.3$ to $0.6 \pm 0.3$ & 587,231 \\
\hline AN-103 - NC & $61 \pm 7.7$ to $62 \pm 7.7$ & $33 \pm 4.3$ & $4.1 \pm 0.6$ to $3.4 \pm 0.5$ & $0.6 \pm 0.1$ & $0.6 \pm 0.2$ & $0.4 \pm 0.09$ & $9.2 \pm 4.6$ to $9.0 \pm 4.5$ & $160, \quad 63$ \\
\hline U-103-7-2 & $23 \pm 1.3$ & $36 \pm 2.1$ to $37 \pm 2.1$ & $40 \pm 2.1$ to $39 \pm 2.1$ & $0.4 \pm 0.03$ & $0.13 \pm 0.04$ to $0.07 \pm 0.02$ & $0.5 \pm 0.05$ & $42 \pm 2.6$ to $41 \pm 2.6$ & $362,142.5$ \\
\hline U-103-7-5 & $14 \pm 0.9$ to $16 \pm 1.0$ & $32 \pm 2.0$ to $36 \pm 2.2$ & $51 \pm 3.1$ to $46 \pm 2.8$ & $0.26 \pm 0.06$ & $1.6 \pm 0.6$ & $0.4 \pm 0.1$ & $9.6 \pm 0.8$ to $8.5 \pm 0.8$ & $217,85.5$ \\
\hline U-103-7-7 & $24 \pm 1.5$ to $25 \pm 1.6$ & $41 \pm 2.6$ to $44 \pm 2.8$ & $32 \pm 1.9$ to $28 \pm 1.7$ & $0.6 \pm 0.1$ & $1.1 \pm 0.3$ & $1.0 \pm 0.1$ to $1.1 \pm 0.1$ & $11 \pm 1.2$ to $10 \pm 1.2$ & $121,47.5$ \\
\hline U-103-7-8 & $31 \pm 3.1$ to $33 \pm 3.3$ & $36 \pm 3.6$ to $39 \pm 3.9$ & $29 \pm 2.9$ to $24 \pm 2.4$ & $0.8 \pm 0.1$ & $1.1 \pm 0.6$ & $1.7 \pm 0.2$ to $1.8 \pm 0.2$ & $7.8 \pm 1.0$ to $7.1 \pm 1.0$ & $72, \quad 28.5$ \\
\hline U-103-NC & $23 \pm 1.4$ to $24 \pm 1.5$ & $36 \pm 2.3$ to $38 \pm 2.4$ & $39 \pm 2.4$ to $37 \pm 2.2$ & $0.4 \pm 0.05$ & $0.6 \pm 0.3$ to $0.5 \pm 0.2$ & $0.7 \pm 0.08$ & $19 \pm 9.5$ to $18 \pm 9.0$ & $277, \quad 109$ \\
\hline S-106-7-3 & $59 \pm 5.0$ to $60 \pm 5.1$ & $32 \pm 3.1$ to $33 \pm 3.2$ & $7.8 \pm 0.7$ to $5.9 \pm 0.5$ & $0.4 \pm 0.2$ & $0.3 \pm 0.2$ & $0.2 \pm 0.1$ & $9.6 \pm 0.9$ to $9.3 \pm 0.9$ & $362,142.5$ \\
\hline$S-106-7-5$ & $62 \pm 5.5$ to $65 \pm 5.7$ & $23 \pm 3.6$ & $14 \pm 1.2$ to $11 \pm 1.0$ & $0.01 \pm 0.01$ & $0.3 \pm 0.1$ & $0.5 \pm 0.2$ to $0.6 \pm 0.2$ & $10 \pm 1.0$ & $265,104.5$ \\
\hline S-106-8-6 & $63 \pm 8.6$ to $65 \pm 8.8$ & $25 \pm 3.6$ to $26 \pm 3.7$ & $9.9 \pm 1.5$ to $7.2 \pm 1.1$ & $0.5 \pm 0.2$ & $0.5 \pm 0.3$ & $0.9 \pm 0.5$ to $1.0 \pm 0.5$ & $7.6 \pm 0.8$ to $7.3 \pm 0.8$ & $217, \quad 85.5$ \\
\hline$S-106-8-10$ & $65 \pm 4.9$ to $66 \pm 5.1$ & $23 \pm 4.2$ to $24 \pm 4.3$ & $11 \pm 0.8$ to $9.0 \pm 0.7$ & $0.2 \pm 0.02$ & $0.2 \pm 0.1$ & $0.4 \pm 0.2$ & $14 \pm 1.2$ & 24, \\
\hline $\mathrm{S}-106-\mathrm{NC}$ & $63 \pm 5.7$ to $65 \pm 5.9$ & $25 \pm 3.7$ to $26 \pm 3.8$ & $11 \pm 1.0$ to $8.4 \pm 0.8$ & $0.3 \pm 0.08$ & $0.3 \pm 0.2$ & $0.5 \pm 0.2$ & $10 \pm 5.0$ & 164 \\
\hline
\end{tabular}


Table 2.3. (contd)

\begin{tabular}{|c|c|c|c|c|c|c|c|c|}
\hline \multirow{2}{*}{$\begin{array}{l}\text { Tank and Sample } \\
\text { (or layer) }\end{array}$} & \multicolumn{6}{|c|}{ Mole Percent of Constituent in Bubbles (water vapor excluded) } & \multirow{2}{*}{$\begin{array}{l}\text { In Situ Gas Volume } \\
\text { (percent) }\end{array}$} & \multirow{2}{*}{$\begin{array}{c}\text { Elevation } \\
\text { (cm, in.) }\end{array}$} \\
\hline & $\mathrm{H}_{2}$ & $\mathrm{~N}_{2}$ & $\mathrm{~N}_{2} \mathrm{O}$ & $\mathrm{CH}_{4}$ & $\mathrm{NH}_{3}$ & Other & & \\
\hline $\mathrm{BY}-109-12 \mathrm{C}-4$ & $35 \pm 3.6$ to $36 \pm 3.8$ & $40 \pm 7.9$ to $42 \pm 8.3$ & $21 \pm 2.2$ to $18 \pm 1.9$ & $1.0 \pm 0.2$ & $0.3 \pm 0.2$ & $2.2 \pm 0.3$ to $2.3 \pm 0.3$ & $6.3 \pm 0.4$ to $6.1 \pm 0.4$ & $121,47.5$ \\
\hline BY-109-10B-5 & $52 \pm 5.5$ to $53 \pm 5.6$ & $29 \pm 5.0$ & $16 \pm 1.7$ to $15 \pm 1.6$ & $0.7 \pm 0.1$ & $0.2 \pm 0.1$ & $1.8 \pm 0.3$ & $8.7 \pm 0.8$ to $8.4 \pm 0.8$ & $121,47.5$ \\
\hline$B Y-109-10 B-6$ & $56 \pm 6.4$ to $57 \pm 6.5$ & $23 \pm 3.8$ & $17 \pm 3.3$ to $16 \pm 3.1$ & $0.9 \pm 0.1$ & $0.2 \pm 0.1$ & $2.6 \pm 0.4$ to $2.7 \pm 0.4$ & $12 \pm 1.0$ & $72,28.5$ \\
\hline BY-109 below ILL & $50 \pm 5.5$ to $51 \pm 5.6$ & $29 \pm 5.1$ & $18 \pm 2.5$ to $16 \pm 2.3$ & $0.9 \pm 0.1$ & $0.2 \pm 0.1$ & $2.3 \pm 0.3$ & $9.4 \pm 4.7$ to $9.2 \pm 4.6$ & 120,47 \\
\hline SX-106-3-2 & $22 \pm 2.9$ to $15 \pm 2.4$ & $63 \pm 11$ to $74 \pm 14$ & $11 \pm 1.5$ to $1.7 \pm 0.3$ & $1.4 \pm 0.5$ to $1.0 \pm 0.4$ & $1.0 \pm 0.2$ to $0.4 \pm 0.1$ & $1.9 \pm 0.7$ to $7.7 \pm 2.9$ & $0.1 \pm 0.04$ to $0.03 \pm 0.03$ & $458,180.5$ \\
\hline SX-106-3-4 & $19 \pm 6.1$ to $16 \pm 5.1$ & $65 \pm 28$ to $78 \pm 34$ & $13 \pm 4.8$ to $2.2 \pm 0.8$ & $0.9 \pm 0.4$ to $0.7 \pm 0.3$ & $0.8 \pm 0.3$ to $0.4 \pm 0.1$ & $1.0 \pm 0.4$ to $2.5 \pm 0.9$ & $0.2 \pm 0.07$ to $0.07 \pm 0.07$ & $362,142.5$ \\
\hline $\mathrm{SX}-106-6-6$ & $50 \pm 5.0$ to $53 \pm 5.4$ & $23 \pm 3.3$ to $25 \pm 3.5$ & $18 \pm 1.9$ to $16 \pm 1.7$ & $1.9 \pm 0.3$ to $2.0 \pm 0.3$ & $6.7 \pm 0.8$ to $3.0 \pm 0.4$ & $1.0 \pm 0.3$ to $1.1 \pm 0.3$ & $9.1 \pm 1.0$ to $8.4 \pm 1.0$ & $265,104.5$ \\
\hline$S X-106-6-6 A$ & $51 \pm 5.6$ to $56 \pm 6.2$ & $19 \pm 3.3$ to $21 \pm 3.7$ & $22 \pm 2.9$ to $17 \pm 2.2$ & $2.7 \pm 0.9$ to $3.0 \pm 1.0$ & $4.0 \pm 0.5$ to $1.8 \pm 0.2$ & $1.4 \pm 0.4$ to $1.6 \pm 0.4$ & $4.1 \pm 0.6$ to $3.6 \pm 0.6$ & $265,104.5$ \\
\hline SX-106-3-7 & $48 \pm 8.5$ to $50 \pm 8.5$ & $19 \pm 8.6$ to $20 \pm 9.0$ & $27 \pm 7.1$ & $0.5 \pm 0.09$ & $5.7 \pm 2.7$ to $2.5 \pm 1.2$ & $0.3 \pm 0.08$ & $30 \pm 11$ to $29 \pm 11$ & $217,85.5$ \\
\hline SX-106-6-9 & $60 \pm 3.6$ to $62 \pm 3.6$ & $17 \pm 2.0$ to $18 \pm 2.0$ & $17 \pm 1.1$ & $0.4 \pm 0.1$ & $4.9 \pm 0.8$ to $2.2 \pm 0.3$ & $0.3 \pm 0.09$ & $36 \pm 2.2$ to $34 \pm 2.2$ & $121,47.5$ \\
\hline$S X-106-3-10$ & $44 \pm 2.8$ to $47 \pm 2.7$ & $21 \pm 2.4$ to $22 \pm 2.5$ & $28 \pm 1.8$ & $0.6 \pm 0.05$ & $5.5 \pm 0.8$ to $2.4 \pm 0.4$ & $0.3 \pm 0.08$ & $32 \pm 2.0$ to $31 \pm 2.0$ & $72,28.5$ \\
\hline $\mathrm{SX}-106-\mathrm{C}$ & $21 \pm 4.9$ to $16 \pm 4.0$ & $64 \pm 21$ to $77 \pm 26$ & $12 \pm 3.4$ to $2.1 \pm 0.6$ & $1.1 \pm 0.4$ to $0.8 \pm 0.4$ & $0.9 \pm 0.2$ to $0.4 \pm 0.1$ & $1.4 \pm 0.5$ to $3.9 \pm 1.4$ & $0.2 \pm 0.1$ to $0.05 \pm 0.05$ & 406,160 \\
\hline $\mathrm{SX}-106-\mathrm{NC}$ & $50 \pm 4.5$ to $52 \pm 4.5$ & $20 \pm 3.8$ to $21 \pm 4.0$ & $24 \pm 2.8$ to $24 \pm 2.7$ & $0.6 \pm 0.1$ & $5.5 \pm 1.2$ to $2.4 \pm 0.5$ & $0.3 \pm 0.08$ & $26 \pm 13$ to $25 \pm 13$ & 133,52 \\
\hline$A X-101-9 D-8$ & $61 \pm 5.5$ to $64 \pm 5.5$ & $17 \pm 2.6$ to $18 \pm 2.7$ & $11 \pm 1.0$ & $2.4 \pm 0.2$ to $2.5 \pm 0.2$ & $8.4 \pm 1.9$ to $4.3 \pm 1.0$ & $0.7 \pm 0.2$ & $17 \pm 1.3$ to $16 \pm 1.3$ & $362,142.5$ \\
\hline$S-102-16-2$ & $36 \pm 2.5$ to $37 \pm 2.5$ & $37 \pm 4.4$ to $38 \pm 4.4$ & $26 \pm 1.8$ to $24 \pm 1.7$ & $0.4 \pm 0.05$ & $0.6 \pm 0.4$ to $0.4 \pm 0.2$ & $0.1 \pm 0.02$ & $33 \pm 4.3$ to $32 \pm 4.3$ & $458,180.5$ \\
\hline$S-102-16-4 R$ & $33 \pm 2.9$ to $37 \pm 3.2$ & $31 \pm 4.1$ to $36 \pm 4.7$ & $34 \pm 3.4$ to $26 \pm 2.5$ & $0.2 \pm 0.07$ to $0.3 \pm 0.08$ & $1.3 \pm 0.9$ to $0.7 \pm 0.5$ & $0.3 \pm 0.09$ & $7.4 \pm 0.7$ to $6.4 \pm 0.7$ & $362,142.5$ \\
\hline S-102-16-7 & $27 \pm 3.1$ to $28 \pm 3.2$ & $29 \pm 4.2$ to $30 \pm 4.4$ & $42 \pm 4.8$ to $41 \pm 4.6$ & $0.4 \pm 0.06$ & $1.5 \pm 0.4$ to $0.8 \pm 0.2$ & $0.07 \pm 0.03$ & $30 \pm 1.9$ to $29 \pm 1.9$ & $217,85.5$ \\
\hline S-102-16-10 & $43 \pm 3.8$ to $46 \pm 4.1$ & $29 \pm 4.3$ to $31 \pm 4.6$ & $25 \pm 2.2$ to $21 \pm 1.9$ & $0.7 \pm 0.08$ to $0.8 \pm 0.08$ & $1.2 \pm 0.3$ to $0.6 \pm 0.2$ & $0.6 \pm 0.1$ & $12 \pm 1.1$ to $11 \pm 1.1$ & $72,28.5$ \\
\hline S-102 tank avg. & $33 \pm 3.0$ to $35 \pm 3.1$ & $32 \pm 4.3$ to $33 \pm 4.5$ & $33 \pm 3.1$ to $31 \pm 2.9$ & $0.4 \pm 0.06$ to $0.5 \pm 0.06$ & $1.1 \pm 0.4$ to $0.6 \pm 0.2$ & $0.2 \pm 0.04$ & $26 \pm 13$ to $25 \pm 13$ & 310,122 \\
\hline$S-111-6-2$ & $6.3 \pm 3.4$ to $5.8 \pm 3.2$ & $90 \pm 68$ to $92 \pm 70$ & $1.7 \pm 1.0$ to $0.7 \pm 0.4$ & $0.3 \pm 0.2$ & $0.2 \pm 0.2$ to $0.1 \pm 0.1$ & $1.0 \pm 0.8$ to $1.2 \pm 0.9$ & $0.8 \pm 0.2$ to $0.7 \pm 0.2$ & $458,180.5$ \\
\hline S-111-6-4 & $48 \pm 24$ to $51 \pm 25$ & $36 \pm 22$ to $38 \pm 23$ & $14 \pm 5.5$ to $9.8 \pm 4.0$ & $0.6 \pm 0.2$ & $0.9 \pm 0.4$ to $0.5 \pm 0.2$ & $0.3 \pm 0.08$ & $6.9 \pm 2.1$ to $6.5 \pm 2.1$ & $362,142.5$ \\
\hline$S-111-6-6$ & $58 \pm 5.1$ to $60 \pm 5.2$ & $26 \pm 3.4$ to $27 \pm 3.5$ & $14 \pm 1.3$ to $11 \pm 1.1$ & $0.8 \pm 0.1$ & $1.2 \pm 0.4$ to $0.7 \pm 0.2$ & $0.5 \pm 0.2$ & $15 \pm 5$ & $265,104.5$ \\
\hline S-111-6-8 & $67 \pm 7.1$ to $68 \pm 7.2$ & $20 \pm 2.8$ & $12 \pm 1.3$ to $11 \pm 1.2$ & $0.6 \pm 0.08$ & $0.7 \pm 0.2$ to $0.4 \pm 0.1$ & $0.2 \pm 0.07$ & $20 \pm 2.8$ to $20 \pm 2.9$ & $169,66.5$ \\
\hline S-111-6-10 & $73 \pm 5.6$ to $74 \pm 5.7$ & $16 \pm 2.0$ to $16 \pm 2.0$ & $9.2 \pm 0.8$ to $8.5 \pm 0.7$ & $0.3 \pm 0.04$ & $1.6 \pm 0.4$ to $0.9 \pm 0.3$ & $0.09 \pm 0.04$ & $23 \pm 3.2$ to $22 \pm 3.2$ & $72,28.5$ \\
\hline $\mathrm{S}-111-\mathrm{C}$ & $6.3 \pm 3.4$ to $5.8 \pm 3.2$ & $90 \pm 68$ to $92 \pm 70$ & $1.7 \pm 1.0$ to $0.7 \pm 0.4$ & $0.3 \pm 0.2$ & $0.2 \pm 0.2$ to $0.1 \pm 0.1$ & $1.0 \pm 0.8$ to $1.2 \pm 0.9$ & $0.8 \pm 0.2$ to $0.7 \pm 0.2$ & 510,201 \\
\hline $\mathrm{S}-111 \cdot \mathrm{NC}$ & $66 \pm 10$ to $67 \pm 11$ & $21 \pm 5.6$ to $22 \pm 5.8$ & $11 \pm 1.7$ to $9.6 \pm 1.5$ & $0.5 \pm 0.08$ & $1.1 \pm 0.4$ to $0.6 \pm 0.2$ & $0.2 \pm 0.05$ & $15 \pm 7.5$ to $14 \pm 7.0$ & 184,72 \\
\hline
\end{tabular}


Table 2.3. (contd)

\begin{tabular}{|c|c|c|c|c|c|c|c|c|}
\hline \multirow{2}{*}{$\begin{array}{l}\text { Tank and Sample } \\
\text { (or layer) }\end{array}$} & \multicolumn{6}{|c|}{ Mole Percent of Constituent in Bubbles (water vapor excluded) } & \multirow{2}{*}{$\begin{array}{c}\text { In Situ Gas Volume } \\
\text { (percent) }\end{array}$} & \multirow{2}{*}{$\begin{array}{l}\text { Elevation } \\
\text { (cm, in.) }\end{array}$} \\
\hline & $\mathrm{H}_{2}$ & $\mathrm{~N}_{2}$ & $\mathrm{~N}_{2} \mathrm{O}$ & $\mathrm{CH}_{4}$ & $\mathrm{NH}_{3}$ & Other & & \\
\hline $\mathrm{U}-109-8-2$ & $20 \pm 2.9$ to $21 \pm 3.1$ & $42 \pm 7.6$ to $45 \pm 8.0$ & $36 \pm 6.3$ to $33 \pm 5.7$ & $0.5 \pm 0.1$ to $0.6 \pm 0.09$ & $0.8 \pm 0.3$ to $0.4 \pm 0.2$ & $0.4 \pm 0.2$ & $20 \pm 2.5$ to $19 \pm 2.5$ & $362,142.5$ \\
\hline U-109-8-4 & $24 \pm 3.2$ to $25 \pm 3.3$ & $38 \pm 6.3$ to $40 \pm 6.6$ & $35 \pm 4.0$ to $33 \pm 3.7$ & $0.6 \pm 0.08$ & $2.2 \pm 0.9$ to $1.2 \pm 0.5$ & $0.3 \pm 0.07$ & $23 \pm 2.2$ to $22 \pm 2.2$ & $265,104.5$ \\
\hline U-109-8-6 & $28 \pm 5.0$ to $30 \pm 5.2$ & $43 \pm 11$ to $45 \pm 11$ & $26 \pm 5.1$ to $23 \pm 4.4$ & $1.1 \pm 0.2$ to $1.2 \pm 0.2$ & $1.0 \pm 0.3$ to $0.5 \pm 0.2$ & $0.7 \pm 0.2$ & $15 \pm 1.0$ to $14 \pm 1.0$ & $169,66.5$ \\
\hline $\mathrm{U}-109-8-8$ & $27 \pm 2.4$ to $28 \pm 2.5$ & $52 \pm 7.5$ to $53 \pm 7.7$ & $19 \pm 1.7$ to $17 \pm 1.6$ & $0.8 \pm 0.09$ & $1.0 \pm 0.4$ to $0.5 \pm 0.2$ & $0.4 \pm 0.07$ & $30 \pm 1.9$ to $29 \pm 1.8$ & $72,28.5$ \\
\hline $\mathrm{U}-109-\mathrm{NC}$ & $25 \pm 3.1$ to $26 \pm 3.2$ & $46 \pm 7.8$ to $48 \pm 8.1$ & $27 \pm 3.5$ to $24 \pm 3.2$ & $0.7 \pm 0.1$ to $0.8 \pm 0.1$ & $1.2 \pm 0.5$ to $0.6 \pm 0.2$ & $0.4 \pm 0.1$ & $22 \pm 11$ to $21 \pm 10$ & 202,80 \\
\hline SY-101-23A-1 & $22 \pm 3.2$ to $23 \pm 3.3$ & $47 \pm 9.4$ to $51 \pm 10$ & $23 \pm 3.4$ to $21 \pm 3.1$ & $0.8 \pm 0.1$ to $0.9 \pm 0.1$ & $6.2 \pm 1.6$ to $2.9 \pm 0.8$ & $0.7 \pm 0.1$ to $0.8 \pm 0.1$ & $20 \pm 1.5$ to $18 \pm 1.5$ & 1022,402 \\
\hline SY-101-23A-2 & $34 \pm 4.8$ to $38 \pm 5.1$ & $27 \pm 4.5$ to $30 \pm 4.8$ & $21 \pm 3.0$ to $23 \pm 3.0$ & $0.6 \pm 0.09$ & $16 \pm 3.7$ to $7.1 \pm 1.6$ & $0.9 \pm 0.3$ to $1.0 \pm 0.3$ & $39 \pm 2.9$ to $35 \pm 2.9$ & $974,383.5$ \\
\hline SY-101-22A-3 & $34 \pm 4.4$ to $37 \pm 4.6$ & $30 \pm 4.9$ to $33 \pm 5.2$ & $24 \pm 3.3$ to $24 \pm 3.2$ & $0.6 \pm 0.2$ to $0.7 \pm 0.2$ & $11 \pm 2.6$ to $5.0 \pm 1.2$ & $0.4 \pm 0.2$ to $0.5 \pm 0.2$ & $33 \pm 2.7$ to $30 \pm 2.7$ & $959,377.5$ \\
\hline SY-101-23A-3 & $40 \pm 4.4$ to $45 \pm 4.4$ & $23 \pm 3.3$ to $26 \pm 3.4$ & $18 \pm 1.9$ to $20 \pm 1.8$ & $0.5 \pm 0.07$ to $0.6 \pm 0.07$ & $18 \pm 4.7$ to $7.6 \pm 1.9$ & $0.5 \pm 0.09$ to $0.6 \pm 0.1$ & $61 \pm 3.9$ to $53 \pm 3.9$ & $926,364.5$ \\
\hline$S Y-101-22 A-4$ & $35 \pm 3.9$ to $44 \pm 3.6$ & $21 \pm 3.2$ to $26 \pm 3.4$ & $17 \pm 1.8$ to $20 \pm 1.6$ & $0.5 \pm 0.08$ to $0.7 \pm 0.08$ & $26 \pm 6.8$ to $8.6 \pm 2.1$ & $0.5 \pm 0.08$ & $73 \pm 7$ to $58 \pm 3.8$ & $911,358.5$ \\
\hline SY-10l-4A-5 & $38 \pm 8.7$ to $43 \pm 10$ & $27 \pm 7.9$ to $33 \pm 9.4$ & $24 \pm 6.1$ to $17 \pm 4.3$ & $1.1 \pm 0.3$ to $1.2 \pm 0.4$ & $8.8 \pm 2.4$ to $4.2 \pm 1.1$ & $1.1 \pm 0.4$ to $1.3 \pm 0.4$ & $6.0 \pm 1.8$ to $4.9 \pm 1.7$ & $845,332.5$ \\
\hline SY-101-23A-8 & $24 \pm 6.6$ to $27 \pm 7.5$ & $46 \pm 14$ to $55 \pm 17$ & $21 \pm 6.3$ to $12 \pm 3.5$ & $1.4 \pm 0.5$ to $1.6 \pm 0.6$ & $5.9 \pm 1.0$ to $2.8 \pm 0.8$ & $1.4 \pm 0.6$ to $1.7 \pm 0.7$ & $2.8 \pm 1.2$ & $685,269.5$ \\
\hline SY-101-22A-10 & $29 \pm 10$ to $35 \pm 12$ & $35 \pm 14$ to $44 \pm 17$ & $25 \pm 8.7$ to $14 \pm 4.7$ & $1.4 \pm 0.5$ to $1.7 \pm 0.6$ & $8.0 \pm 2.7$ to $3.8 \pm 1.3$ & $1.4 \pm 0.5$ to $1.8 \pm 0.6$ & $3.2 \pm 1.1$ to $2.4 \pm 1.0$ & $621,244.5$ \\
\hline SY-101-23A-13 & $29 \pm 9.9$ to $34 \pm 12$ & $37 \pm 14$ to $46 \pm 18$ & $25 \pm 8.6$ to $13 \pm 4.4$ & $1.2 \pm 0.4$ to $1.4 \pm 0.5$ & $6.7 \pm 1.5$ to $3.2 \pm 1.2$ & $1.5 \pm 0.6$ to $2.0 \pm 0.8$ & $2.8 \pm 0.9$ to $2.1 \pm 0.9$ & $443,174.5$ \\
\hline SY-101-22A-17 & $30 \pm 7.5$ to $36 \pm 9.2$ & $35 \pm 11$ to $45 \pm 14$ & $27 \pm 7.0$ to $13 \pm 3.5$ & $1.5 \pm 0.4$ to $1.8 \pm 0.5$ & $4.8 \pm 0.9$ to $2.3 \pm 0.7$ & $1.3 \pm 0.4$ to $1.7 \pm 0.6$ & $2.5 \pm 0.7$ to $1.8 \pm 0.7$ & $316,124.5$ \\
\hline SY-101-23A-21 & $29 \pm 8.8$ to $34 \pm 10$ & $40 \pm 13$ to $49 \pm 17$ & $23 \pm 6.9$ to $11 \pm 3.2$ & $1.6 \pm 0.5$ to $1.8 \pm 0.6$ & $4.6 \pm 0.9$ to $2.2 \pm 0.7$ & $1.4 \pm 0.5$ to $1.9 \pm 0.6$ & $2.3 \pm 0.7$ to $1.7 \pm 0.7$ & $75,29.5$ \\
\hline SY-101-22A-23 & $32 \pm 8.7$ to $38 \pm 10$ & $36 \pm 12$ to $45 \pm 15$ & $26 \pm 7.6$ to $12 \pm 3.6$ & $1.3 \pm 0.4$ to $1.6 \pm 0.5$ & $4.0 \pm 0.6$ to $1.9 \pm 0.6$ & $1.2 \pm 0.4$ to $1.7 \pm 0.6$ & $2.5 \pm 0.8$ to $1.9 \pm 0.8$ & 28,11 \\
\hline SY-101-23A crust & $35 \pm 4.4$ to $39 \pm 4.5$ & $28 \pm 4.6$ to $32 \pm 4.9$ & $20 \pm 2.5$ to $21 \pm 2.4$ & $0.6 \pm 0.09$ & $16 \pm 3.9$ to $6.7 \pm 1.6$ & $0.7 \pm 0.2$ & $40 \pm 20$ to $35 \pm 18$ & 953,375 \\
\hline SY-101-23A liq. & $27 \pm 8.3$ to $31 \pm 9.8$ & $41 \pm 14$ to $51 \pm 17$ & $23 \pm 7.2$ to $12 \pm 3.7$ & $1.4 \pm 0.5$ to $1.6 \pm 0.6$ & $5.8 \pm 1.8$ to $2.8 \pm 0.9$ & $1.4 \pm 0.5$ to $1.8 \pm 0.7$ & $2.8 \pm 1.4$ to $2.2 \pm 1.1$ & 445,175 \\
\hline SY-101-22A crust & $33 \pm 3.9$ to $38 \pm 4.0$ & $27 \pm 4.5$ to $32 \pm 5.0$ & $20 \pm 2.4$ to $22 \pm 2.3$ & $0.6 \pm 0.1$ to $0.7 \pm 0.1$ & $19 \pm 4.8$ to $6.6 \pm 1.6$ & $0.4 \pm 0.1$ to $0.5 \pm 0.1$ & $54 \pm 27$ to $46 \pm 23$ & 942,371 \\
\hline SY-101-22A liq. & $32 \pm 8.8$ to $38 \pm 10$ & $33 \pm 11$ to $42 \pm 14$ & $26 \pm 7.3$ to $14 \pm 4.1$ & $1.3 \pm 0.4$ to $1.6 \pm 0.5$ & $6.4 \pm 1.9$ to $3.1 \pm 0.9$ & $1.2 \pm 0.4$ to $1.6 \pm 0.6$ & $3.1 \pm 1.6$ to $2.4 \pm 1.2$ & 451,177 \\
\hline
\end{tabular}


Table 2.4. Changes in In Situ Compositions and Volume Fractions of Free Gas from RGS Data ${ }^{(a)}$

\begin{tabular}{|c|c|c|c|c|c|c|c|c|c|c|}
\hline \multirow{3}{*}{$\begin{array}{l}\text { Tank and Sample } \\
\text { (or layer) }\end{array}$} & \multicolumn{8}{|c|}{ Mole Percent of Constituent in Bubbles (at low-solubility end of the gas solubility range) } & \multicolumn{2}{|c|}{$\begin{array}{l}\text { In Situ Gas Volume } \\
\text { (percent, low-sol.) }\end{array}$} \\
\hline & \multicolumn{2}{|c|}{$\mathrm{H}_{2}$} & \multicolumn{2}{|c|}{$\mathrm{N}_{2}$} & \multicolumn{2}{|c|}{$\mathrm{N}_{2} \mathrm{O}$} & \multicolumn{2}{|c|}{$\mathrm{NH}_{3}$} & \multirow[t]{2}{*}{ Previous } & \multirow[t]{2}{*}{ Changed } \\
\hline & Previous & Changed & Previous & Changed & Previous & Changed & Previous & Changed & & \\
\hline $\mathrm{AW}-101-\mathrm{C}$ & $26 \pm 9.4$ & $26 \pm 9.4$ & $67 \pm 32$ & $68 \pm 32$ & $2.3 \pm 0.8$ & $1.8 \pm 0.7$ & $0.6 \pm 0.3$ & $0.4 \pm 0.2$ & $0.8 \pm 0.3$ & $0.8 \pm 0.3$ \\
\hline $\mathrm{AW}-101-\mathrm{NC}$ & $32 \pm 3.2$ & $32 \pm 3.2$ & $55 \pm 6.2$ & $56 \pm 6.2$ & $7.5 \pm 0.8$ & $7.2 \pm 0.8$ & $0.9 \pm 0.4$ & $0.6 \pm 0.3$ & $3.7 \pm 1.8$ & $3.7 \pm 1.8$ \\
\hline AN-105 - C & $25 \pm 12$ & $25 \pm 12$ & $57 \pm 41$ & $58 \pm 42$ & $13 \pm 6.6$ & $11 \pm 5.6$ & $0.8 \pm 0.5$ & $0.6 \pm 0.4$ & $0.6 \pm 0.2$ & $0.5 \pm 0.2$ \\
\hline $\mathrm{AN}-105-\mathrm{NC}$ & $59 \pm 5.4$ & $60 \pm 5.4$ & $24 \pm 4.0$ & $24 \pm 4.0$ & $15 \pm 1.5$ & $14 \pm 1.5$ & $0.6 \pm 0.3$ & $0.5 \pm 0.2$ & $5.2 \pm 2.6$ & $5.1 \pm 2.6$ \\
\hline$A-101-N C$ & $70 \pm 7.3$ & $72 \pm 7.1$ & $19 \pm 4.9$ & $19 \pm 4.9$ & $5.7 \pm 0.6$ & $5.8 \pm 0.6$ & $4.8 \pm 1.8$ & $2.5 \pm 0.9$ & $18 \pm 9.0$ & $18 \pm 9.0$ \\
\hline$A-101-C$ & $14 \pm 4,3$ & $15 \pm 4.5$ & $60 \pm 22$ & $64 \pm 24$ & $15 \pm 5.4$ & $14 \pm 4.9$ & $7.8 \pm 4.0$ & $3.5 \pm 1.8$ & $0.8 \pm 0.3$ & $0.7 \pm 0.3$ \\
\hline $\mathrm{AN}-104-\mathrm{C}$ & $24 \pm 13$ & $25 \pm 13$ & $55 \pm 48$ & $56 \pm 49$ & $15 \pm 8.4$ & $14 \pm 7.6$ & $1.0 \pm 0.7$ & $0.8 \pm 0.5$ & $0.5 \pm 0.2$ & $0.5 \pm 0.2$ \\
\hline AN-104-NC & $45 \pm 6.9$ & $45 \pm 6.9$ & $29 \pm 4.8$ & $29 \pm 4.8$ & $23 \pm 3.8$ & $23 \pm 3.7$ & $1.4 \pm 0.7$ & $0.9 \pm 0.4$ & $8.1 \pm 4.0$ & $8.0 \pm 4.0$ \\
\hline $\mathrm{AN}-103$ crust & $62 \pm 6.4$ & $62 \pm 6.4$ & $29 \pm 3.2$ & $29 \pm 3.2$ & $6.9 \pm 0.7$ & $6.9 \pm 0.7$ & $1.8 \pm 0.8$ & $1.4 \pm 0.6$ & $16 \pm 7.9$ & $16 \pm 7.9$ \\
\hline $\mathrm{AN}-103-\mathrm{C}$ & $19 \pm 12$ & $19 \pm 12$ & $68 \pm 61$ & $70 \pm 62$ & $8.3 \pm 5.3$ & $7.5 \pm 4.8$ & $1.2 \pm 0.9$ & $0.9 \pm 0.6$ & $0.7 \pm 0.3$ & $0.7 \pm 0.3$ \\
\hline $\mathrm{AN}-103-\mathrm{NC}$ & $61 \pm 7.7$ & $61 \pm 7.7$ & $33 \pm 4.3$ & $33 \pm 4.3$ & $4.2 \pm 0.6$ & $4.1 \pm 0.6$ & $0.9 \pm 0.4$ & $0.6 \pm 0.2$ & $9.2 \pm 4.6$ & $9.2 \pm 4.6$ \\
\hline $\mathrm{U}-103-\mathrm{NC}$ & $23 \pm 1.4$ & $23 \pm 1.4$ & $36 \pm 2.3$ & $36 \pm 2.3$ & $40 \pm 2.4$ & $39 \pm 2.4$ & $0.6 \pm 0.3$ & $0.6 \pm 0.3$ & $19 \pm 9.6$ & $19 \pm 9.5$ \\
\hline$S-106-N C$ & $63 \pm 5.7$ & $63 \pm 5.7$ & $25 \pm 3.7$ & $25 \pm 3.7$ & $11 \pm 1.0$ & $11 \pm 1.0$ & $0.4 \pm 0.2$ & $0.3 \pm 0.2$ & $10 \pm 5.2$ & $10 \pm 5.0$ \\
\hline BY- 109 below ILL & $50 \pm 5.5$ & $50 \pm 5.5$ & $28 \pm 5.0$ & $29 \pm 5.1$ & $18 \pm 2.5$ & $18 \pm 2.5$ & $0.3 \pm 0.1$ & $0.2 \pm 0.1$ & $9.5 \pm 4.7$ & $9.4 \pm 4.7$ \\
\hline$S X-106-C$ & $21 \pm 4.8$ & $21 \pm 4.9$ & $61 \pm 20$ & $64 \pm 21$ & $15 \pm 4.2$ & $12 \pm 3.4$ & $0.6 \pm 0.1$ & $0.9 \pm 0.2$ & $0.2 \pm 0.1$ & $0.2 \pm 0.1$ \\
\hline $\mathrm{SX}-106-\mathrm{NC}$ & $51 \pm 4.7$ & $50 \pm 4.5$ & $20 \pm 4.0$ & $20 \pm 3.8$ & $24 \pm 2.7$ & $24 \pm 2.8$ & $4.4 \pm 0.9$ & $5.5 \pm 1.2$ & $26 \pm 13$ & $26 \pm 13$ \\
\hline AX-101-9D-8 & $60 \pm 5.5$ & $61 \pm 5.5$ & $16 \pm 2.6$ & $17 \pm 2.6$ & $11 \pm 1.1$ & $11 \pm 1.0$ & $9.2 \pm 2.1$ & $8.4 \pm 1.9$ & $17 \pm 1.3$ & $17 \pm 1.3$ \\
\hline S-102 tank avg. & $33 \pm 3.0$ & $33 \pm 3.0$ & $32 \pm 4.3$ & $32 \pm 4.3$ & $33 \pm 3.3$ & $33 \pm 3.1$ & $1.0 \pm 0.3$ & $1.1 \pm 0.4$ & $26 \pm 13$ & $26 \pm 13$ \\
\hline $\mathrm{S}-111-\mathrm{C}$ & $6.4 \pm 3.4$ & $6.3 \pm 3.4$ & $90 \pm 68$ & $90 \pm 68$ & $2.2 \pm 1.3$ & $1.7 \pm 1.0$ & $0.1 \pm 0.1$ & $0.2 \pm 0.2$ & $0.8 \pm 0.3$ & $0.8 \pm 0.2$ \\
\hline S-111-NC & $66 \pm 10$ & $66 \pm 10$ & $21 \pm 5.6$ & $21 \pm 5.6$ & $11 \pm 1.8$ & $11 \pm 1.7$ & $1.0 \pm 0.3$ & $1.1 \pm 0.4$ & $15 \pm 7.5$ & $15 \pm 7.5$ \\
\hline $\mathrm{U}-109-\mathrm{NC}$ & $25 \pm 3.0$ & $25 \pm 3.1$ & $46 \pm 7.7$ & $46 \pm 7.8$ & $27 \pm 3.6$ & $27 \pm 3.5$ & $0.9 \pm 0.3$ & $1.2 \pm 0.5$ & $22 \pm 11$ & $22 \pm 11$ \\
\hline SY-101-23A-3 & $37 \pm 4.4$ & $40 \pm 4.4$ & $21 \pm 3.2$ & $23 \pm 3.3$ & $17 \pm 2.0$ & $18 \pm 1.9$ & $24 \pm 6.1$ & $18 \pm 4.7$ & $65 \pm 3.9$ & $61 \pm 3.9$ \\
\hline SY-101-22A-4 & $34 \pm 3.9$ & $35 \pm 3.9$ & $20 \pm 3.1$ & $21 \pm 3.2$ & $16 \pm 1.8$ & $17 \pm 1.8$ & $28 \pm 7.3$ & $26 \pm 6.8$ & $72 \pm 7$ & $73 \pm 7$ \\
\hline SY-101-23A crust & $34 \pm 4.4$ & $35 \pm 4.4$ & $27 \pm 4.5$ & $28 \pm 4.6$ & $19 \pm 2.5$ & $20 \pm 2.5$ & $19 \pm 4.7$ & $16 \pm 3.9$ & $40 \pm 20$ & $40 \pm 20$ \\
\hline SY-101-23A liq. & $26 \pm 8.1$ & $27 \pm 8.3$ & $40 \pm 14$ & $41 \pm 14$ & $24 \pm 7.4$ & $23 \pm 7.2$ & $7.1 \pm 2.2$ & $5.8 \pm 1.8$ & $2.9 \pm 1.4$ & $2.8 \pm 1.4$ \\
\hline SY-101-22A crust & $32 \pm 3.9$ & $33 \pm 3.9$ & $27 \pm 4.5$ & $27 \pm 4.5$ & $19 \pm 2.4$ & $20 \pm 2.4$ & $21 \pm 5.1$ & $19 \pm 4.8$ & $52 \pm 26$ & $54 \pm 27$ \\
\hline SY-101-22A liq. & $31 \pm 8.5$ & $32 \pm 8.8$ & $32 \pm 11$ & $33 \pm 11$ & $26 \pm 7.5$ & $26 \pm 7.3$ & $7.8 \pm 2.3$ & $6.4 \pm 1.9$ & $3.1 \pm 1.5$ & $3.1 \pm 1.6$ \\
\hline
\end{tabular}


Table 2.5. In Situ Composition Ratios in Free Gas from RGS Data ${ }^{(a)}$

\begin{tabular}{|c|c|c|c|c|}
\hline \multirow{3}{*}{$\begin{array}{l}\text { Tank and Sample } \\
\text { (or layer) }\end{array}$} & \multicolumn{4}{|c|}{ Ratios in Free Gas (at low-solubility end of solubility range) } \\
\hline & \multicolumn{2}{|c|}{$\mathrm{H}_{2} / \mathrm{N}_{2} \mathrm{O}$} & \multicolumn{2}{|c|}{$\mathrm{H}_{2} / \mathrm{N}_{2}$} \\
\hline & Previous & Changed & Previous & Changed \\
\hline $\mathrm{AW}-101-\mathrm{C}$ & 12.3 & 14.1 & 0.386 & 0.382 \\
\hline $\mathrm{AW}-101-\mathrm{NC}$ & 4.26 & 4.43 & 0.574 & 0.574 \\
\hline $\mathrm{AN}-105-\mathrm{C}$ & 1.84 & 2.21 & 0.433 & 0.426 \\
\hline $\mathrm{AN}-105-\mathrm{NC}$ & 3.99 & 4.11 & 2.50 & 2.50 \\
\hline $\mathrm{A}-101-\mathrm{NC}$ & 12.3 & 12.3 & 3.75 & 3.75 \\
\hline$A-101-C$ & 0.942 & 1.08 & 0.239 & 0.235 \\
\hline $\mathrm{AN}-104-\mathrm{C}$ & 1.59 & 1.80 & 0.442 & 0.438 \\
\hline $\mathrm{AN}-104-\mathrm{NC}$ & 1,94 & 1.96 & 1.53 & 1.53 \\
\hline AN-103 crust & 8.98 & 9.03 & 2.16 & 2.16 \\
\hline AN-103-C & 2.30 & 2.56 & 0.279 & 0.276 \\
\hline $\mathrm{AN}-103-\mathrm{NC}$ & 14.8 & 14.9 & 1.89 & 1.89 \\
\hline $\mathrm{U}-103-\mathrm{NC}$ & 0.574 & 0.580 & 0.630 & 0.630 \\
\hline $\mathrm{S}-106-\mathrm{NC}$ & 5.89 & 6.00 & 2.54 & 2.53 \\
\hline BY-109 below ILL & 2.77 & 2.79 & 1.75 & 1.75 \\
\hline $\mathrm{SX}-106-\mathrm{C}$ & 1.32 & 1.68 & 0.333 & 0.320 \\
\hline $\mathrm{SX}-106-\mathrm{NC}$ & 2.11 & 2.11 & 2.55 & 2.55 \\
\hline$A X-101-9 D-8$ & 5.26 & 5.29 & 3.66 & 3.66 \\
\hline S-102 tank avg. & 0.988 & 0.994 & 1.04 & 1.03 \\
\hline S-111-C & 2.94 & 3.64 & 0.071 & 0.070 \\
\hline S-111-NC & 5.80 & 5.94 & 3.07 & 3.06 \\
\hline $\mathrm{U}-109-\mathrm{NC}$ & 0.920 & 0.931 & 0.552 & 0.551 \\
\hline$S Y-101-23 A-3$ & 2.20 & 2.20 & 1.72 & 1.72 \\
\hline$S Y-101-22 A-4$ & 2.15 & 2.15 & 1.68 & 1.68 \\
\hline SY-101-23A crust & 1.76 & 1.76 & 1.25 & 1.25 \\
\hline SY-101-23A liq. & 1.11 & 1.17 & 0.662 & 0.659 \\
\hline SY-101-22A crust & 1.66 & 1.67 & 1.19 & 1.19 \\
\hline SY-101-22A lig. & 1.18 & 1.24 & 0.958 & 0.955 \\
\hline \multicolumn{5}{|c|}{$\begin{array}{l}\text { (a) Values in bold indicate a correction of more than } 10 \% \text { to the value in Mahoney et al. } \\
\text { (1999). Such changes occurred only in the convective layer, where gas volume fractions of } \\
\text { less than } 0.01 \text { mean that solubility changes have amplified effect on } \mathrm{N}_{2} \mathrm{O} \text {, which is } \\
\text { somewhat more soluble than other sparingly soluble gases. }\end{array}$} \\
\hline
\end{tabular}


Table 2.6. Concentrations of Dissolved Gases Calculated from RGS Data

\begin{tabular}{|c|c|c|c|c|c|c|}
\hline \multirow{3}{*}{$\begin{array}{l}\text { Tank and Sample } \\
\text { (or layer) }\end{array}$} & \multicolumn{6}{|c|}{$\begin{array}{l}\text { Concentration of Dissolved Constituent in Liquid, gmol/L liquid } \\
\text { (at low end of solubility range) }\end{array}$} \\
\hline & \multicolumn{2}{|c|}{$\mathrm{H}_{2}$} & \multicolumn{2}{|c|}{$\mathrm{N}_{2}$} & \multicolumn{2}{|c|}{$\mathrm{N}_{2} \mathrm{O}$} \\
\hline & Wrong & Corrected & Wrong & Corrected & Wrong & Corrected \\
\hline $\mathrm{AW}-101-\mathrm{C}$ & $3.18 \mathrm{E}-06$ & $5.89 \mathrm{E}-06$ & $2.41 \mathrm{E}-06$ & $4.53 \mathrm{E}-06$ & $4.63 \mathrm{E}-06$ & $6.89 \mathrm{E}-06$ \\
\hline $\mathrm{AW}-101-\mathrm{NC}$ & $6.81 \mathrm{E}-06$ & $9.93 \mathrm{E}-06$ & $4.14 \mathrm{E}-06$ & $6.05 \mathrm{E}-06$ & $3.21 \mathrm{E}-05$ & $4.46 \mathrm{E}-05$ \\
\hline $\mathrm{AN}-105-\mathrm{C}$ & $4.64 \mathrm{E}-06$ & $6.70 \mathrm{E}-06$ & $3.40 \mathrm{E}-06$ & $4.99 \mathrm{E}-06$ & $4.23 \mathrm{E}-05$ & $5.09 \mathrm{E}-05$ \\
\hline AN-105-NC & $1.59 \mathrm{E}-05$ & $2.28 \mathrm{E}-05$ & $4.55 \mathrm{E}-06$ & $6.63 \mathrm{E}-06$ & $8.39 \mathrm{E}-05$ & $1.10 \mathrm{E}-04$ \\
\hline$A-101-N C$ & $1.05 \mathrm{E}-05$ & $1.59 \mathrm{E}-05$ & $7.87 \mathrm{E}-07$ & $1.19 \mathrm{E}-06$ & $1.07 \mathrm{E}-05$ & $1.60 \mathrm{E}-05$ \\
\hline$A-101-C$ & $3.11 \mathrm{E}-06$ & $4.89 \mathrm{E}-06$ & $3.54 \mathrm{E}-06$ & $5.67 \mathrm{E}-06$ & $3.60 \mathrm{E}-05$ & $4.91 \mathrm{E}-05$ \\
\hline $\mathrm{AN}-104-\mathrm{C}$ & $3.44 \mathrm{E}-06$ & $4.74 \mathrm{E}-06$ & $2.32 \mathrm{E}-06$ & $3.23 \mathrm{E}-06$ & $3.50 \mathrm{E}-05$ & $4.27 \mathrm{E}-05$ \\
\hline $\mathrm{AN}-104-\mathrm{NC}$ & $1.13 \mathrm{E}-05$ & $1.56 \mathrm{E}-05$ & $2.61 \mathrm{E}-06$ & $3.59 \mathrm{E}-06$ & $6.94 \mathrm{E}-05$ & $9.35 \mathrm{E}-05$ \\
\hline AN-103 crust & $6.36 \mathrm{E}-06$ & $8.55 \mathrm{E}-06$ & $8.44 \mathrm{E}-07$ & $1.13 \mathrm{E}-06$ & $1.19 \mathrm{E}-05$ & $1.59 \mathrm{E}-05$ \\
\hline $\mathrm{AN}-103-\mathrm{C}$ & $2.64 \mathrm{E}-06$ & $3.56 \mathrm{E}-06$ & $2.65 \mathrm{E}-06$ & $3.60 \mathrm{E}-06$ & $1.80 \mathrm{E}-05$ & $2.16 \mathrm{E}-05$ \\
\hline $\mathrm{AN}-103-\mathrm{NC}$ & $1.16 \mathrm{E}-05$ & $1.56 \mathrm{E}-05$ & $1.79 \mathrm{E}-06$ & $2.40 \mathrm{E}-06$ & $1.25 \mathrm{E}-05$ & $1.66 \mathrm{E}-05$ \\
\hline $\mathrm{U}-103-\mathrm{NC}$ & $5.07 \mathrm{E}-06$ & $7.27 \mathrm{E}-06$ & $2.61 \mathrm{E}-06$ & $3.74 \mathrm{E}-06$ & $1.75 \mathrm{E}-04$ & $2.47 \mathrm{E}-04$ \\
\hline $\mathrm{S}-106-\mathrm{NC}$ & $2.14 \mathrm{E}-05$ & $2.78 \mathrm{E}-05$ & $3.20 \mathrm{E}-06$ & $4.17 \mathrm{E}-06$ & $8.14 \mathrm{E}-05$ & $1.04 \mathrm{E}-04$ \\
\hline BY-109 below ILL & $4.52 \mathrm{E}-06$ & $6.20 \mathrm{E}-06$ & $7.59 \mathrm{E}-07$ & $1.04 \mathrm{E}-06$ & $3.16 \mathrm{E}-05$ & $4.31 \mathrm{E}-05$ \\
\hline SX-106-C & $1.76 \mathrm{E}-06$ & $2.47 \mathrm{E}-06$ & $1.39 \mathrm{E}-06$ & $2.04 \mathrm{E}-06$ & $2.35 \mathrm{E}-05$ & $2.61 \mathrm{E}-05$ \\
\hline SX-106-NC & $5.26 \mathrm{E}-06$ & $7.30 \mathrm{E}-06$ & $5.47 \mathrm{E}-07$ & $7.59 \mathrm{E}-07$ & $3.63 \mathrm{E}-05$ & $5.02 \mathrm{E}-05$ \\
\hline$A X-101-9 D-8$ & $1.18 \mathrm{E}-05$ & $1.57 \mathrm{E}-05$ & $8.98 \mathrm{E}-07$ & $1.19 \mathrm{E}-06$ & $2.77 \mathrm{E}-05$ & $3.67 \mathrm{E}-05$ \\
\hline S-102 tank avg. & $9.70 \mathrm{E}-06$ & $1.29 \mathrm{E}-05$ & $2.86 \mathrm{E}-06$ & $3.81 \mathrm{E}-05$ & $1.47 \mathrm{E}-04$ & $1.94 \mathrm{E}-04$ \\
\hline S-111-C & $2.09 \mathrm{E}-06$ & $2.86 \mathrm{E}-06$ & $1.16 \mathrm{E}-05$ & $1.62 \mathrm{E}-05$ & $1.62 \mathrm{E}-05$ & $1.78 \mathrm{E}-05$ \\
\hline $\mathrm{S}-111-\mathrm{NC}$ & $2.50 \mathrm{E}-05$ & $3.48 \mathrm{E}-05$ & $4.48 \mathrm{E}-06$ & $6.26 \mathrm{E}-06$ & $1.14 \mathrm{E}-04$ & $1.52 \mathrm{E}-04$ \\
\hline $\mathrm{U}-109-\mathrm{NC}$ & $7.39 \mathrm{E}-06$ & $9.92 \mathrm{E}-06$ & $4.74 \mathrm{E}-06$ & $6.37 \mathrm{E}-06$ & $1.87 \mathrm{E}-04$ & $2.48 \mathrm{E}-04$ \\
\hline SY-101-23A-3 & $3.27 \mathrm{E}-06$ & $5.94 \mathrm{E}-06$ & $5.09 \mathrm{E}-07$ & $9.24 \mathrm{E}-07$ & $2.08 \mathrm{E}-05$ & $3.77 \mathrm{E}-05$ \\
\hline SY-101-22A-4 & $3.33 \mathrm{E}-06$ & $5.59 \mathrm{E}-06$ & $5.32 \mathrm{E}-07$ & $8.92 \mathrm{E}-07$ & $2.18 \mathrm{E}-05$ & $3.66 \mathrm{E}-05$ \\
\hline SY-101-23A crust & $2.42 \mathrm{E}-06$ & $4.28 \mathrm{E}-06$ & $7.68 \mathrm{E}-07$ & $1.32 \mathrm{E}-06$ & $2.63 \mathrm{E}-05$ & $4.51 \mathrm{E}-05$ \\
\hline SY-101-23A liq. & $3.94 \mathrm{E}-06$ & $6.87 \mathrm{E}-06$ & $1.52 \mathrm{E}-06$ & $2.66 \mathrm{E}-06$ & $4.66 \mathrm{E}-05$ & $7.71 \mathrm{E}-05$ \\
\hline SY-101-22A crust & 4.17E-06 & $7.07 \mathrm{E}-06$ & $1.42 \mathrm{E}-06$ & $2.42 \mathrm{E}-06$ & $5.00 \mathrm{E}-05$ & $8.48 \mathrm{E}-05$ \\
\hline SY-101-22A liq. & $4.48 \mathrm{E}-06$ & $7.84 \mathrm{E}-06$ & $1.30 \mathrm{E}-06$ & $2.27 \mathrm{E}-06$ & $5.29 \mathrm{E}-05$ & $8.79 E-05$ \\
\hline
\end{tabular}


Table 2.7. Figures and Tables in Mahoney et al. (1999) Affected by Correction

\begin{tabular}{|c|c|c|}
\hline Tables/Figures in Mahoney et al. (1999) & Type & Action \\
\hline Table S.1 & Overview & $\begin{array}{l}\text { Replace with Table S.1 of this } \\
\text { report }\end{array}$ \\
\hline Figures 4.1.3, 4.2.3, 4.4.3, 4.5.3, and 4.15.4 & $\begin{array}{l}\text { RGS and VFI gas } \\
\text { volume fractions }\end{array}$ & $\begin{array}{l}\text { The RGS gas fractions change } \\
\text { negligibly except for SY-101; see } \\
\text { Table } 2.3 \text { of this report }\end{array}$ \\
\hline $\begin{array}{l}\text { Tables 4.1.6, 4.2.6, 4.3.6, 4.4.6, 4.5.6, 4.6.6, } \\
4.7 .6,4.9 .6,4.10 .6,4.11 .6,4.12 .6,4.13 .5 \text {, } \\
4.14 .5 \text {, and } 4.15 .5\end{array}$ & $\begin{array}{l}\text { Retained gas } \\
\text { composition }\end{array}$ & $\begin{array}{l}\text { Replace with compositions from } \\
\text { Table } 2.3 \text { of this report }\end{array}$ \\
\hline $\begin{array}{l}\text { Tables 4.1.7, 4.2.7, 4.3.7, 4.4.7, 4.5.7, 4.6.7, } \\
4.7 .7,4.9 .7,4.10 .7,4.11 .7,4.12 .7,4.13 .6 \text {, } \\
4.14 .6 \text {, and } 4.15 .6\end{array}$ & $\begin{array}{l}\text { Retained gas } \\
\text { volume fraction }\end{array}$ & $\begin{array}{l}\text { Replace with gas volume fractions } \\
\text { from Table } 2.3 \text { of this report; } \\
\text { changes negligible except for SY- } \\
101\end{array}$ \\
\hline $\begin{array}{l}\text { Tables 4.1.8, 4.2.8, 4.3.8, 4.4.8, 4.5.8, 4.6.8, } \\
4.7 .8,4.9 .8,4.10 .8,4.11 .8,4.12 .8,4.13 .7 \text {, } \\
4.14 .7 \text {, and } 4.15 .7\end{array}$ & Gas inventory & $\begin{array}{l}\text { Changes negligible except for SY- } \\
101 \text {, whose gas volume at the time } \\
\text { can be scaled from layer volume } \\
\text { fractions in Table } 2.3 \text { of this report }\end{array}$ \\
\hline $\begin{array}{l}\text { Tables 4.1.9, 4.2.9, 4.3.9, 4.4.9, 4.5.9, 4.6.9, } \\
4.7 .9,4.9 .9,4.10 .9,4.11 .9,4.12 .9,4.13 .8, \\
4.14 .8, \text { and } 4.15 .8\end{array}$ & $\begin{array}{l}\text { Speciated gas } \\
\text { inventory }\end{array}$ & $\begin{array}{l}\text { Gas-phase inventory can be } \\
\text { calculated from total gas volume } \\
\text { and compositions in Table } 2.3 \text { of } \\
\text { this report. Dissolved inventories } \\
\text { of } \mathrm{H}_{2}, \mathrm{~N}_{2} \mathrm{O} \text {, and } \mathrm{N}_{2} \text { can be scaled } \\
\text { from the dissolved concentrations } \\
\text { (before and after correction) in } \\
\text { Table } 2.6 \text { of this report. }\end{array}$ \\
\hline $\begin{array}{l}\text { Tables 4.1.10, 4.2.10, 4.3.10, 4.4.10,4.5.10, } \\
4.6 .10,4.7 .10,4.9 .10,4.10 .10,4.11 .10, \\
4.12 .10,4.13 .9,4.14 .9 \text {, and } 4.15 .9\end{array}$ & $\begin{array}{l}\mathrm{X} \text {-ray gas } \\
\text { fractions and } \\
\text { observations } \\
\end{array}$ & $\begin{array}{l}\text { The RGS gas fractions change } \\
\text { negligibly except for SY-101; see } \\
\text { Table } 2.3 \text { of this report }\end{array}$ \\
\hline $\begin{array}{l}\text { Figures } 4.1 .4,4.2 .4,4.3 .3,4.4 .4,4.5 .4,4.6 .3 \text {, } \\
4.7 .4,4.9 .4,4.10 .3,4.11 .3,4.12 .3,4.13 .3, \\
4.14 .3,4.15 .5 \text {, and } 4.15 .6\end{array}$ & $\begin{array}{l}\text { Gas fraction and } \\
\text { composition } \\
\text { profiles }\end{array}$ & $\begin{array}{l}\text { The RGS gas fractions change } \\
\text { negligibly except for SY- } 101 \text {; see } \\
\text { Table } 2.3 \text { of this report }\end{array}$ \\
\hline $\begin{array}{l}\text { Tables } 4.1 .12,4.2 .12,4.3 .12,4.4 .12,4.5 .12, \\
4.6 .12,4.7 .12,4.9 .12,4.10 .12,4.11 .12, \\
4.12 .12,4.13 .11,4.14 .11 \text {, and } 4.15 .12\end{array}$ & $\begin{array}{l}\text { Comparison to } \\
\text { drillstring and } \\
\text { domespace data }\end{array}$ & $\begin{array}{l}\text { Comparisons are based on } \mathrm{H}_{2} / \mathrm{N}_{2} \mathrm{O} \\
\text { ratios, whose averages are in Table } \\
2.5 \text { of this report; changes are } \\
\text { negligible except in some } \\
\text { convective layers }\end{array}$ \\
\hline Table 5.1 & $\begin{array}{l}\text { RGS and BPE gas } \\
\text { inventories }\end{array}$ & $\begin{array}{l}\text { Changes in the RGS gas inventories } \\
\text { are negligible }\end{array}$ \\
\hline Table 5.2 & $\begin{array}{l}\text { Overall RGS } \\
\text { summary }\end{array}$ & $\begin{array}{l}\text { Replace with Table } 2.3 \text { of this } \\
\text { report }\end{array}$ \\
\hline
\end{tabular}




\subsection{Ammonia Concentration}

Measuring ammonia by RGS methods is a complex process. The RGS extraction of gas from core samples collected only the small amount of ammonia that evaporated from the sample. A much larger amount remained dissolved in the sample, and this residual ammonia could not be calculated from a mass balance. Furthermore, careful data analysis was required to calculate how much ammonia vapor had been extracted. Much of it dissolved in the water that condensed on the walls of the collection canister as a result of pumping and so was not detected by mass spectrometry of the gas and vapor in the collection canister. Four different methods were used during the RGS program to measure ammonia concentrations in RGS samples (Mahoney et al. 1999):

1) The total ammonia concentration was calculated for most AW-101 samples and a few others, by adding the extracted ammonia to the amount of ammonia that was found by ion-specific electrode (ISE) in the sample after it had undergone extraction and removal from the extractor. For these samples, the accuracy of the ammonia concentration primarily depended on whether the sample lost significant ammonia during postextraction exposure to the air. The accuracy of the calculation of extracted ammonia played a smaller part because $25 \%$ or less of the sample ammonia was indeed extracted.

2) For waste from many tanks in the first year of the program, the total ammonia concentration was roughly estimated by scaling the AW-101 concentrations by the ratio of the initial ammonia partial pressure in the extractor for the tank's samples divided by the pressure for AW-101 samples. The accuracy of the ammonia concentration depended on the AW-101 accuracy, the accuracy of the ammonia partial pressure, and the assumption that the AW-101 and other tank ammonia partial pressures were equally close to (or far from) the equilibrium vapor pressure.

3) In the second year of the program, a known amount of ${ }^{15} \mathrm{NH}_{3}$ vapor standard was added to the sample partway through extraction and the isotopic ratio of the extracted ammonia was used to calculate the residual ammonia. Accuracy depended on whether the isotopic ratio $\left({ }^{15} \mathrm{NH}_{3} /{ }^{14} \mathrm{NH}_{3}\right)$ represented a true equilibrium between the standard and the sample and, to a lesser extent, on the accuracy of the extracted ammonia calculation.

4) In the last two years of the program, a known amount of ${ }^{15} \mathrm{NH}_{4} \mathrm{OH}$ solution standard was added to the sample partway through extraction. The accuracy depended on the same issues as the isotopic vapor standard, though a closer equilibrium between standard and sample was expected because the liquid standard was mechanically mixed with the sample.

Table 3.1 summarizes the RGS ammonia measurement methods that were used for all the samples. Each of the methods was used on a large number of tank samples. The measurement accuracies of the methods were vulnerable (in varying degrees) to three different physical phenomena: ammonia adsorption on surfaces, mass-transfer limitations on ammonia equilibration between phases, and ammonia evaporation. Therefore, "post-calibration" experiments were conducted in FY 2000 to investigate the accuracy of RGS ammonia measurement methods, particularly the isotopic solution method. Section 3.1 discusses the 
Table 3.1. RGS Ammonia Measurement Methods

\begin{tabular}{||l|l||}
\hline \multicolumn{1}{|c|}{ Samples } & \multicolumn{1}{|c|}{ Method } \\
\hline AW-101, all but 24A-21 & Extracted ammonia plus post-extraction \\
AN-105 7B-4, 12A-15, 7B-18 & ISE \\
\hline AW-101 24A-21 & $\begin{array}{l}\text { Comparison to AW-101 by initial } \\
\text { ammonia partial pressure }\end{array}$ \\
A-101 $7 \mathrm{~B}-16,12 \mathrm{~A}-17,12 \mathrm{~A}-19,12 \mathrm{~A}-21$ & \\
AN-104 & \\
AN-103 & \\
\hline U-103 & \\
S-106 & $\begin{array}{l}\text { Isotopic vapor method was carried out } \\
\text { but gave different results than AW-101 } \\
\text { comparison (the preferred method) }\end{array}$ \\
\hline BY-109 & $\begin{array}{l}\text { Isotopic vapor and AW-101 comparison } \\
\text { methods were consistent }\end{array}$ \\
\hline SX-106 & $\begin{array}{l}\text { Three methods were used: extracted } \\
\text { plus post-extraction ISE, comparison to }\end{array}$ \\
S-102 & AW-101, and isotopic solution (usually \\
S-111 & preferred) \\
\hline AX-101 & $\begin{array}{l}\text { Two methods were used: comparison } \\
\text { to AW-101, and isotopic solution } \\
\text { (usually preferred) }\end{array}$ \\
\hline SY-101 &
\end{tabular}

vulnerabilities of each method, and the ways in which the FY 2000 experiments addressed the concerns. Section 3.2 describes the FY 2000 experiments, and Section 3.3 discusses the results of the isotopic method tests. Section 3.4 assesses the initial partial pressure method of determining ammonia, and Section 3.5 the method of ISE analysis.

\subsection{Vulnerabilities of Ammonia Measurement Methods}

The measurement by ISE of the ammonia remaining in the sample after RGS extraction was vulnerable to ammonia evaporation. The sample had to be scraped or poured from the extractor after extraction was complete, and it was exposed to the airflow in the hot cell for roughly 15 minutes while it was put into a jar. The sample jar would then sit in the hot cell awaiting loadout for a period of days or weeks. After loadout, a subsample would be taken, often requiring dilution before analysis, with further handling and air exposure. It is expected that some ammonia would evaporate and that the ammonia measured in the sample would be a lower bound on the true residual ammonia (i.e., that which was present immediately after extraction was completed). This hypothesis was tested in the FY 2000 experiments by conducting ISE analyses on $\mathrm{NH}_{4} \mathrm{OH}$ standards before and after they were extracted.

Extracted ammonia was measured largely by indirect means. Some of the ammonia in the collection canisters (into which extracted gas was pumped) was present in the gas phase, but a roughly equal amount was dissolved in water condensed in the collection apparatus. Measurements of the dry composition by mass spectrometry and the pressure, temperature, and volume of the collection apparatus were made. As detailed in Section 3.3 of Mahoney et al. (1999), these measurements were used to determine the total amount of water and ammonia in the collector by assuming that standard data for ammonia and water vapor pressures over 
$\mathrm{NH}_{4} \mathrm{OH}$ solutions were applicable. This assumption allowed the composition and amount of the liquid phase to be determined. However, the condensate is present in very small amounts, probably as a film, and its equilibrium properties may be affected by adsorption and not be the same as the bulk solutions used for standard data (Reid et al. 1987; AIChE 1973; Prausnitz et al. 1986). The FY 2000 experiments did not explore the accuracy of the extracted ammonia measurement because it is but a small contributor to the overall ammonia uncertainty.

The initial ammonia vapor pressure was calculated by subtracting the sample gas and water vapor pressures, both calculated quantities, from the measured total pressure in the extractor before extraction began. The sample gas pressure was found from the moles of gas in the sample (determined by extraction) and the extractor temperature and pressure, using the ideal gas law. The sample water vapor pressure was calculated by assuming that the water in the collector (determined as part of the condensate calculations) was pumped equally in each stroke. This assumes a constant water vapor pressure over the sample, with no changes produced by (for example) surface drying. The uncertainties in the total pressure and in the gas and water partial pressures are magnified in the initial ammonia vapor pressure calculated from them because it is obtained as the difference between them. There is further uncertainty in the assumption that the initial ammonia partial pressure is the same as the vapor pressure, because equilibrium might not have been reached. All these uncertainties affect the accuracy of the ammonia concentration obtained by using ammonia partial pressure measurements to scale from a tank (such as AW-101) with known partial pressures and concentrations. The FY 2000 experiments compared the calculated ammonia partial pressure with the expected vapor pressure over the standard solution.

The vapor and solution isotopic standard methods were adopted on the basis of two assumptions. First, it was assumed that the ${ }^{15} \mathrm{NH}_{3}$ in the standard reached phase equilibrium with the ${ }^{14} \mathrm{NH}_{3}$ in the sample. That is, the isotopic ratio was assumed to be the same in both liquid and vapor phases. Data from use of the vapor standard indicated that slow diffusive mass-transfer and mixing in the liquid made this assumption dubious for the vapor standard-which probably created a thin zone on the sample surface that was enriched in ${ }^{15} \mathrm{NH}_{3}$. The liquid standard was more thoroughly mixed with the sample, but the data did not make it clear how much time was required for the mixed isotopic liquid in the sample to fully equilibrate with the vapor phase ammonia. The second assumption was that the RGS equipment and collection canisters and the mass spectrometry equipment had no significant adsorbed ammonia inventory (also called holdover) that could influence the isotopic ratio. ("Holdover" refers specifically to the adsorbed ammonia inventory that was present in the system before the isotopic standard was introduced and whose isotopic ratio therefore was not representative of the sample-standard mixture.) The no-holdover assumption was plausible on the basis of the limited information that was available before isotopic standards were used, but some doubt was cast on it as the program continued.

Over the course of the RGS program it became evident that mass transfer limitations and adsorbed ammonia both affected RGS results. Therefore, the primary purpose of the FY 2000 experiments was to test the accuracy of the isotopic method. Other tests, those related to ammonia loss from sample handling and initial ammonia vapor pressure, were secondary, but the data required for them were collected during the isotopic tests without extra effort. 


\subsection{FY 2000 Experimental Design}

The FY 2000 test plan (Crawford 2000) describes the experiments in detail. Only a brief summary is given here. Figure 3.1 is a schematic of the RGS extraction system; note that the actual valves and lines are more complex and have been simplified to illustrate the extraction procedure. (More details of the extraction procedure are given in Section 4 of Mahoney et al. [1999], from which this figure is taken.)

The first tests in the series (Phase 1) investigated the ammonia holdover. In these tests, $300 \mathrm{~mL}$ of $0.04 \mathrm{M}^{15} \mathrm{NH}_{4} \mathrm{OH}$ solution was introduced through a port in the top of the previously evacuated extractor vessel and then stirred. After 24 hours, the vapor and gas that had come out of solution were pumped to the collection canisters outside the cell. The ammonia in the standard solution was measured by ISE before addition to the extractor. This simple experiment (which included a primary and replicate test) determined whether there was enough ${ }^{14} \mathrm{NH}_{3}$ holdover in the RGS system to affect the isotopic ratio.

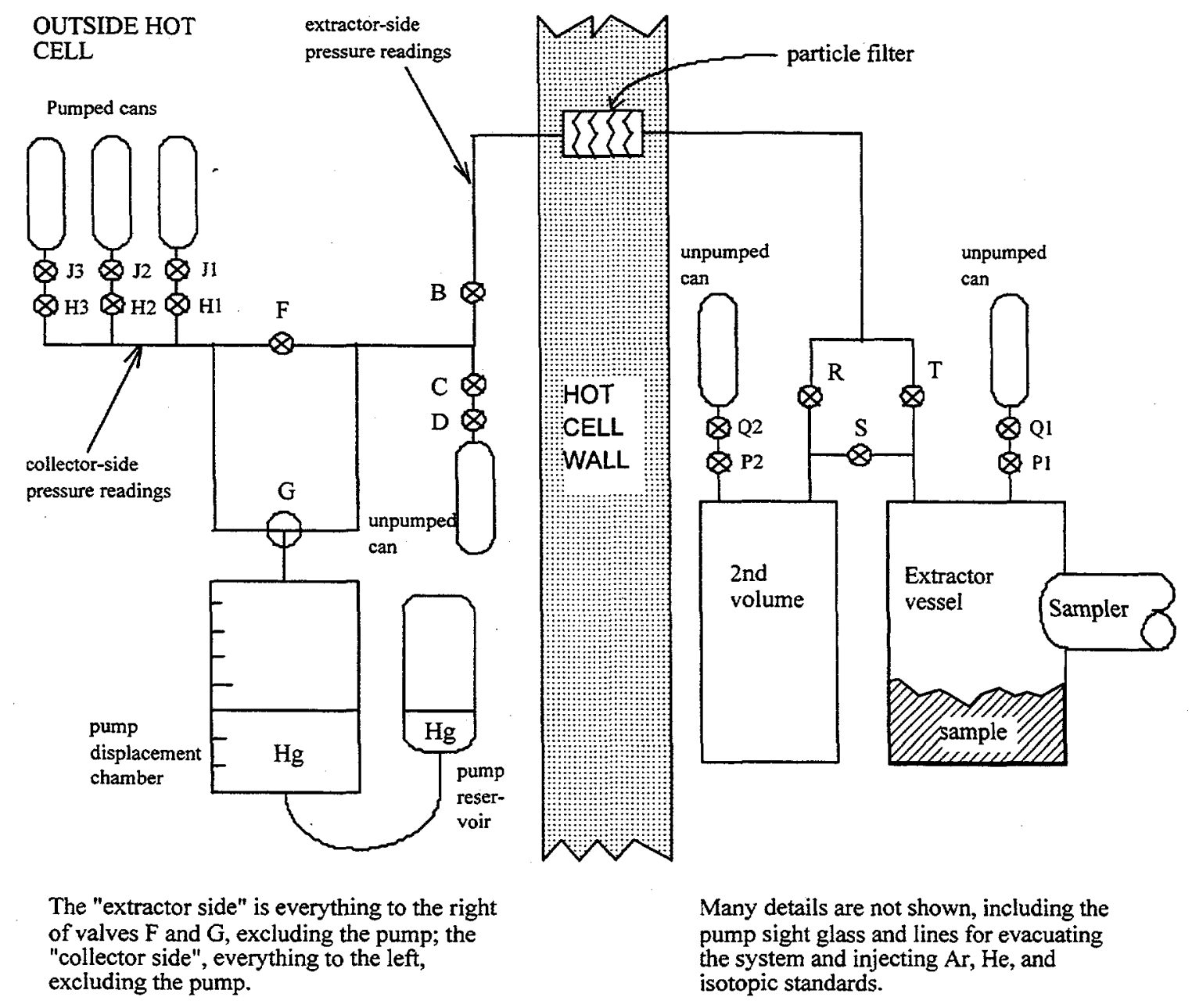

Figure 3.1. Schematic of the RGS Extraction System 
A more complex set of tests followed in Phase 2, using an extraction procedure similar to that used for SY-101 samples (Mahoney et al. 1999; Hey 1999). In these tests, a standard 300$\mathrm{mL}$ sample of ${ }^{14} \mathrm{NH}_{4} \mathrm{OH}$ was introduced through a port in the top of the previously evacuated extractor vessel and then stirred. A canister of the unpumped vapor and gas was taken, followed by two canisters in parallel that were pumped for 13 strokes of the mercury pump. Next, $300 \mathrm{~mL}$ of $0.04 \mathrm{M}{ }^{15} \mathrm{NH}_{4} \mathrm{OH}$ was added. Parallel pairs of pumped canisters were taken one day, four days, and 16 days after adding the isotopic standard. The ammonia in the ${ }^{14} \mathrm{NH}_{4} \mathrm{OH}$ standard was measured by ISE before addition and after removal from the extractor. These tests checked how much time was required for equilibration.

The Phase 2 tests were planned to test a range of different simulants to find out the effect on accuracy of high and low sample ammonia concentrations, salt concentration, and high solids fraction. Past work had suggested that high sample ammonia tended to reduce the effects of ammonia holdover, and that high solids fraction hastened equilibration by supplying wetted pore area for mass transfer. Unfortunately, laboratory staff shortages and the breakdown of both system vacuum pumps ended the test program prematurely. Only one run was completed in Phase 2, the one for a "sample" of $0.04 \underline{\mathrm{M}}^{14} \mathrm{NH}_{4} \mathrm{OH}$ (low ammonia and no solids).

All canisters were sent to the 325 Building mass spectrometry laboratory, where their composition and isotopic ratios were measured by the same methods used for SY-101 samples (Mahoney et al. 1999). The mass spectrometer was pumped down overnight before the RGS sample isotopic ratios were measured, and there was a five-minute pumpdown between samples. The collector and extractor temperatures and pressures were measured by the RGS system instrumentation. System volumes were known from previous work; data analysis methods mirrored previous work (Mahoney et al. 1999) with some additions, as described in later sections.

\subsection{Results of Isotopic Method Tests}

The isotopic method tests that were completed show that the isotopic method can overestimate the ammonia by $40 \%$ or more in samples over which there are very low ammonia partial pressures. No conclusions can be drawn about the amount of bias for samples with high ammonia partial pressures, because the test program ended before such samples could be tested.

Table 3.2 shows the measured and expected ${ }^{15} \mathrm{NH}_{3} /{ }^{14} \mathrm{NH}_{3}$ ratios for the Phase 1 and 2 tests. The ratios are presented in the order in which the canisters were analyzed at the mass spectrometry laboratory. Several subsamples were drawn from each canister because experience showed that several subsamples were required before the ratio would settle at a consistent value (Mahoney et al. 1999). This effect was attributed to sorption. In all cases, the ratios are substantially smaller than the values expected from the known amounts of ${ }^{15} \mathrm{NH}_{3}$ and ${ }^{14} \mathrm{NH}_{3}$.

The isotopic ratios measured for the Phase 2 run, before adding any ${ }^{15} \mathrm{NH}_{4} \mathrm{OH}$, showed that $50 \%$ of the ammonia in the unpumped canister was ${ }^{15} \mathrm{NH}_{3}$ and 10 to $20 \%$ of the ammonia in the pumped canisters was ${ }^{15} \mathrm{NH}_{3}$. The presence of any ${ }^{15} \mathrm{NH}_{3}$ at all clearly indicates ${ }^{15} \mathrm{NH}_{3}$ holdover in the system. The measured percentages amount to $0.5 \mu \mathrm{mol}$ of ${ }^{15} \mathrm{NH}_{3}$ extracted from the unpumped system and an additional 3 to $5 \mu \mathrm{mol}$ extracted by pumping in Phase 2 . Similarly, $2 \mu \mathrm{mol}$ of ${ }^{14} \mathrm{NH}_{3}$ would have been enough to cause the low isotopic ratios measured for the 
Table 3.2. Isotopic Ratio Results from FY 2000 Tests

\begin{tabular}{|c|c|c|}
\hline Test Phase & $\begin{array}{l}\text { Measured }{ }^{15} \mathrm{NH}_{3}{ }^{14} \mathrm{NH}_{3} \\
\text { ratios }\end{array}$ & $\begin{array}{l}\text { Expected }{ }^{15} \mathrm{NH}_{3} /{ }^{14} \mathrm{NH}_{3} \\
\text { ratio }\end{array}$ \\
\hline \multicolumn{3}{|l|}{ Phase 1 (measured $3 / 6 / 00$ ) } \\
\hline Sample 1, pumped, Can A & $0.76,1.02,0.95,1.09,1.06$ & $\infty$ \\
\hline Sample 1, pumped, Can B & $1.01,1.1,1.08,1.08,1.13$ & $\infty$ \\
\hline Sample 2, pumped, Can $A$ & $0.69,0.75,0.73,0.77,0.72$ & $\infty$ \\
\hline Sample 2, pumped, Can B & $0.72,0.68,0.72,0.70,0.68$ & $\infty$ \\
\hline \multicolumn{3}{|l|}{ Phase 2 (measured $4 / 11 / 00$ ) } \\
\hline $\begin{array}{l}\text { Sample 1, pumped } 24 \mathrm{hr} \\
\text { after isotopic addition, Can B }\end{array}$ & $--, 0.10,0.10,0.09,0.10$ & 1.0 \\
\hline $\begin{array}{l}\text { Sample } 1, \text { pumped } 3 \text { days } \\
\text { after isotopic addition, Can B }\end{array}$ & $0.54,0.62,0.52,0.59,0.58$ & 1.0 \\
\hline $\begin{array}{l}\text { Sample } 1 \text {, pumped } 3 \text { days } \\
\text { after isotopic addition, Can A }\end{array}$ & $0.60,0.56,0.60,0.57,0.58$ & 1.0 \\
\hline Sample 1 , unpumped & $1,1,1,1,1^{*}$ & 0 \\
\hline $\begin{array}{l}\text { Sample 1, pumped } 24 \mathrm{hr} \\
\text { after isotopic addition, Can A }\end{array}$ & $0.3,0.3,0.2,0.2,0.2$ & 1.0 \\
\hline $\begin{array}{l}\text { Sample 1, pumped before } \\
\text { isotopic addition, Can B }\end{array}$ & $0.2,0.2,0.2,0.1$ & 0 \\
\hline $\begin{array}{l}\text { Sample 1, pumped before } \\
\text { isotopic addition, Can A }\end{array}$ & $0.2,0.1,0.1,0.1,0.1,0.1$ & 0 \\
\hline $\begin{array}{l}\text { Sample } 1, \text { pumped } 16 \text { days } \\
\text { after isotopic addition, Can B }\end{array}$ & $\begin{array}{l}0.35,0.49,0.52,0.59,0.62, \\
0.65\end{array}$ & 1.0 \\
\hline $\begin{array}{l}\text { Sample } 1 \text {, pumped } 16 \text { days } \\
\text { after isotopic addition, Can A }\end{array}$ & $0.60,0.60,0.64,0.65,0.72$ & 1.0 \\
\hline \multicolumn{3}{|c|}{$\begin{array}{l}\text { (a) The ammonia peaks were microvolts instead of the normal millivolts level, and the ratios } \\
\text { had a much wider spread. }\end{array}$} \\
\hline
\end{tabular}

Phase 1 samples. The RGS system and canisters had been unused for months before the Phase 1 runs and that the system was evacuated between runs, indicating the persistence (strong adsorption) of ammonia holdover.

Clearly, when the amount of ammonia extracted from a sample is less than about $20 \mu \mathrm{mol}$, the ammonia holdover can bias the isotopic ratios substantially. Less than $5 \mu \mathrm{mol}$ of ammonia were collected in each of the Phase 1 runs and in the unpumped Phase 2 canister. The largest amount of ammonia that was collected at any point in the FY 2000 runs was about $30 \mu \mathrm{mol}$, collected in the Phase 2 pumped canisters before isotopic standard addition.

Waste sample runs have also indicated the presence of ammonia holdover (Mahoney et al. 1997). Gas that was collected from sample BY-109-12C-4 before adding any isotopic standard showed isotopic ratios of 0.092 for the initial unpumped canister and 0.052 for the subsequent pumped canister. The measured percentages amount to $0.2 \mu \mathrm{mol}$ of ${ }^{15} \mathrm{NH}_{3}$ extracted from the unpumped system and an additional 1 to $2 \mu \mathrm{mol}$ extracted by pumping. Once again, the absolute 
amount of holdover of the undesired isotope was small but had a measurable impact on the ratios because the extracted ammonia was also small.

Because of the effect of holdover, it is hard to determine the rate at which interphase equilibration of the two isotopes progressed. The average ratio was 0.18 one day after adding the isotopic standard, 0.58 three days after addition, and 0.6316 days after addition. There appeared to be substantial progress toward equilibration between one and three days. It is not clear whether the small ratio increase from the three-day to the 16-day values came from further slow equilibration or from a gradual replacement of ${ }^{15} \mathrm{NH}_{3}$ holdover (removed by extraction) with a ${ }^{15} \mathrm{NH}_{3}{ }^{14} \mathrm{NH}_{3}$ mixture representative of the sample. Studies of waste samples (Mahoney 1999) have also left this point ambiguous.

Table 3.3 lists the tank waste samples on which the isotopic solution tests were used and the amount of ammonia extracted in the post-isotopic canisters. The measurements for which there was $30 \mu \mathrm{mol}$ or more of extracted ammonia, enough to greatly reduce bias by holdover, are in boldface type. Very few of the measurements combine sufficiently high extracted ammonia with an equilibration time of a day or more. The exceptions are sample SX-106-6-6A and almost all of the SY-101 samples. Because of the relatively high extracted ammonia, it is unlikely that these ammonia measurements were biased high (or low) by holdover. It is harder to say whether these measurements were affected by incomplete equilibration, which is expected to overestimate the amount of ${ }^{14} \mathrm{NH}_{3}$ because the ${ }^{15} \mathrm{NH}_{3}$ in solution would not have evaporated fully.

While the accuracy of isotopic method results is doubtful when the extracted ammonia is low, some samples with low extracted ammonia gave reasonable results. Several of the SX-106 and SY-101 samples that had low extracted ammonia gave measured ammonia concentrations by the isotopic method that were close to those obtained for the samples with high extracted ammonia and compared well to post-RGS ISE ammonia measurements on the same samples (for SX-106). Samples with high ammonia concentrations can nevertheless have low extracted ammonia, so low extracted ammonia does not necessarily indicate low ammonia concentration.

The ammonia concentrations measured by the isotopic method for SY-101 samples were in reasonable agreement with those measured in 1991 by ISE in core composites from Windows C and $\mathrm{E}$ (Mahoney et al. 1999). This correspondence is consistent with the theory that ammonia concentration measurements by the isotopic method are less affected by holdover for samples with high extracted ammonia.

In summary, most of the ammonia measurements made by the isotopic solution method are doubtful because they could have been biased in either direction by ammonia holdover from previous work. The direction of the bias would depend on whether the previous work had contained more or less ${ }^{15} \mathrm{NH}_{3}$ than the sample in question. This difficulty with holdover may account for the ammonia inconsistencies that were observed in Tank S-102 and S-111 samples and noted by Mahoney et al. (1999, Appendix C). It may also account for the fact that RGS ammonia measurements are typically higher than other types of ammonia measurements. However, the measurements in SY-101 and in sample SX-106-6-6A (which is reasonably consistent with other RGS results for the SX-106 nonconvective layer) are thought to be unaffected by holdover. As discussed by Mahoney et al. (1999), ammonia overestimation resulting from incomplete equilibration cannot be ruled out. 
Table 3.3. Waste Sample Extracted Ammonia

\begin{tabular}{|c|c|c|}
\hline Sample & $\begin{array}{l}\text { Hr after } \\
\text { addition }\end{array}$ & Total $\mu \mathrm{mol} \mathrm{NH}_{3}$ extracted \\
\hline \multirow[t]{2}{*}{$S X-106-3-2$} & 1 & 18 \\
\hline & 24 & $<1$ \\
\hline \multirow[t]{2}{*}{ SX-106-3-4 } & 2 & 2 \\
\hline & 70 & 1 \\
\hline \multirow[t]{2}{*}{ SX-106-6-6 } & 2 & 88 \\
\hline & 140 & 2 \\
\hline \multirow[t]{2}{*}{$S X-106-6-6 A$} & 1 & 61 \\
\hline & 69 & 48 \\
\hline \multirow[t]{2}{*}{ SX-106-3-7 } & 2 & 15 \\
\hline & 24 & 7 \\
\hline \multirow[t]{2}{*}{ SX-106-6-9 } & 1 & 73 \\
\hline & 21 & 8 \\
\hline \multirow[t]{2}{*}{ SX-106-3-10 } & 2 & 85 \\
\hline & 24 & $<1$ \\
\hline \multirow[t]{2}{*}{ AX-101-9D-8 } & 2 & 50 \\
\hline & 24 & 2 \\
\hline \multirow{2}{*}{ S-102-16-2 } & 24 & 17 \\
\hline & 94 & 4 \\
\hline \multirow[t]{2}{*}{ S-102-16-4R } & 22 & 3 \\
\hline & 94 & $<1$ \\
\hline \multirow[t]{4}{*}{ S-102-16-7 } & 2 & 17 \\
\hline & 29 & 1 \\
\hline & 53 & $<1$ \\
\hline & 169 & 1 \\
\hline \multirow[t]{4}{*}{ S-102-16-10 } & 2 & 8 \\
\hline & 28 & $<1$ \\
\hline & 49 & 1 \\
\hline & 191 & 1 \\
\hline$S-111-6-2$ & \multicolumn{2}{|c|}{$\begin{array}{l}\text { Composition data were not taken for post- } \\
\text { isotopic canisters, so the amount of extracted } \\
\text { ammonia is unknown }\end{array}$} \\
\hline$S-111-6-4$ & 22 & 4 \\
\hline$S-111-6-6$ & 46 & 6 \\
\hline$S-111-6-8$ & 476 & 21 \\
\hline S-111-6-10 & 18 & 4 \\
\hline $\mathrm{U}-109-8-2$ & 16 & 5 \\
\hline $\mathrm{U}-109-8-4$ & 19 & 58 \\
\hline $\mathrm{U}-109-8-6$ & 22 & 16 \\
\hline $\mathrm{U}-109-8-8$ & 22 & 11 \\
\hline \multirow[t]{2}{*}{ SY-101-23A-1 } & 26 & 14 \\
\hline & 116 & 60 \\
\hline SY-101-23A-2 & 22 & 90 \\
\hline \multirow{2}{*}{ SY-101-22A-3 } & 26 & 109 \\
\hline & 98 & 150 \\
\hline SY $-101-23 \mathrm{~A}-3$ & 20 & 30 \\
\hline \multirow[t]{2}{*}{ SY-101-22A-4 } & 22 & 7 \\
\hline & 46 & 46 \\
\hline SY-101-4A-5 & 24 & 38 \\
\hline
\end{tabular}


Table 3.3 (contd)

\begin{tabular}{||l|c|c|}
\hline \multicolumn{1}{|c|}{ Sample } & $\begin{array}{c}\text { Hr after } \\
\text { addition }\end{array}$ & Total $\mu \mathrm{mol} \mathrm{NH}_{3}$ extracted \\
\hline & 142 & $\mathbf{1 8 7}$ \\
\hline SY-101-23A-8 & 115 & $\mathbf{4 6}$ \\
\hline SY-101-22A-10 & 24 & 11 \\
\cline { 2 - 4 } & 139 & $\mathbf{6 3}$ \\
\hline SY-101-23A-13 & 94 & $\mathbf{3 6}$ \\
\hline SY-101-22A-17 & 22 & 26 \\
\cline { 2 - 4 } & 162 & $\mathbf{1 4 8}$ \\
\hline \multirow{2}{*}{ SY-101-23A-21 } & 26 & 11 \\
\hline \multirow{2}{*}{ SY-101-22A-23 } & 166 & $\mathbf{1 3 1}$ \\
\cline { 2 - 4 } & 23 & $\mathbf{4 8}$ \\
\hline \multirow{2}{*}{$\begin{array}{l}\text { It should be noted that low extracted ammonia does not necessarily indicate low } \\
\text { ammonia concentrations. }\end{array}$} & 116 & $\mathbf{1 5 2}$ \\
\hline
\end{tabular}

\subsection{Results of Tests of the Initial Ammonia Partial Pressure Method}

The measured ammonia partial pressure is useful in estimating ammonia concentration if three things are true: 1) the partial pressure can be accurately calculated by subtracting the gas and water partial pressures from the total extractor pressure, 2) the ammonia partial pressure accurately represents the ammonia vapor pressure (implying complete equilibration between liquid and gas and no significant loss of ammonia vapor to adsorption on the walls), and 3) all the ammonia in solution is present as $\mathrm{NH}_{3}$, not as non-volatile $\mathrm{NH}_{4}{ }^{+}$. This section discusses the extent to which the FY 2000 tests, as well as earlier work, shed light on the inaccuracies in these assumptions.

Taking point (3) first, the ammonia partial pressure over the "samples" in the FY 2000 tests would not have been affected significantly by the $\mathrm{NH}_{3} / \mathrm{NH}_{4}{ }^{+}$equilibrium. The "samples" all had concentrations of $0.04 \mathrm{M} \mathrm{NH} \mathrm{NH}_{4} \mathrm{OH}$, at which concentration the $\mathrm{NH}_{3}$ vapor pressure is $0.05 \mathrm{kPa}$ (AIChE 1973). A $0.04 \underline{\mathrm{M} \mathrm{NH}} 4 \mathrm{OH}$ solution has a $\mathrm{pH}$ of 11.6 and an $\mathrm{NH}_{4}{ }^{+} / \mathrm{NH}_{3}$ ratio of 0.1 , based on a dissociation constant of $1.6 \times 10^{-5}$ (CRC 1975), so dissociation causes only a small reduction in the ammonia vapor pressure. At the higher $\mathrm{pH}$ conditions of the RGS waste samples, even less $\mathrm{NH}_{4}^{+}$would have been present.

Although ammonium ion is not an issue, the FY 2000 tests showed serious accuracy problems with the ammonia partial pressure measurement at low ammonia partial pressures. Table 3.4 shows the partial pressures of ammonia and water over a $0.04 \mathrm{M} \mathrm{NH}_{4} \mathrm{OH}$ solution (AIChE 1973, Table 3-24) compared with the partial pressures measured during the FY 2000 RGS tests. The RGS-measured water partial pressure is typically underestimated by about $0.1 \mathrm{kPa}$. This underestimation could have been caused by water vapor pressure depression by a small amount of salt left in the extractor vessel from earlier waste samples, from incomplete phase equilibration of water, or from sorption of water on the system walls.

Although the underestimation of water partial pressure should lead to an overestimation of ammonia pressure, the two Phase 1 samples showed the opposite effect, with the ammonia vapor pressure underestimated by about $0.1 \mathrm{kPa}$. The negative pressures are clearly nonphysical and 
Table 3.4. Ammonia and Water Partial Pressures over Standard $\mathrm{NH}_{4} \mathrm{OH}$ Solution

\begin{tabular}{||l|c|c||}
\hline \multicolumn{1}{|l|}{ Conditions } & $\begin{array}{c}\text { Ammonia } \\
\text { Partial Pressure } \\
(\mathrm{kPa})\end{array}$ & $\begin{array}{c}\text { Water Partial } \\
\text { Pressure } \\
(\mathrm{kPa})\end{array}$ \\
\hline Vapor pressure @ $11^{\circ}$ to $12^{\circ} \mathrm{C}^{(\mathrm{a})}$ & 0.05 & $1.40-1.45$ \\
\hline Phase 1, Sample 1 & $-0.056^{(\mathrm{b})}$ & 1.28 \\
\hline Phase 1, Sample 2 & $-0.034^{(\mathrm{b})}$ & 1.32 \\
\hline Phase 2, Sample 1 & 1.34 \\
\hline initial & 0.29 & 1.48 \\
\hline 24 hr after isotopic addition & & 1.35 \\
\hline 3 days after isotopic addition & & 1.33 \\
\hline 16 days after isotopic addition & & \\
\hline $\begin{array}{l}\text { (a) AIChE (1973, Table 3-24). } \\
\text { (b) Negative ammonia partial pressures are nonphysical and are caused by the } \\
\text { uncertainties in the data used to calculate the pressures. }\end{array}$ \\
\hline
\end{tabular}

should be taken to indicate that the measured pressure was actually somewhere between a minimum of zero and a maximum of about $0.15 \mathrm{kPa}$ (which equals $0.1 \mathrm{kPa}$ plus the expected pressure). In the Phase 2 sample, the ammonia vapor pressure was overestimated by $0.24 \mathrm{kPa}$. These measurement errors resulted in part from the uncertainty in the pressures that are subtracted to give the ammonia partial pressure. The estimated uncertainties are $0.09 \mathrm{kPa}$ in the total pressure and $0.07 \mathrm{kPa}$ in the water partial pressure. The absolute uncertainty in the initial gas partial pressure is about $0.005 \mathrm{kPa}$ for the Phase 1 tests and $0.05 \mathrm{kPa}$ for the Phase 2 test (in which there was more gas in the extractor). Thus there is considerable scatter because the ammonia pressure is found as a small difference between larger numbers that have relatively large uncertainties.

Clearly, the initial ammonia partial pressure cannot be relied on as a representation of the ammonia vapor pressure, at least in samples whose ammonia vapor pressure is about the same as the uncertainty. Because a substantially overestimated ammonia pressure of $0.29 \mathrm{kPa}$ was obtained in Phase 2, it appears that any initial ammonia partial pressure of $0.3 \mathrm{kPa}$ or less that was obtained by subtraction of pressures should be considered spurious. Extending this criterion to include all samples with less than $0.5 \mathrm{kPa}$ initial ammonia partial pressure, the RGS waste samples that should be considered unreliable were two of the four U-103 samples (U-103-7-2 and -7-8), three of the four S-106 samples (S-106-7-3, -7-5, and -8-10), all of the BY-109 samples, three of the six SX-106 samples (SX-106-3-2, -3-4, and -6-6A), two of the four S-102 samples (S-102-16-2 and -16-4R), two of the five S-111 samples (S-111-6-2 and -6-4), and one of the four U-109 samples (U-109-8-2). Samples from Tanks A-101, AN-103, AN-104, AN-105, AW-101, AX-101, and SY-101 all had high enough initial ammonia partial pressures to avoid the difficulty with subtraction uncertainty.

A second concern with using the initial ammonia partial pressure as an indicator of sample ammonia concentration is that the partial pressure, even if not affected by subtraction uncertainty, may not always equal the vapor pressure or be the same fraction of the true vapor pressure. Variations in mass-transfer limitations and sorption of ammonia on the walls could cause the partial pressure of one sample to underestimate the ammonia vapor pressure much 
more than the partial pressures of other samples did. If that were the case, it would be inaccurate to use the ammonia partial pressure to scale the ammonia concentration from AW-101 partial pressures and concentrations.

First, consider the effect of mass-transfer limitations. The major limitation is the slow diffusion of ammonia through the sample liquid to replace what is lost by evaporation. A thin ammonia-depleted layer forms rapidly on the top of the sample and is on the order of $1 \mathrm{~mm}$ thick one hour after evaporation begins. ${ }^{(a)}$ This layer retards evaporation from the bulk of the sample and is not effectively mixed into the bulk sample by the maximum mixer blade speed of $3 \mathrm{rpm}$ (Recknagle et al. 1997). Based on RGS data, Kubic (1997) concluded that one sample, AW-101-24B-22 (a nonconvective layer sample with 2 vol\% gas and 83 vol\% liquid), showed little if any sign of continuing equilibration during pumping.

Based on qualitative considerations, it is not clear that all samples would approach equilibrium equally at the time the initial ammonia partial pressure was measured. Mass-transfer limitation is expected to be most pronounced in samples with high liquid volume fractions, such as most convective-layer samples and all samples to which isotopic standard solution had been added. Samples that contain a large amount of gas would probably come closer to initial equilibrium as a result of the sample's being disrupted by gas release into the evacuated extractor vessel and of ammonia evaporation from wetted pore surfaces into pore space, through which diffusion is relatively rapid. Samples with low gas content but high solids might also have substantial pore space because excess liquid might drain to the bottom of the solids and leave pores open. High-solids simulants were not tested in the FY 2000 program because of system vacuum pump breakdowns.

Finally, consider the effect of sorption of ammonia on the walls of the RGS extraction system and the mass spectrometer. The discussion of holdover that was given in Section 3.3 implied that absorption on the RGS system walls removes a substantial amount of ammonia from the vapor. For samples with low ammonia partial pressures, absorption will result in a large error in the ammonia concentration measurement made using the partial pressure. In addition, this could lower the ammonia partial pressure below the equilibrium vapor pressure in cases where mass-transfer limitations prevented the initial sorbed ammonia loss from being replaced by evaporation.

The RGS Acceptance Test Report (Cannon and Knight 1996) states that about $40 \mathrm{~mL}$ of gas of known composition was injected at $28^{\circ} \mathrm{C}$ and $100 \mathrm{kPa}$ pressure. The gas was dry and contained $5 \mathrm{~mol} \% \mathrm{NH}_{3}$, but, when the extracted gas was subjected to mass spectroscopy, as little as $2 \mathrm{~mol} \% \mathrm{NH}_{3}$ was measured. Under these conditions, each percent of $\mathrm{NH}_{3}$ loss corresponds to $16 \mu \mathrm{mol} \mathrm{NH}$, so up to $50 \mu \mathrm{mol}$ of $\mathrm{NH}_{3}$ was lost in the system. In a total system volume of roughly $2000 \mathrm{~mL}, 50 \mu \mathrm{mol}$ is equivalent to a partial pressure loss of $0.06 \mathrm{kPa}$.

Other researchers noted that, when known quantities of ammonia vapor were added to the otherwise empty RGS system, the increase in system pressure was less than would be expected

(a) Person JC and BE Hey. 1997. Tests of Ammonia Collection Efficiency in the Retained Gas Sampler System and Results of Ammonia Additions to Tank Waste. HNF-SD-WM-TRP-291 Rev. 0 (draft), Numatec Hanford Corporation, Richland, Washington. 
from the pressures and volumes involved. ${ }^{(a)}$ In addition, the pressure declined with time after the initial peak. Both of these observations indicated that some of the vapor was lost to sorption. This study stated that the RGS-measured ammonia concentrations were 11 to $16 \mathrm{~mol} \%$ in a dry gas standard that was known to contain $20 \mathrm{~mol} \%$ ammonia. When the gas standard contained $1 \mathrm{~mol} \%$ ammonia, 70 to $90 \%$ of the injected ammonia was lost. The report did not provide pressure and volume data to allow calculations of the number of moles that were lost, but knowledge of typical injection canister volumes ( 27 to $40 \mathrm{~mL}$ ) suggests that the losses were less than $150 \mu \mathrm{mol}$ (equivalent to $0.18 \mathrm{kPa}$ of partial pressure).

As shown in Table 3.1, Tanks A-101, AN-103, AN-104, AN-105, U-103, S-106, and BY-109 ammonia concentrations were estimated by comparing their initial ammonia partial pressures with those measured in AW-101, where both partial pressure and post-extraction ISE data were available. The initial partial pressure technique was also employed for tanks measured later to compare them with the isotopic solution method (usually preferred for the "later" tanks).

Table 3.5 summarizes the results of comparisons among the several methods, based on Appendix C of Mahoney et al. (1999) and subsequent TWINS data. ${ }^{(b)}$ Most of the ammonia concentrations measured by the RGS isotopic standard method are suspect because of short equilibration times and low extracted ammonia. Many of the ammonia concentrations estimated from initial ammonia partial pressures are probably spurious because of low ammonia pressure. The RGS-measured concentrations on which the FY 2000 study does not cast doubt are bolded.

The initial partial pressure method estimates somewhat greater ammonia concentrations than those found by post-extraction ISE analysis, and less than or equal to those found by the isotopic solution method. There is no unambiguous evidence that the partial pressure method systematically underestimates the ammonia concentrations in waste samples, as might be expected from sorption losses. The partial pressure method may overestimate the ammonia concentration because its results are higher than those of post-extraction ISE, but that method has been suspected of underestimation.

\subsection{Results of ISE Ammonia Analysis Tests}

As shown in Table 3.5, all the RGS methods (except isotopic vapor addition) give greater ammonia concentrations than measurements carried out by ISE on non-RGS samples. In addition, post-extraction ISE on RGS samples almost always gives lower ammonia concentrations than other methods used on RGS samples.

As part of the FY 2000 program, standard solutions of $0.04 \mathrm{M}^{14} \mathrm{NH}_{4} \mathrm{OH}$ and ${ }^{15} \mathrm{NH}_{4} \mathrm{OH}$ were subjected to ISE analysis before and after RGS extraction. Table 3.6 contains the results. The measured ammonia concentration should have been $680 \mu \mathrm{g} / \mathrm{mL}$ before extraction and slightly less than that after extraction, based on the very low extracted ammonia.

(a) Person JC and BE Hey. 1997. Tests of Ammonia Collection Efficiency in the Retained Gas Sampler System and Results of Ammonia Additions to Tank Waste. HNF-SD-WM-TRP-291 Rev. 0 (draft), Numatec Hanford Corporation, Richland, Washington.

(b) TWINS database, http://twins.pnl.gov:8001/data/datamenu.htm. 
Table 3.5. Comparison of Ammonia Concentrations by Different Methods

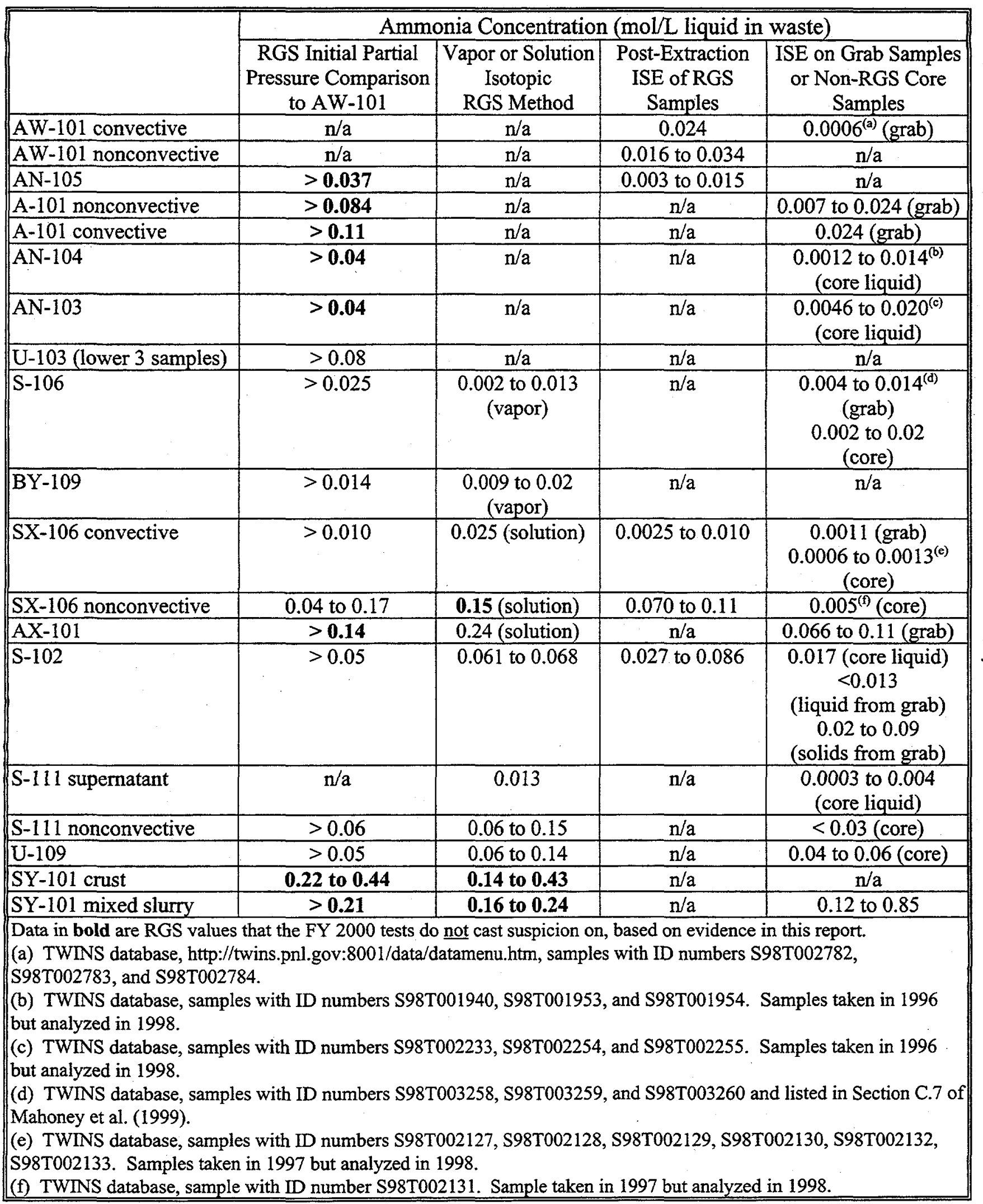


Table 3.6. Results of ISE Analysis of FY 2000 Standards

\begin{tabular}{|c|c|c|c|}
\hline Sample ID & Description & $\begin{array}{c}\mu \mathrm{g} / \mathrm{mL} \\
\mathrm{NH}_{3}\end{array}$ & Error \\
\hline \multicolumn{4}{|c|}{ Before extraction } \\
\hline S00M00075 & Phase 1, Sample 1 & 798 & $+17 \%$ \\
\hline S00M00077 & Phase 1, Sample 2 & 655 & $-4 \%$ \\
\hline S00M00079 & Phase 2, Sample 1 simulant & 524 & $-23 \%$ \\
\hline S00M00080 & Phase 2, Sample 1 diluent & 915 & $+34 \%$ \\
\hline \multicolumn{4}{|c|}{ After extraction } \\
\hline S00M00076 & Phase 1, Sample 1 spent & 140 & \\
\hline S00M00078 & Phase 1 , Sample 2 spent & 470 & \\
\hline S00M00081 & Phase 2, Sample 1 simulant & 453 & \\
\hline
\end{tabular}

The FY 2000 ammonia measurements made before extraction show scatter of about $30 \%$ but no clear bias toward either under- or overestimation. (In Mahoney et al. 1999, Section 3.4.2, a $\mathrm{NH}_{4} \mathrm{OH}$ standard was measured at $29 \%$ lower than the nominal value, consistent with the FY 2000 results.) The scatter could be the result of ISE measurement uncertainty or of variation in the concentration of the solutions or both; the data are not sufficient to distinguish the two causes. The two Phase 1 samples were from the same solution, but the Phase 2 samples were made up independently.

If the ISE measurements of the Phase 2 simulant and diluent are accurate-that is, if the concentration difference came from solution preparation-the ${ }^{15} \mathrm{NH}_{3} /{ }^{14} \mathrm{NH}_{3}$ ratio in the Phase 2 experiments should have been 1.7 rather than 1.0, as was given in Table 3.2. In that case, the isotopic solution method overestimated the ammonia by a factor of 2.4 rather than the 1.4 calculated from the nominal simulant and diluent concentrations.

The data in the first part of Table 3.6 do not support the theory that ISE analysis per se tends to underestimate ammonia in dilute $\mathrm{NH}_{4} \mathrm{OH}$ solutions, in spite of the possibility of losing ammonia through evaporation during handling. This does not exclude the possibility (in fact, likelihood) that ammonia losses could occur during the more extensive handling required to remove RGS samples from the extractor and prepare them for ISE analysis. The same is true for the more extensive handling undergone by core samples.

The FY 2000 analyses of "spent" samples-those that had undergone extraction, then been poured out of the extractor into jars, stored for three to six months, and subjected to ISE analysis-consistently gave ammonia concentrations that were lower than the original preextraction standards. The amounts of ammonia that had been extracted during RGS pumping were much too small to account for the differences. Losses during post-RGS handling and storage were probably the cause. Because the delay between extraction and ISE analysis was months longer for the FY 2000 samples than for RGS waste samples, the FY 2000 data cannot establish that the losses were from handling alone and would have been representative for waste samples. Measurement scatter also cannot be ruled out as the source of the difference.

However, in five RGS samples that had been subjected to the isotopic solution method, the post-extraction ISE analysis measured as much as $76 \%$ less ammonia than was present in the 
isotopic solution alone. In the case of waste samples, of course, there was no way to recognize any overestimated post-extraction ammonia concentrations. As was the case for the FY 2000 work, the error from solution preparation could not be distinguished from the error in the ISE analysis. 


\subsection{Results and Conclusions}

The purpose of this report is to provide a final overview of the ammonia measurement methods and solubility models used in RGS studies. Although the originally envisioned FY 2000 test program was not completed, certain results were indicated and some conclusions can be drawn.

- The Hanford database of ammonia solubility measurements was reviewed and used to provide revised coefficients for the Schumpe model. The model changes have the greatest effect on the mole fraction of ammonia vapor in the retained gas in cases where the gas volume fraction is high, as it was in the crust of SY-101 before transfer and dilution (Mahoney et al. 1999).

- The molal/molar units error had an insignificant effect on the composition of the lowsolubility portion of the retained gas. Table 2.3 is the replacement for Table 5.2 of Mahoney et al. (1999), and provides corrected values of the gas compositions and gas volume fractions that were given in a number of tables in Sections 4.1 through 4.15 of that report.

- The accuracy of RGS ammonia measurement methods is doubtful for samples from which only a small amount of ammonia can be extracted-that is, samples that have a low ammonia partial pressure in the extractor. The low partial pressure may result from a low ammonia vapor pressure (caused by low ammonia concentration or high solubility) or from mass transfer limitations that keep the partial pressure lower than the equilibrium vapor pressure. Most of the samples whose ammonia was measured by the isotopic solution method (samples from Tanks SX-106, AX-101, S-102, S-111, U-109, and SY-101) fall into the low-partial-pressure category. The exceptions are sample SX-1066-6A and almost all of the SY-101 samples. Some of the samples on which the initial partial pressure method was used to measure ammonia also had low ammonia pressures. These latter include most of the samples from U-103, S-106, and BY-109. Samples from AW-101, A-101, AN-105, AN-104, and AN-103 had higher ammonia partial pressures, and their ammonia partial pressures are considered more reliable.

- Because the FY 2000 tests were incomplete, they provided no basis for any conclusions about the accuracy of RGS ammonia measurement methods when used on samples with high ammonia partial pressures.

- The ISE analyses that were performed on $\mathrm{NH}_{4} \mathrm{OH}$ standards showed scatter of $\pm 30 \%$ with no evident bias. The minimal amount of sample handling required for these solids-free liquid samples did not cause any apparent systematic losses.

In general, we regard the uncertainties of RGS ammonia measurement methods as being larger for samples with low ammonia partial pressures than the uncertainties stated by Mahoney et al. (1999). That reference estimated the ammonia concentration uncertainties as $\pm 50 \%$ for the initial partial pressure method and (in most cases) less than $\pm 30 \%$ for the isotopic solution method. Based on FY 2000 work, the ammonia measurements made by either of these methods 
could be a factor of 2 to 3 higher or lower than the true concentration for samples with low ammonia partial pressure. As was shown in Table 3.5, different measurement methods can yield ammonia concentrations that differ by a factor of 2 or more, though there are also cases in which different methods give similar results. Unfortunately, the FY 2000 program was not completed, and the high uncertainty cannot be quantified. 


\subsection{References}

AIChE. 1973. Chemical Engineers' Handbook, 5th Edition, RH Perry and CH Chilton, eds. American Institute of Chemical Engineers, McGraw-Hill, New York.

Cannon NS and RC Knight. June 1996. Retained Gas Sampler System Acceptance Test Report. WHC-SD-WM-ATR-137 Rev 1, Westinghouse Hanford Company, Richland, Washington.

Clegg SL and P Brimblecombe. 1989. "Solubility of Ammonia in Pure Aqueous and Multicomponent Solutions." Journal of Physical Chemistry 93:7237-7248.

Crawford BA. 2000. Retained Gas Sampler Calibration and Simulant Tests. HNF-5443 Rev. 1, Fluor Daniel Hanford Corporation, Richland, Washington.

CRC. 1975. Handbook of Chemistry and Physics, 56th Edition. CRC Press, Cleveland.

Hedengren DC. 2000. Methodology for Predicting Flammable Gas Mixtures in DoubleContained Receiver Tanks. RPP-4941 Rev. 0A, CH2M Hill Hanford Group, Inc., Richland, Washington.

Hedengren DC, SJ Geelhood, VF Medina, SK Early, and M Mercer. August 2000. "Ammonia Solubility Project Report." Washington State University, Richland, Washington.

Hermann C, I Dewes, and A Schumpe. 1995. "The estimation of gas solubilities in salt solutions." Chem. Eng. Sci. 50:1673-4.

Hey BE. September 1999. Retained Gas Sampler Extraction System Operation. LT-160101, Fluor Daniel Hanford Corporation, Richland, Washington.

Kubic WL Jr. 1997. Maximum Likelihood Data Reconciliation for the Retained Gas Sampler Data from Tank 241-AW-101. TSA10-CN-WT-SA-DA-004 Rev. 0, Los Alamos National Laboratory, Los Alamos, New Mexico.

Mahoney LA, ZI Antoniak, and JM Bates. 1997. Composition and Quantities of Retained Gas Measured in Hanford Waste Tanks 241-U-103, S-106, BY-101, and BY-109. PNNL-11777, Pacific Northwest National Laboratory, Richland, Washington.

Mahoney LA, ZI Antoniak, JM Bates, and ME Dahl. 1999. Retained Gas Sampling Results for the Flammable Gas Program. PNNL-13000, Pacific Northwest National Laboratory, Richland, Washington.

Mahoney LA, JL Huckaby, SA Bryan, GD Johnson. 2000. Overview of the Flammability of Gases Generated in Hanford Waste Tanks. PNNL-13269, Pacific Northwest National Laboratory, Richland, Washington.

Norton JD and LR Pederson. 1994. Ammonia in Simulated Hanford Double-Shell Tank Wastes: Solubility and Effects on Surface Tension. PNL-10173, Pacific Northwest Laboratory, Richland, Washington.

Norton JD and LR Pederson. 1995. Solubilities of Gases in Simulated Tank 241-SY-101 Wastes. PNL-10785, Pacific Northwest Laboratory, Richland, Washington.

Peurrung LM, LA Mahoney, CW Stewart, PA Gauglitz, LR Pederson, SA Bryan, and CL Shepard. 1998. Flammable Gas Issues in Double-Contained Receiver Tanks. PNNL11836 Rev. 2, Pacific Northwest National Laboratory, Richland, Washington. 
Prausnitz JM, RN Lichtenthaler, and EG de Azevedo. 1986. Molecular Thermodynamics of Fluid-Phase Equilibria, 2nd Ed. Prentice-Hall, Inc., Englewood Cliffs, New Jersey.

Recknagle KP, JM Bates, and A Shekarriz. 1997. Retained Gas Sampler Extractor Mixing and Mass Transfer Rate Study: Experimental and Simulation Results. PNNL-11759, Pacific Northwest National Laboratory, Richland, Washington.

Reid RC, JM Prausnitz, and BE Poling. 1987. The Properties of Gases and Liquids, 4th Ed. McGraw-Hill, New York.

Schumpe A. 1993. "The Estimation of Gas Solubilities in Salt Solutions." Chem. Eng. Sci., Vol. 48 , p. 153.

Sechenov J. 1889. Z. Phys. Chem. 4:117.

Sing R, B Rumpf, and G Maurer. 1999. "Solubility of Ammonia in Aqueous Solutions of Single Electrolytes Sodium Chloride, Sodium Nitrate, Sodium Acetate, and Sodium Hydroxide." Ind. Eng. Chem. Res. 38(5):2098-2109.

Shekarriz A, DR Rector, LA Mahoney, MA Chieda, JM Bates, RE Bauer, NS Cannon, BE Hey, CG Linschooten, FJ Reitz, and ER Siciliano. 1997. Composition and Quantities of Retained Gas Measured in Hanford Waste Tanks 241-AW-101, A-101, AN-105, AN-104, and AN-103. PNNL-11450 Rev. 1, Pacific Northwest National Laboratory, Richland, Washington.

Sorina GA, VM Miniovich, and GD Efremova. 1967. "Solubility of Ammonia in Aqueous Solutions of Sodium Hydroxide." J. General Chem. USSR 37(10):2150-2154.

Van Keuren JC, JS Davis, and ML Dentler. 1996. Toxic Chemical Considerations for Tank Farm Releases. WHC-SD-WM-SARR-011, Rev. 2, Westinghouse Hanford Co., Richland, Washington.

Weisenberger S and A Schumpe. 1996. "Estimation of Gas Solubilities in Salt Solutions at Temperatures from 273K to 363K." AIChE J. 42(1):298-300.

Wootan DW. 1995. Functional Design Criteria for the Retained Gas Sampler System. WHC-SD-WM-FRD-018, Westinghouse Hanford Company, Richland, Washington. 


\section{Distribution}

No. of

Copies

Offsite

2 DOE Office of Scientific and Technical Information

H. Babad

2540 Cordoba Ct.

Richland, WA 99352

M. J. Barnes

Savannah River Site

Aiken, SC 29802

D. O. Campbell

102 Windham Road

Oak Ridge, TN 37830

C. W. Forsberg

Oak Ridge National Laboratory

P.O. Box 2008, MS-6495

Oak Ridge, TN 37831-6495

B. C. Hudson

P.O. Box 271

Lindsborg, KS 67456

M. S. Kazimi

Massachusetts Institute

of Technology

Department of Nuclear Engineering

77 Massachusetts Avenue

Cambridge, MA 02139
.No. of

Copies

T. S. Kress

102-B Newridge Road

Oak Ridge, TN 37830

W. L. Kubic

Los Alamos National Laboratory

P.O. Box 1663

Los Alamos, NM 87545

T. E. Larson

2711 Walnut St.

Los Alamos, NM 87545

D. A. Powers

Sandia National Laboratory

Nuclear Facilities Safety Department

MS-0744

Albuquerque, NM 87185-0744

W. R. Rossen

University of Texas at Austin

Department of Petroleum/Geosystems

Engineering

Austin, TX 78712

S. E. Slezak

806 Hermosa NE

Albuquerque, NM 87110

Leon Stock

6695 SW 86th Ave.

Portland, OR 97223
J. L. Kovach
P.O. Box 29151
70000 Huntley Road
Columbus, $\mathrm{OH} 43229$ 
No. of

Copies

Onsite

3 DOE Office of River Protection

C. A. Groendyke

S7-54

G. W. Rosenwald

J.-S. Shuen

37 PHMC Team

R. P. Anantatmula

S. A. Barker

W. B. Barton

R. E. Bauer (3)

R. J. Cash

N. S. Cannon

A. F. Choho

J. M. Conner

M. E. Dahl

J. G. Field

L.A. Fort

J. M. Grigsby

K. M. Hall

B. E. Hey

D.C. Hedengren

K. M. Hodgson

T. A. Hu

J. W. Hunt

G. D. Johnson

N. W. Kirch

C. E. Leach

C. G. Linschooten
S7-54

S7-54

R1-04

R1-44

R2-11

S7-70

R1-44

S7-70

R3-73

R2-11

P8-15

$\mathrm{R} 2-12$

R2-11

R1-44

$\mathrm{R} 2-82$

S3-30

R2-11

R2-11

R2-11

$\mathrm{R} 2-12$

H4-20

R2-11

R1-44

X4-01
No. of

Copies

L. L. Lockrem

T6-07

D. J. McCain

R2-11

S. G. McKinney

R2-12

J. C. Person

T6-07

J. H. Rasmussen

R2-12

R. E. Raymond

T4-08

D. A. Reynolds

R2-11

L. M. Sasaki

R2-12

B.C. Simpson

R2-11

H6-64

J. E. Van Beek

R1-49

41 Pacific Northwest National Laboratory

Z. I. Antoniak

J. M. Bates

B. O. Barnes

S. Q. Bennett

J. W. Brothers (10)

S. A. Bryan

J. A. Fort

P. A. Gauglitz

J. L. Huckaby

L. A. Mahoney (10)

P. A. Meyer

L. R. Pederson

L.M. Peurrung

S. D. Rassat

K. P. Recknagle

D. R. Rector

C. W. Stewart

G. Terrones

Information Release (5)
K7-15

K7-15

P8-50

K7-90

K9-20

P7-25

K7-15

K6-28

K7-15

$\mathrm{K} 7-15$

$\mathrm{K} 7-15$

$\mathrm{K} 2-50$

K6-24

K6-28

K7-15

K7-15

K7-15

K7-15

K1-06 